\title{
TECHNOLOGICAL DISPLACEMENT:
}

\section{THE COAT CHECK INTERACTIVE AUGMENTED REALITY INSTALLATION IN PERSPECTIVE}

by

\section{AYSEGUL KOC}

M.A. in Film, York University, Toronto 2004

A dissertation presented to Ryerson University and York University

In partial fulfillment of the requirements of the degree of

Doctor of Philosophy

in the Program of

Communication and Culture

Toronto, Ontario, Canada, 2013

(C) Aysegul Koc, 2013 
I hereby declare that I am the sole author of this dissertation. This is a true copy of the dissertation, including any required final revisions, as accepted by my examiners.

I authorize Ryerson University to lend this dissertation to other institutions or individuals for the purpose of scholarly research.

I further authorize Ryerson University to reproduce this dissertation by photocopying or by other means, in total or in part, at the request of other institutions or individuals for the purpose of scholarly research.

I understand that my dissertation may be made electronically available to the public. 


\begin{abstract}
Technological Displacement: The Coat Check Interactive AR Installation in Perspective is a two-part dissertation that involves the research/creation of an augmented reality installation and a textual critique of displacement both as a socio-cultural phenomenon and a technology-driven status quo. Digital technologies involve a series of displacements from data storage and transfer to creating global networks. Going hand in hand with human mobilities technological displacement affects our lives and interactions deeply. Multimedia and digital overlaying of information and interconnectedness (mobile devices, tracking technologies, the internet...) make up our quotidian in various degrees, impelling us to be 'present' in time and places we actually are not. Technological displacement may be viewed as an extension of physical displacement of individuals and communities in that the need to reconcile, re-invent and innovatively market proximity becomes more and more an underlying theme of contemporary lives. Nowhere the reorientations of presence is more accentuated than 'augmented space', as described by Lev Manovich, “ a physical space overlaid with dynamically changing information, multimedia in form and localized for each user."(219) It may be argued that our sense of reality is already 'augmented' by digital stimuli in many ways. Here I make the case that in an augmented or digitally enhanced environment we are displaced multiple times, or "multiplaced". Augmentation is superimposing multimedia to real space, blurring the boundary between the real and the virtual, creating a heterogeneous space defined neither by the standards of the virtual nor the real but the coexistence and cooperation of both.
\end{abstract} Augmented reality functions on the principle of multiple displacements in that 
real space is not a backdrop to multimedia: it is indispensable to the overall embodied experience. I created The Coat Check in 2011 using motion tracking technologies (Intersense IS900), specialized cameras (Point Grey 360 Spherical Vision Camera), screens (FogScreen), software (Max/MSP), tools and applications (Snapdragon AR). The conceptualization of The Coat Check is based on an analogy between digital technologies and coat checks that are both storage, retrieval and displacement systems. The Coat Check also raises questions on identity and history as it refers to belonging, temporality, and mobility.

This project is inspired by the work of Mona Hatoum and Kutluğ Ataman. Both artists' installations focus on the dialectics of the interior and exterior, past and present, memory and amnesia. This research originates from questions of identity, mobility and memory and evolves towards an understanding of technological displacement. 


\section{Acknowledgements}

This research/creation is the result of the generous technical support of Ryerson University (specifically Rogers Communication Center RTA staff and facilities) and York University Augmented Reality Lab. It has been a privilege to be at the Joint Program in Communication and Culture and access equipment and expertise of personnel of two universities at all times. I would like to thank Sal Greco, Richard Grunberg, Ryan Sykes of RTA Labs at Ryerson University. Andrew Roth, the technical manager of the Augmented Reality Lab at York University has helped me in each phase of the making of the installation. Lingying Cheng has spent innumerable hours doing programming and operating the immersive part of the installation during the two sessions open to public. To both of them, I am very grateful. Workers at Dynamic Iron Limited in Toronto custom made and delivered the steel ring central to the installation to the AR Lab. We bonded over migrant experiences as I explained to them my project and they told me their stories. Matthew Moreland of Art Gallery of Ontario assisted Andrew Roth and I during the filming of AGO's automated coat check. TCDD Istanbul Haydarpasa Gari Mudurlugu (Turkish Railroads Istanbul Haydarpasa Station Management) issued me an authorization to film at the premises on the day of shooting, two days before a fire destroyed the roof of the historic station. Mukaddes Koç, my mother, accompanied me during the filming and has a cameo appearance in the fog screen sequence of "the crowd at the station". I thank my supervisors Michael Zyrd and Caitlin Fisher, and committee member Michael Prokopow who were supportive even when I was stubborn and took many detours. I am indebted to Gail Vanstone who encouraged me to keep working on the final draft. Paula Gardner gave me invaluable feedback while Paul Moore facilitated the long and painstaking process of completion. I thank anthropologist Sarah Green for an inspiring discussion on borders in Lesvos, Greece. My gratitude goes to my family, Mukaddes, Mustafa, Koçer, Çağlar, Eren and Yonca Koç, and friends who have contributed to this work in more ways than I could recount here. A special thanks to Boris Pantev, Jona Pelovska and Anne Wordsworth. I am also very indebted to the late Robin Wood, my master's thesis supervisor, mentor and friend whose sense of critical thinking, dedication to teaching and philosophy of life anchor me at being true to myself and loving the journey. 
To Eren Koc, whose five-year-old fingers know their way around any mobile device and to whom the topics discussed here may appear archaic once he is old enough to read in English. 


\section{LIST OF FIGURES}

Figure 0.1 The Coat Check fog screen projection 11

Figure 0.2 The Coat Check fog screen projection, touch screen___ 12

Figure 1.1 The Coat Check overview ___ 19

Figure 1.2 The Coat Check sketch __ 23

Figure 1.3 The Coat Check screenshot__ 23

Figure 1.4 The Coat Check, making of ___ 24

Figure 1.5 The Coat Check screenshot___ 24

Figure 1.6 The Coat Check screenshot from webcam 25

Figure 1.7 The Coat Check overview, immersant in HMD__ 27

Figure 1.8 The Coat Check, webcam attached to HMD _ 27

Figure 1.9 The Coat Check, webcam on HDM 28

Figure 1.10 The Coat Check lab window projection _ 28

Figure 1.11 The Coat Check fogscreen projection, arrival of train _ 30

Figure 1.12 The Coat Check, fogscreen projection, exiting train__ 31

Figure 1.13 The Coat Check, fogscreen projection, participant dancing__ 31

Figure 1.14 The Coat Check, fogscreen projection, touch _ 32

Figure 1.15 The Coat Check, fogscreen projection, participant inside the fog __ 32

Figure 1.16 The Coat Check, through the fogscreen projection__ 33

Figure 1.17 The Coat Check the luggage___ 35

Figure 1.18 The Coat Check the luggage__ 36

Figure 1.19 Elsewheres (2008) screen shot___ 40

Figure 1.20 Elsewheres hand tracker pointed to lace tablecloth and ID cards__ 40

Figure 3.1 Homebound (2000) Mona Hatoum__ 72

Figure 3.2 Interior Landscape (2008) Mona Hatoum__ 75

Figure 3.3 Interior Landscape detail __ 76

Figure 3.4 Present Tense (1996) Mona Hatoum _ 77

Figure 3.5 + and - (1994) Mona Hatoum__ 78

Figure 3.6 It's a Vicious Circle (2002) Kutluğ Ataman___ 82

Figure 3.7 Testimony (2006) Kutluğ Ataman___ 84 


\section{TABLE OF CONTENTS}

Author's declaration __ ii

Abstract__ iii

Acknowledgements _ $v$

Dedication _ $v i$

List of Figures___vii

Introduction

Background ___ 1

Digital Routes, virtual homes and displacement as entrustment __ 6

Entrustment and "emanethane" ___ 9

The Coat Check via installations of Mona Hatoum and Kutluğ Ataman 12

From socio-cultural displacement to technological displacement 15

Chapter I: AR in relation to movement and identity ___ 18

The Coat Check, an immersive, interactive AR Installation __ 20

Technical specifications 20

Components of The Coat Check_ 20

The experience of The Coat Check

At the intersection of memory and technology

Chapter II: Querying technology and the notion of space___ 43

Technology and Historicity: towards an understanding of space $\_44$

Installation, enhanced spaces, identity

Chapter III: Dispositive displacement, an artistic inquiry __ 60 
Displacement: an overview

This Place/Displace: Mona Hatoum's intimate and intimidating spaces

On Hatoum: the familiar estranged

Home as an impossibility or anywhere is home: Homebound

Inside and outside, here and there Interior Landscape

This place, dis-place, misplace

This Place Meant/Displacement: Kutluğ Ataman's memory work 80

Of running in circles

Memory, amnesia and hypomnesia to hypermnesia

The Coat Check as a series of displacements 88

\section{Conclusion} 90

References 94

Appendices 98 


\section{INTRODUCTION}

I occasionally experience myself as a cluster of flowing currents. I prefer this to the idea of a solid self, the identity to which so many attach so much

significance. These currents, like the themes of one's life, flow along during the waking hours, and at their best, they require no reconciling, no harmonizing. They are "off" and may be out of place, but at least they are always in motion, in time, in place, in the form of all kinds of strange combinations moving about, not necessarily forward, sometimes against each other, contrapuntally yet without a central theme. A form of freedom, I'd like to think, even if I am far from being totally convinced that it is. That skepticism too is one of the themes I particularly want to hold on to. With so many dissonances in my life I have learned actually to prefer being not quite right and out of place.

Edward Saïd (295)

\section{Background}

This study developed out of an initial interest in multiculturalism, particularly concerning identity, memory and the in/communicability of the experience of displacement. It evolved into a research creation using augmented reality technology to understand digital technologies in terms of their innate quality of displacement as in data storage and transfer, and as part of a framework of global mobility of peoples. The Coat Check installation examines the intertwined relationship between digital technologies and human flows. Understanding digital technologies in relation to movement and within a paradigm of displacement has enabled me to situate such innovations as augmented reality in historicity and contextualize them as directly relating to socio-political questions and identity. The Coat Check asks if augmented reality technology could be seen as analogous to how memory functions in relation to movement and space. Because this technology is the overlaying of digital information onto real world at real time, it creates border crossings of tempo-spatial relations where "here and now" is always counterpointed by the real and the 
virtual, the tangible and the visceral, the inside and the outside. The Coat Check as research creation is also a narrative experimentation of form and content, by using personal archival footage of the author in conjunction with immersive, interactive digital environments

In 2002, a year after I arrived in Canada from my native Turkey to undertake graduate studies in film, I came across a television interview with the author, scholar and critic Edward Saïd on the topic of multiculturalism. Saïd claimed that Canada was unique in the way it institutionalized the idea of exile under the name of multiculturalism. ${ }^{1}$ I was intrigued by this remark, not only with regards to Saïd's writings on exile, the Palestinian conflict, and his own personal trajectory of displacement, but also as an individual who had made Toronto, a city with a dense immigrant population, her home. I was not in exile in the sense of being forcibly moved. Indeed, if anything, it was self-inflicted. Yet I was certainly displaced, transplanted to a new cultural context. This seemed "normal" in a city where half of the population is born outside of Canada ${ }^{2}$. In reality, there is little that is "normal" in leaving behind what is familiar and the reassurance of a present built upon a shared past. Displacement, and the new cultural environments that emerge as a consequence of it, became central to my research.

In fall 2007, together with Professor Kate Eichhorn, I designed a directed reading course in the Communication and Culture Program at Ryerson University entitled, "Personal Narratives, Memory and the Multicultural Identity." Through the readings for this course, I not only familiarized myself with the works of Will Kymlicka, Neil Bissoondath and Charles Taylor, among others, but also began to look into the ways in which narratives, especially self-writing, play an important role in understanding the

\footnotetext{
${ }^{1}$ Saïd mentions this in Reflections on Exile and Other Essays as well.

${ }^{2}$ Demographic information on the City of Toronto can be found on the website Toronto.ca
} 
subtleties of lived experiences. Cholars and authors such as Sidonie Smith, Marlene Kadar, Trinh T Minh-Ha, and Caren Kaplan, among others, guided me in the direction of feminist, marginalized, and post-colonial positionalities. It is partly due to the influence of their work that I diverged from my interest in multiculturalism as a policy towards self-writing and idiosyncratic narratives of displacement.

In the prologue to The Human Condition, Hannah Arendt observes that humans negotiate the boundaries of their condition.(1) One continually dismantles existing structures, resettles, and forms new physical, mental and affective bonds. It is precisely these new bonds, new settings, and the unique ways in which they tie to former ones that attract me to the study of the nature of displacement, the significance of space, and the workings of memory. Specifically, I was attracted to the role of memory in its function of preserving continuity within rupture or preserving an imagined continuity across a series of ruptures. In digitally enhanced spaces we inhabit, the many displacements of our lives are increasingly intertwined with technology. Via satellites, the World Wide Web and mobile devices actual and virtual spaces merge and create new presences/absences in which people are increasingly in more places than one.

My interest in displacement manifested itself in creative work, in fiction and documentary film. It gradually moved to installation art as the form allowed for spatial probing more than any other. I started creating installations using augmented reality technology (AR) in order to examine 'spaces of transition' while challenging notions of here and the present, there and the past. My work in AR began while taking graduate courses at the Communication and Culture Program. This was a new field for me, I had no prior experience and AR seemed to generate disorientations similar to the process of immigration for me: I had to unlearn preconceived ideas of what digital technology is, learn 
its language and customs, familiarize myself with its issues and comply while keeping a critical gaze.

In winter 2008, I took Future Cinema II, a course offered by the Film Program at York University, where I had earned my MA in 2004. The course director, Professor Caitlin Fisher, also the co-founder of the Future Cinema Lab at York University, agreed to let me take the highly technical and hands-on course which introduced me to augmented reality technologies. I was encouraged to test, using the hardware and software available in the lab, some of the ideas I was exploring with regards to identity and tempo-spatiality. Elsewheres (2008), the installation project I submitted for the course, became a prototype of what I could do in my critical inquiries involving space, memory and belonging.

In Elsewheres, using Designer's Augmented Reality Toolkit application ${ }^{3}$ I virtually overlaid black and white stills of my grandparents' village in the Aegean (Pisi, Mugla) to the lab walls, visible via a head mounted display (HMD). The person who wore HMD could see the photos superimposed to the actual walls. I also placed my Turkish ID card, Quebec driver's license and my Canadian permanent resident card on a table, alongside a lace tablecloth. While the immersant could see both the lab and the black and white stills s/he could touch these real objects via the hand tracker. Each card, once the immersant touched it, triggered an audio clip in which I read out loud the contents of the cards, taking on an accent: Turkish 'public broadcaster' voice for the Turkish ID, Quebecois accent for my license, and an Anglophone accent for my permanent resident card. Once the immersant touched the tablecloth, a spherical image appeared on the top of the object, of an elderly lady, my grandmother, making that very tablecloth and looking up at the camera saying in

\footnotetext{
${ }^{3}$ DART is a set of software tools that enable AR experiences and applications. Developed
} at Georgia Institute of Technology, DART facilitates creation of AR environments. 
Turkish, 'That's enough, stop filming.'

What does it mean to belong to different affective, linguistic and cognitive realms simultaneously? Could immersive technologies serve as a tool to explore the simultaneity of diverse experiences? How does technology relate to embodied experiences? How relevant is memory to the present moment? What sets apart augmented reality technology from other forms of storytelling? The making of Elsewheres paved the way for The Coat Check, the project at hand. While Elsewheres dwells on the idea of home and citizenship The Coat Check explores the notion of space and movement both physically and technically. 


\section{Digital Routes, Virtual Homes and Displacement as Entrustment}

The research I undertake links the phenomenon of displacement to digital technologies that challenge traditional borders of movement, presence, accessibility and proximity. Locative media, ubiquitous computing and augmented reality are some of the new technologies and conceptual paradigms in which a reassessment of space is inherent; which in turn call for epistemological and ontological critical inquiries. This research lends itself to the study of many displacements at work within the practice of technologically enhanced space: digital displacement that enables data to be available and transferable (as in code, programming); displacement of individuals inhabiting real space while partaking in virtual and/or mixed environments; and on a transnational scale, the displacement of peoples for whom technologically enhanced space is crucial to ideas of home, family, community, belonging, cultural and political identity. Within this broad theme, the focus is on a personal narrative of displacement in the context of installation art because the form urges us to view tempo-spatial relations from multiple vantage points, unique to each inhabitant/participant, dynamically reconditioned as one moves or stands still. This study inquires into the digital enhancement of AR by creating a non-linear storytelling environment composed of digital media, real/virtual objects, hardware and software.

Displacement is at the core of digital technologies. The binary numeric system of ones and zeros, the very image of difference, stands for all of the digital interactions with which we are involved. Hardware components such as discs and drives around the globe are entrusted with the safekeeping of digital information. Digital media are transferred from one electronic device to the other. We need memory and space in computing. Satellites send back signals from space to specific locations on earth to enable global positioning systems 
(GPS). The Internet, while accessible globally and wirelessly, is composed of fiber-optic lines connected to servers, routers and other components stored in points of presence (PoP). Internet terminology self reflexively maps out networks and bodies that "house/host" and “displace": colocation centers, interexchange points (IXP) and interexchange carriers (IXC) refer to the use of digital and actual space as well as circulation of digital data around the world. With merchants, transporters, innkeepers and middlemen, Internet resembles a digital Silk Road where displacement is the lingua franca.

Our lives are more and more entrusted to digital displacements. As we circulate around the world physically and virtually, we rely on digital technologies to sustain interactions, transactions, access to information and intimacy. Because, for example, we can connect with others through social media or voice over IP services such as Skype from anywhere around the world via Internet, we have a sense of continuity that surpasses the immediate settings of our present moment. There are multiple displacements involved in this sense of interconnectedness. We make room for virtual interactions while vacating full awareness of the given circumstances, for example looking around in public transit, noticing a person needs help with a stroller. We are also reminded of distances and time zones as we reach loved ones across screens, in their mediated presence the fact that they are elsewhere and out of reach may feel even more tangible.

What we store, how we store and retrieve digitally becomes increasingly crucial to our identity. The recent loss of a portable drive in the possession of Human Resources and Skills Development Canada containing information on more than half a million students who, between 2000 and 2006, were in Canada Student Loans Program is an example of the 
kind of privacy breach that is at stake with loss or misplacement of data. ${ }^{4}$ Security and surveillance of stored data increasingly becomes an industry of its own. Computers are searched at border checkpoints much like luggage. Our personal lives documented and uploaded on social network sites become commodities. We participate in geographically dispersed activities, and share with diverse communities within the practice of technologically enhanced space.

Donna Haraway’s 1985 article "A Cyborg Manifesto: Science, Technology, and Socialist-Feminism in the Late Twentieth Century" heralds an anti-essentialist feminist potential in what Haraway calls a cyborg: theorized and fabricated hybrids of machine and organism. (149-181) The 1982 sci-fi classic Blade Runner (Dir. Ridley Scott), based on Philip K Dick's 1968 novel Do Androids Dream of Electric Sheep? depicts an authoritarian witch hunt for rebellious replicas, created with the motto "more human than human". Both the article and the film point to the potentiality of technology in transforming human life and altering life as we know it. In 2012, scientists succeed with 100\% accuracy in storing and retrieving data in synthesized DNA. (Goldman et al, 77-80) While a blurring between the machine and the organism, the natural and man-made is not news, enabling DNA to store digital data opens up unprecedented archival possibilities. Owing to interdisciplinary research in nanotechnology, information technology and synthetic biology, DNA as a digital archive has the potential to transform the ways in which digital media is safeguarded and transferred.

Storage and retrieval of media in a digital safekeeping system resembles a coat check: items are assigned numeric identifiers, transferred to corresponding designated spaces, kept

\footnotetext{
${ }^{4}$ There is much media coverage on the topic, including a Globe and Mail article dated January 17, 2013.
} 
and returned in a framework of multiple displacements. Coat checks are centers of transition and interaction with the understanding that the entrusted objects will be retrieved upon demand, when an arbitrary and unique signifier, a numbered ticket is exchanged for the signified, an object. In this sense The Coat Check installation refers to the nature of the very technology it utilizes while addressing the broader issue of displacement of peoples around the globe.

\section{Entrustment and "Emanethane"}

The Turkish words of Arabic etymological origin "emanet" (the entrusted) and the derivative "emanethane" (a place of safekeeping, usually designated storage area in train stations, bus stations and airports) lend themselves to a nuanced reading of the relationship between digital technologies and displacement. Emanet could be both material and abstract, both animate and inanimate. The idiomatic phrase "Allaha emanet ol!" when someone travels, literally translates as "Be entrusted to god!" The word used in this sense refers to the transitory nature of the being in the world ultimately under god's care. In the Ottoman tax system, emanet is one of the two methods of tax collection via a trustee who acts on behalf of the state. The word "emin," from which "emanet" derives, means sure, safe, secure and trustworthy. Likewise, digital technologies displace and replace based on a principle of trusteeship. For example, fiducials, or fiduciary markers in digital imaging technologies act in a system of trust not much different than that of the legal meaning of the word "fiduciary," holding something in trust. Emanet, in this sense, comes close to emphasizing the safeguarding of that which is in transition, including the self in relation to digital technologies.

Although emanethane as a metaphor was instrumental in the conceptualization of the installation, in its design The Coat Check was modelled after a coat check. Firstly this was 
a choice with participants in mind. Coming from diverse backgrounds, the participants, familiar with coat checks, could interact easily in the immersive environment. Secondly, participants placing and replacing the coat hanging on a circular rod with place markers facilitated the technical work behind the installation, creating clearly defined boundaries for virtual objects. Physically, because the HMD is attached to the main computer board with a cord, it limited the movements of the immersant to the closed circuit of the coat check without restricting their interactive capacities.

The Coat Check positions emanet, its connotations of trust, transition and temporality as affect. It is a juxtaposition of bodies, animate, inanimate, physical and virtual in dynamic relations, gliding, attaching and rubbing against one another. Its narrative structure triggers affects without telling a coherent story of any particular person or persons, without amounting to a singular discourse. The enhanced sensory perceptions move the immersant in intimate and intimidating directions as familiarity and foreignness blend.

"Affect arises in the midst of in-betweenness: in the capacities to act and be acted upon...Affect in its most anthropomorphic is the name we give to those visceral forces beneath, alongside or generally other than conscious knowing, vital forces insisting beyond emotion that can serve to drive us toward movement toward thought and extension that can likewise suspend us (as if in neutral) across a barely registering accretion of force relations or that can even leave us overwhelmed by the world's apparent intractability. Indeed affect is a proof of a body's never less than ongoing immersion in and among the world's obstinacies and rhythms, its refusals as much as its invitations " (Seigworth and Gregg, 1)

One component of the installation particularly pays tribute to the concept of emanethane. Onto the fog screen (a screen made up of very fine particles of water) images of a train station in Istanbul is projected. I had visited that particular train station in search of an emanethane and instead I found digitally operated lockers bearing a sign that said "Emanethane / Left Luggage Lockers". I filmed sequences of the arrival of trains, the crowds moving about in the station and people trying to entrust their belongings to these 
lockers. The affects resonate around these images as the participants engage bodily and often playfully with the projection. Fig 0.1 shows a participant "exiting" the train as the doors open, by traversing the fog screen with a luggage.

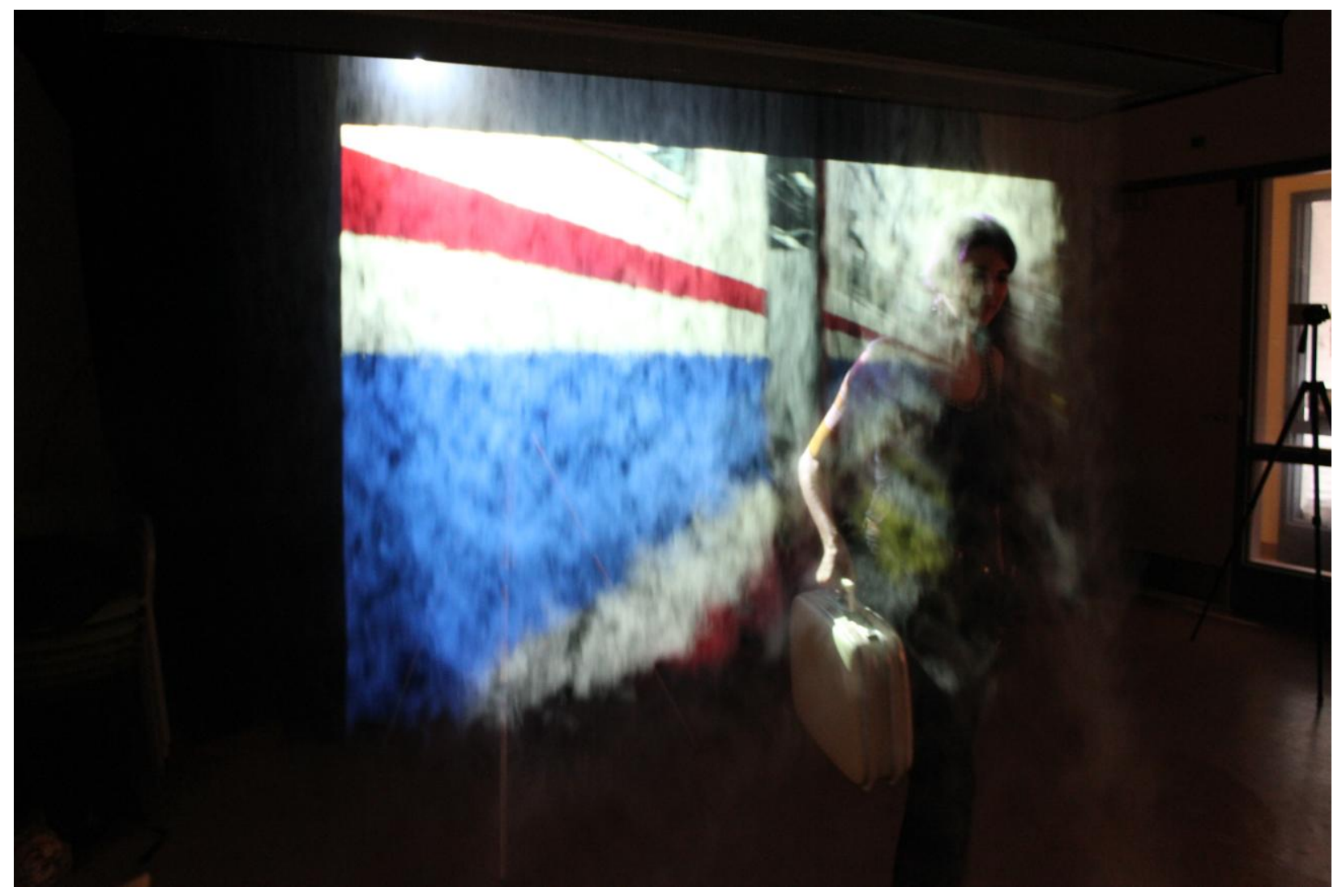

Figure 0.1 The Coat Check fog screen projection, arrival of train, the doors open.

While the fog screen displays a looping video of the train station where a traditional emanethane is replaced by touch-screen lockers, participants could interact with images in various ways. As Istanbul commuters spend many long moments trying to figure out how to make these new digitally operated "emanethane"s work, The Coat Check pays homage to a 
world in quiet passing. ${ }^{5}$

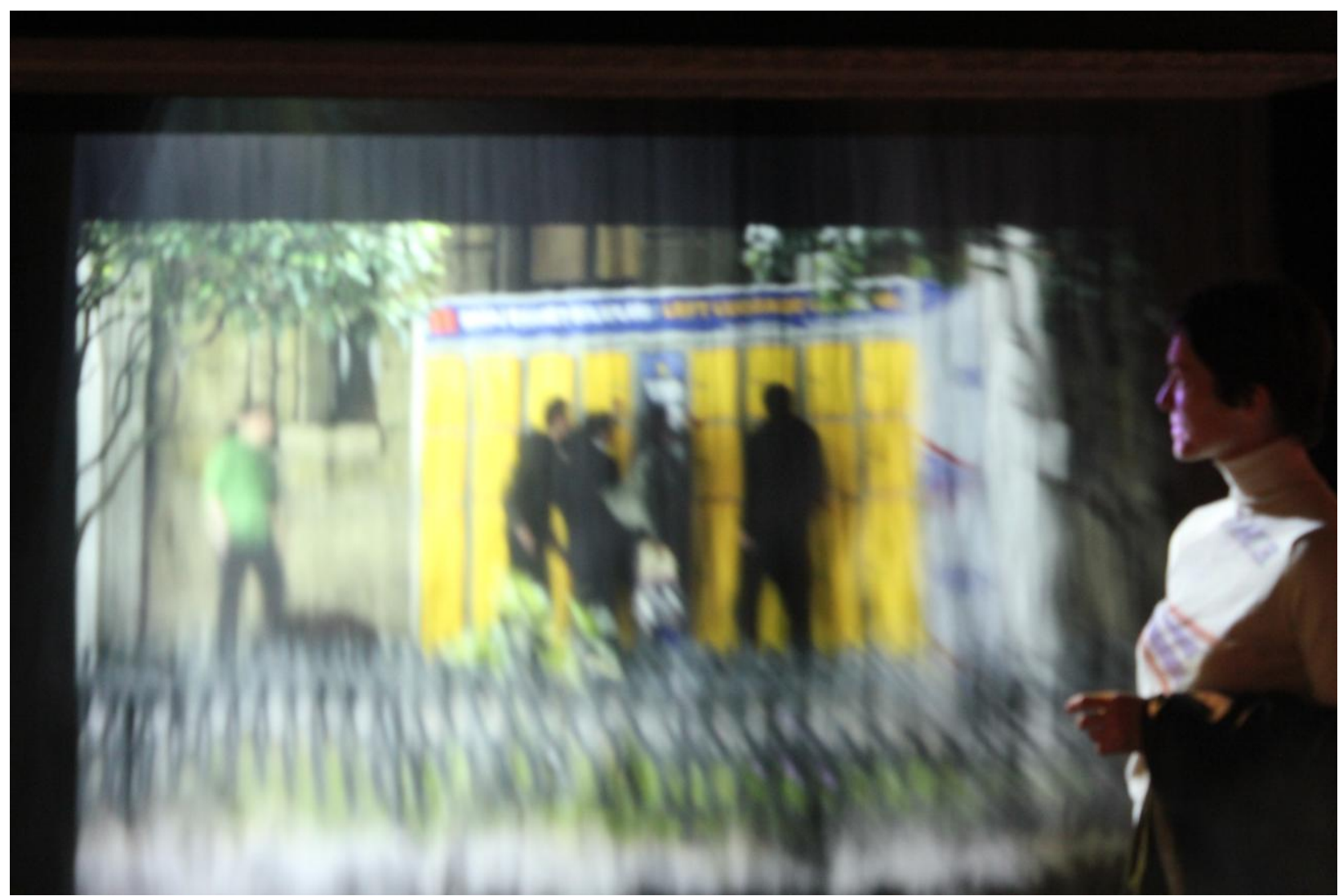

Figure 0.2 The Coat Check fog screen projection, touch-screen lockers at the train station.

\section{The Coat Check via installations of Mona Hatoum and Kutluğ Ataman}

In the process of creating The Coat Check as an immersive interactive AR

experience, I was inspired by the installations of Kutluğ Ataman and Mona Hatoum.

Though neither of the artists' oeuvre is in AR, their installations have been instrumental in my explorations of displacement. While Hatoum plays with the notions of home, familiarity, alienation, distance and global politics at large; Ataman painstakingly archives

${ }^{5}$ The historical train station featured on the fog screen partially burnt down the day after I filmed the sequences in this installation and is no longer in use except for suburban trains. 
amnesiac narratives, cacophonies, pluralities and vicious monologues woven around identity, belonging, marginality and history. Both artists ultimately question the dialectics of the interior and the exterior, the real-time/space versus memory time/space implicit in displacement.

I am interested in installation art with a core concern in examining manifestations of presence, absence, an enhanced tempo/spatial embodiment that challenges the participant to be both at the site of encounter with the artwork as a witness and make part of it via inhabiting the very space, always a transgression of inside and outside, being simultaneously both. As I will more fully explore in Chapter Three, Kutluğ Ataman and Mona Hatoum's œuvre exemplify a preoccupation with the intimate and intimidating space all being one, an epistemological influx between the self and the Other and identity being continually negotiated in distancing and nearing. Hatoum and Ataman inspired The Coat Check and helped me theorize the conceptual outline of the installation by way of providing a critical distance rather than solely focusing on my own research creation.

When I look around me in the subway, I observe people bent over their cell phones, sometimes holding them as if they are in a trance or in midst of praying. When I ask someone directions on the street often the person needs a few seconds to adjust to "our common reality", taking off her earpiece. Watching people take photos with tablets in front of monuments, or seeing more phones record a concert than people just listening to the music on stage, I ask myself where we collectively are. It seems to me that such 'distractions' are sanctioned with new technologies of communication where inclusive and exclusive experiences of being-there-in-the-moment are traversed. The uniqueness of an adventurous road trip for two is enhanced by a 'traceability' of the entire trajectory via GPS and perhaps the accompanying voiced instructions in English with a Spanish flare, if we're 
off to a South American destination. A voice enabled virtual personal assistant may even be the fourth 'person'. As Siri jokes circulate on the internet we grow accustomed to -while simultaneously grow into- mediated, mixed and digitally manipulated environments.

We have not always lived like this, but there seems to be a self-effacing quality to new technologies that lead us to forget that it has only been half a century that computers are made commercially available and less than a quarter of a century that World Wide Web protocol was written and Internet put in use of the public. In perspective of the history of humanity, this is a very short time frame but we are so accustomed to navigating innovations that "pre-digital interconnectedness" almost has the aura of the archaic. We are also accustomed to bringing forth data and multi media at a glance, a click or a touch on screen to the point that "ancien regime" of the non-computing world exits as an afterthought to our command of the present and its assumed difference also dissociates us from the heavy burden (relics, manuscripts, real-life archives, tapes and so on) of physicality. A humorous take on this subject comes from Leo Burnett France, an ad agency that created the viral video of a man who keeps pointing to his wife that anything she can do on paper she could do on a tablet (playing Sudoku, drawing, reading, sticky notes) except when he is in the bathroom, realizes there is no toilet paper and his wife slides the tablet with the picture of a roll of toilet paper from under the bathroom door. (Leo Burnett France, web)

In The Coat Check, the juxtaposition of the material objects with AR objects and devices serves as a means to draw attention to our ambiguous, often contradictory relationship with materiality in a digitally enhanced world. Hence the use of a luggage full of tickets, transfers, days passes, baggage tags, a wool coat on a steel rack and more indirectly Super $8 \mathrm{~mm}$ footage imbedded in the immersive central piece. What are the points 
of collision, collaboration, reconciliation between the material and the digital? As Instagram gives us the Polaroid vintage feel, for example, what happens to nostalgia? Are we more in tune with the simulacra than "the real thing"?

Where exactly are we in this present instance? It is hard to tell while we are accustomed to being part of that ambiguity, being displaced as many times as it takes in a matter of seconds, navigating life as a digitally enhanced space. Once displacements are habitual and perpetual, one wonders whether they culminate to Other mediated spaces of heterogeneity, a plurality which may be viewed as a series of simultaneous displacements or multiplacement, a term I coin to address the complexity of technological displacements.

\section{From political, socio-cultural displacement to technological displacement}

The term displacement is mainly associated with global migrations (both individual and collective), refugee rights, policy making and diasporic identity. Displacement emphasizes the uprooting from an "origin," and hence bears in itself the stigma of an essential, initial belonging. By utilizing the term multiplacement, I focus on the process in which one transitions in different linguistic, cultural and affective settings, exemplified in postcolonial literature and film, and in this specific study, the installations of Hatoum and Ataman, but to a further degree and in particular the digitally enhanced space and the ways in which, for example, AR functions. I nevertheless keep in mind the socio-political implications of displacement in the face of forced migration, deterritorialization, genocide and ethnic cleansing. In such cases the "dis" always refers to a political landmark, a constant reminder of a historic rupture and/or massive trauma. Multiplacement on the other hand is situated in the present, in everyday interactions, in the complexities of navigating through technology and geographic/affective distances.

Multiplacement, within the context of this study, is a technologically enhanced space of 
physical, virtual and affective realms embodied in flux, between actuality, memory and tactility, between lived experiences and imaginaire. The Coat Check's central immersive component is created by overlaying a "memory arcade" of media on real space in the form of interplay on borders and boundaries. Like the leitmotif of Palestinian displacement in the life and oeuvre of Mona Hatoum and the place of the marginal exemplified by Kutluğ Ataman's work, multiplacement is the continuum of displace and this place. It follows in the footsteps of post-colonial preoccupation with hybridity in the vein of Bhabha and Saï, who, on Hatoum's work has written “The Art of Displacement: Mona Hatoum's Logic of Irreconcilables", literary criticism and semiotics such as Bakhtinian heteroglossia and human geography in Foucauldian heterotopia.

What are the nuances to displacement? Is it possible to see displacement as "a process," thereby arguing that it is not so much about leaving one place for another but evolving continually in the renegotiations of the self bound to the Other irreversibly through time and space? It is possible to explore the nuances of displacement by focusing on movements and shifts, returns and remembrances, mental and affective processes? What is at stake when a discourse on displacement shifts its axis towards multiplacement?

These questions can be posed only with an interdisciplinary approach, engaging readers to rethink the intricate networks of a digitally enhanced contemporary life and art. The Coat Check augmented reality installation becomes a test ground where the discussion around space, mobility and displacement is furthered by introducing technologies of proximity, for example tracking systems, as a key role player in understanding identity. While Chapter II serves as a historical overview of technology, it also addresses issues of surveillance and control, more and more bound to digital technologies. As such this work brings together social and cultural studies of displacement on the one hand and new media, 
communication technologies on the other. 


\section{Chapter I}

$\mathrm{AR}$ in relation to Movement and Identity

The Coat Check, an immersive, interactive AR Installation

Technical Specifications of The Augmented Reality Lab

Components of The Coat Check

The Experience of The Coat Check

At the intersection of memory and technology 


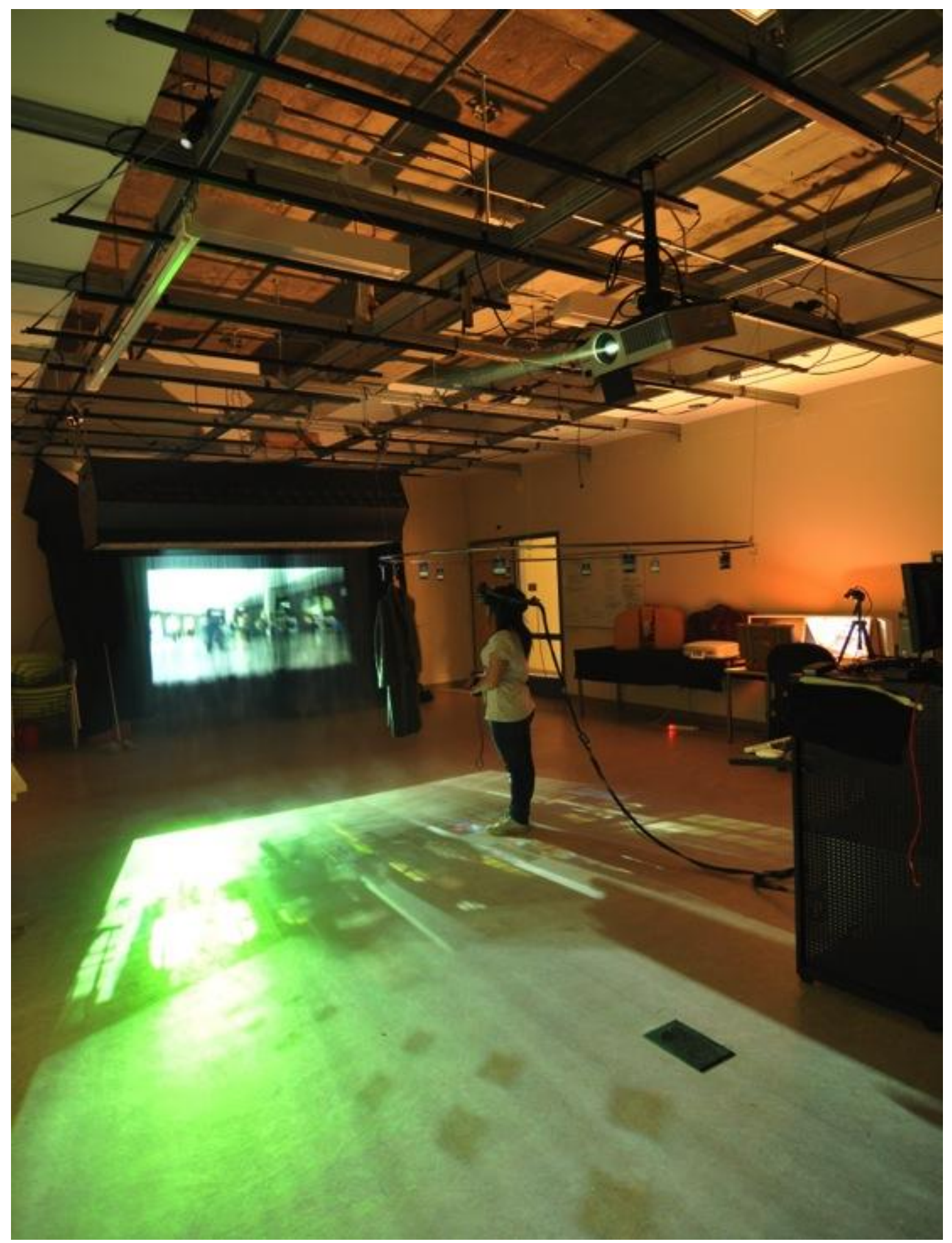

Figure 1.1 The Coat Check overview, immersant in head mounted display (HMD) and a hand tracker, with ceiling mounted sensors. 


\section{The Coat Check, an immersive, interactive AR Installation.}

\section{Technical specifications of the Augmented Reality Lab, York University}

Dimensions of the lab are approximately $9.2 \mathrm{~m} \times 6.1 \mathrm{~m} \times 2.8 \mathrm{~m}$

The intersense VETracker IS-900 has 30 rails (15 x 2 rows) with 7 available ports for trackers. (Used for the positioning of virtual objects that stand for video-clips in the circular coat check immersive experience with HMD and hand trackers)

Wireless trackers

SnapdragonAR is currently on version 1.2.4. Developed in the lab in collaboration with Dr. Mark Fiala using a tracking library he invented called mfd-5 specifically for this software. Uses black and white markers and renders video on a plane.

Though the tracking library is no longer ARTag.

Fogscreen Model name Inia is made by Fogscreen Inc. It uses ultrasonic pulses to create a super fine particulate curtain of water. 8 emitters with 3 speakers each. Fogscreen fog is $2 \mathrm{mx} 2 \mathrm{~m}$, weights about $200 \mathrm{lbs}$ plus 20L of water. Mounted using teralift pulleys.

Overhead grid is made by Unistrut.

Projectors are Infocus IN42+

Webcam for Snapdragon AR is Dynex 1.3 MP webcam.

Max/MSP version 5 was used at the time of the installation. Though version 6 contains many new features that make programming for virtual environments easier, therefore the Cosm objects used to create the Arlab Max objects is no longer necessary (and parts of it are not compatible with Max 6).

Mac Pro with 3 GeForce 7600

Mac Pro with 1 Nvidia Quadro 5200

Head mounted display is an Nvis optical see through display xga 1024x728pixels per eye.

\section{Components of The Coat Check}

Central coat check ring with 24 markers that trigger 24 videos (Intersense, HMD, handtracker)

Fog screen projection (a video loop of boats on Bosphorus, arrival of trains, crowd at the 
station and people at left luggage lockers).

A luggage with tickets and transfers in it. Placed on a table, with a webcam directed toward its contents. Tickets are attached to AR markers that trigger 6 videos (via Snap Dragon AR) Lab window projection of a video shot with a spherical vision camera (Lady Bug Camera)

\section{The experience of The Coat Check:}

One person at a time can immerse in the central coat check area, clearly defined within the borders of a steel ring hanging mid air. Once the immersant wears the HMD and the hand tracker, she can, inside the ring, navigate through 24 video clips that play when the hand that wears the tracker touches and enables them one by one by placing the coat in different hooks on the ring. The videos are semi-transparent and their scale changes with the movement of the hand: larger when hand moves away from the immersant and smaller when the hand is closer to the HMD.

Other components, the luggage, the fog screen projection and the lab window projection are accessible to everyone in the room, at all times. They surround the central ring: the looping video on fog screen creates a sense of transit and dispersion while the lab window projection of a coat turning in a vicious circle on an automated coat check alludes to cycles and repetitiveness of displacement. Participants can interact with the luggage on a corner and its contents, by showing to the webcam travel documents inside the luggage. Videos play simultaneously or one by one, depending on how the participant positions the travel documents. 
The Coat Check was created collaboratively, over the course of two academic years at the Augmented Reality Lab, York University where it met with the public twice in two open houses in April 2011 and May 2011. While I conceptualized the installation and created the content I am indebted to many behind the scenes collaborators.

I began the research creation process by digitizing my personal archives in various formats (16mm, Super 8, PAL High-8, DV, mini-DV, HD, audio tapes) at Radio Television Arts Media Lab, Ryerson University. The footage in question consisted of a decade long journeys between cities and countries, since my arrival in Canada in 2001. I planned to suspend these scattered moments of diverse experiences in the air, against the backdrop of the AR Lab and access them at the real and symbolic gesture of moving a coat from one hook to the other. The idea was to integrate a memoryscape to the present landscape and experience disorientation (where am I?) and a sense of multiplacement (I am both immersed in these images and sounds while being aware of the room, people, objects around me, who in a way become part of the 'expanded screen-world').

The memoryscape or the memory arcade posed an immediate a challenge: we could only utilize so many clips without slowing down or crashing the program. Like in many dealings with technology, the challenge also became an opening, dictating the work to be compact, bared down to its core. We began experimenting with audio/video clips, scattering them in the $3 \mathrm{D}$ coordinates of the lab space. 


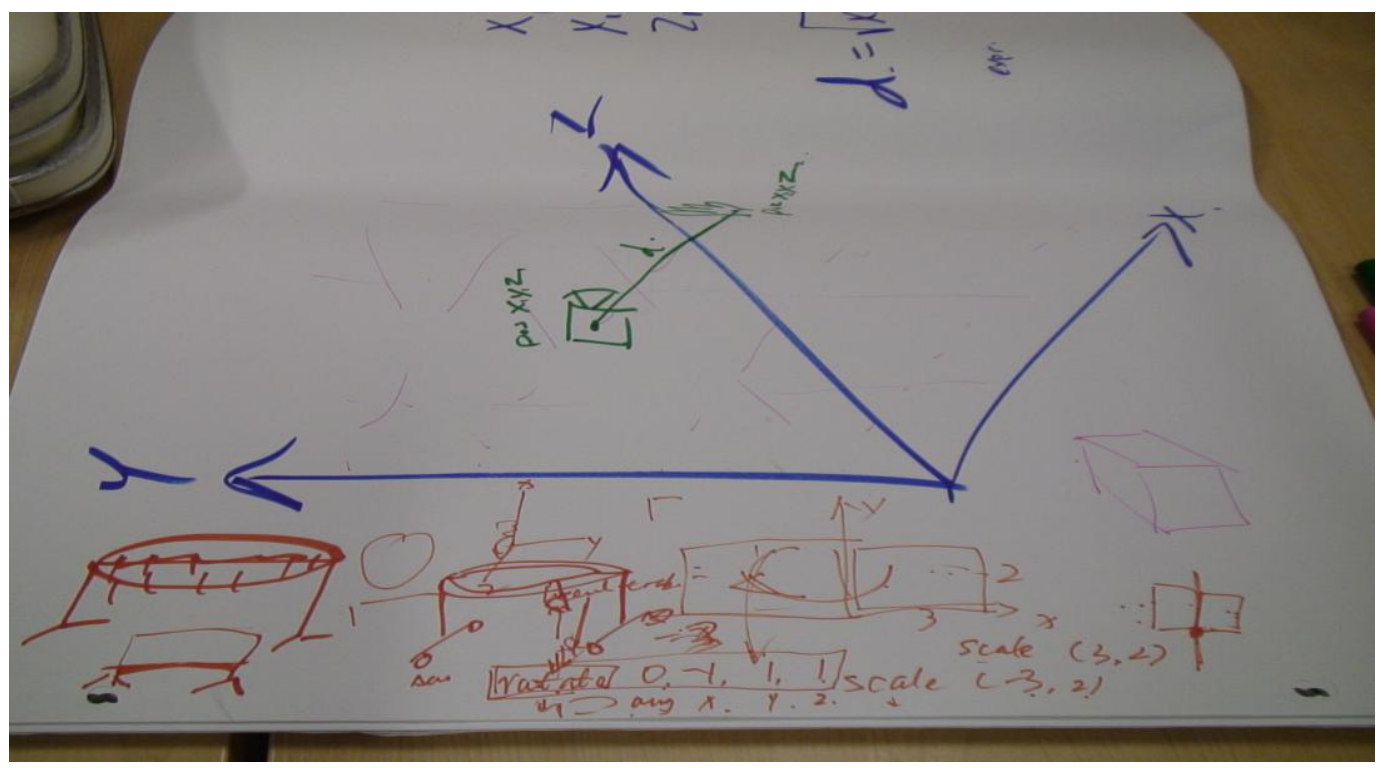

Figure 1.2 The Coat Check sketch, X, Y, Z coordinates of space.

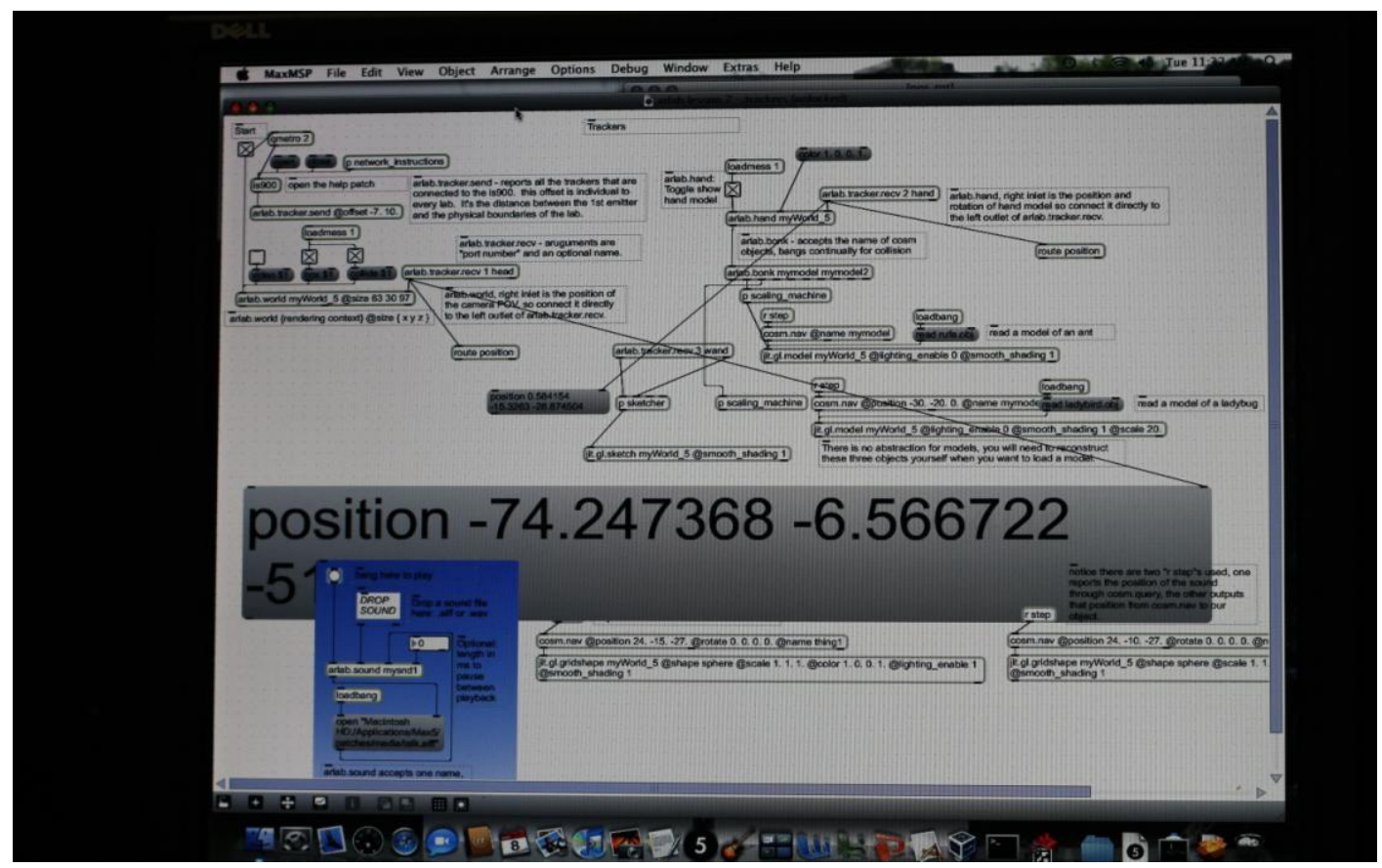

Figure 1.3 The Coat Check screenshot, tracking position in real time. 


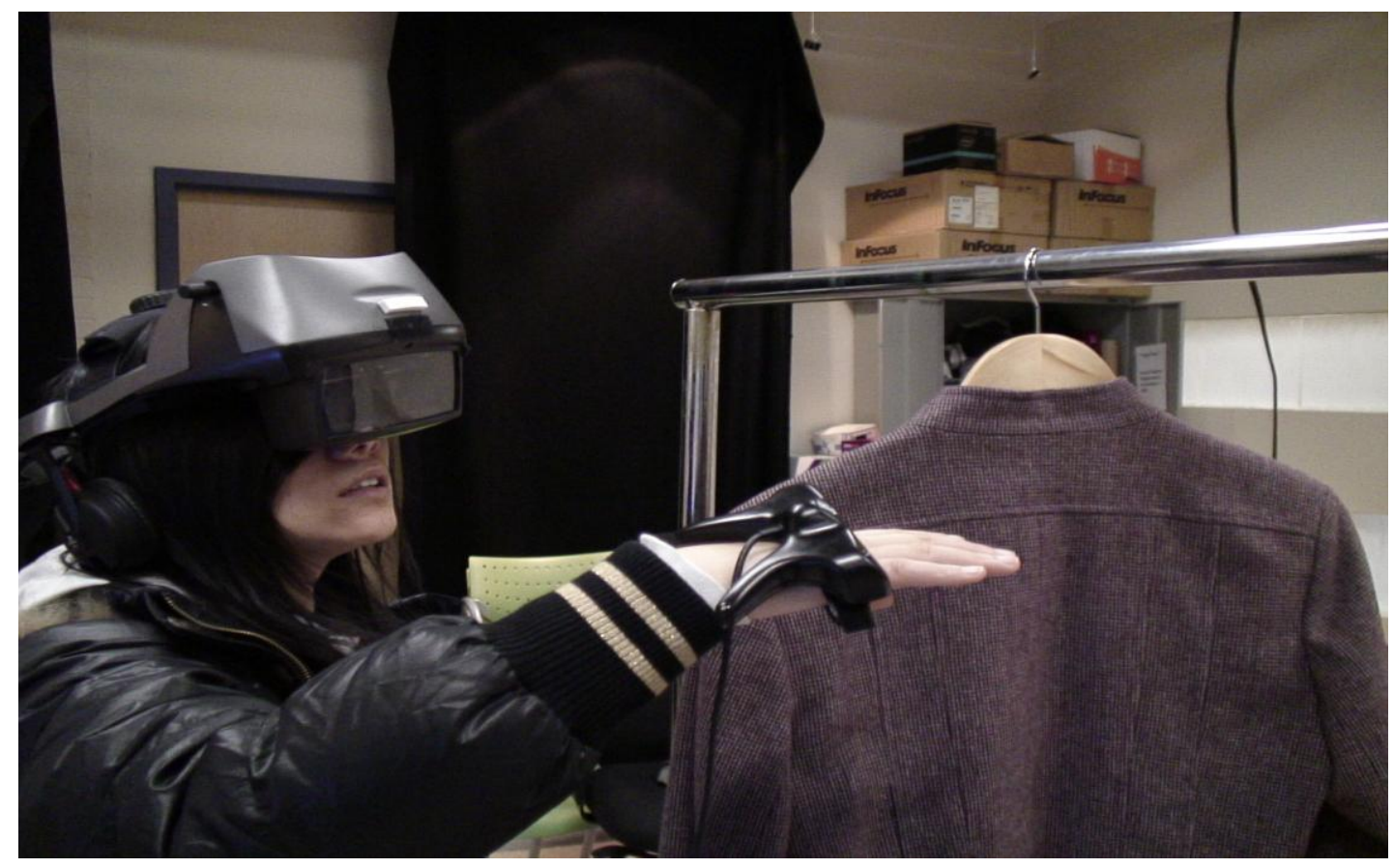

Figure 1.4 The Coat Check, making of, immersant in HMD, hand tracker.

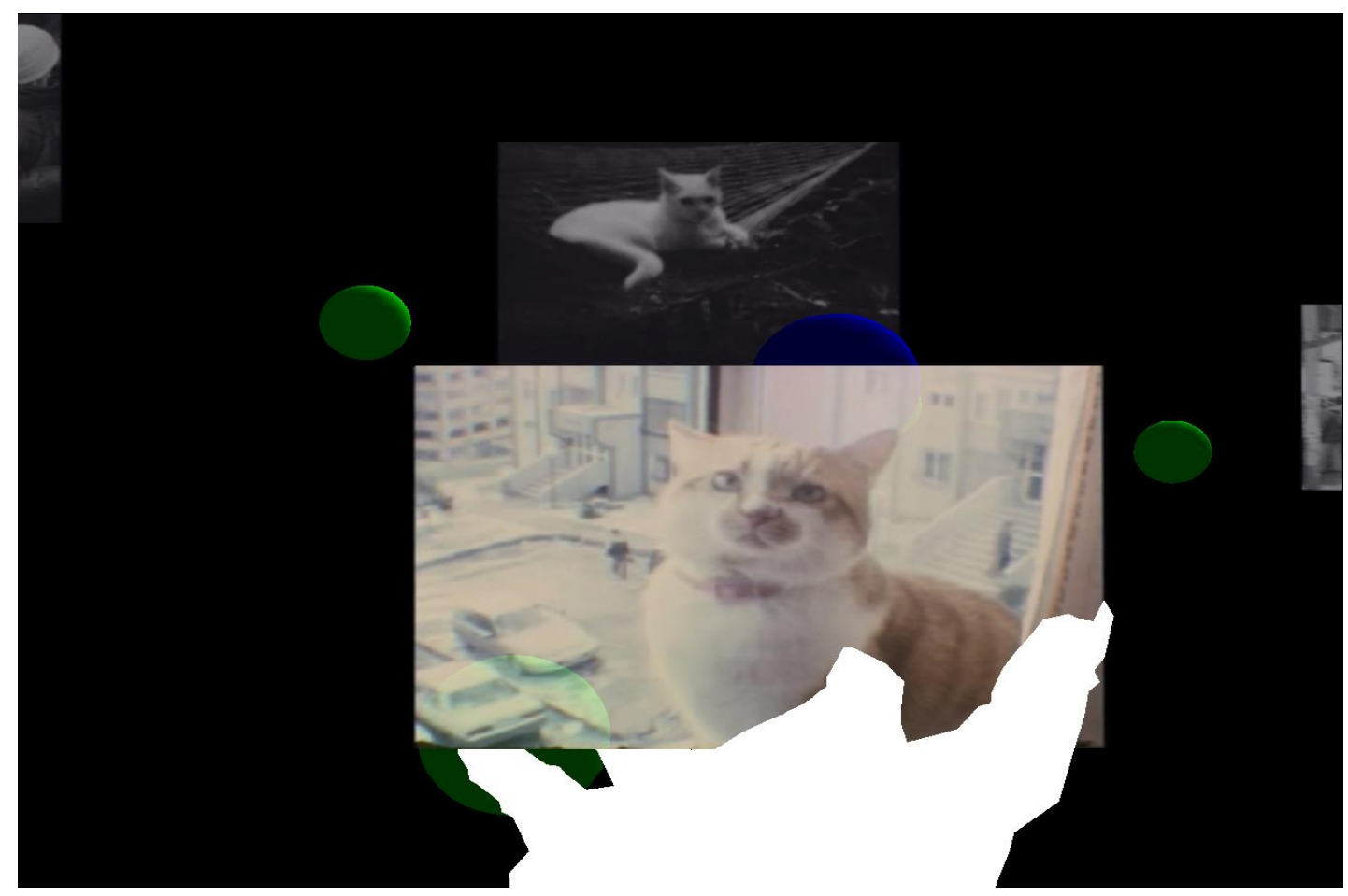

Figure 1.5 The Coat Check screenshot, video vignettes positioned in space. 


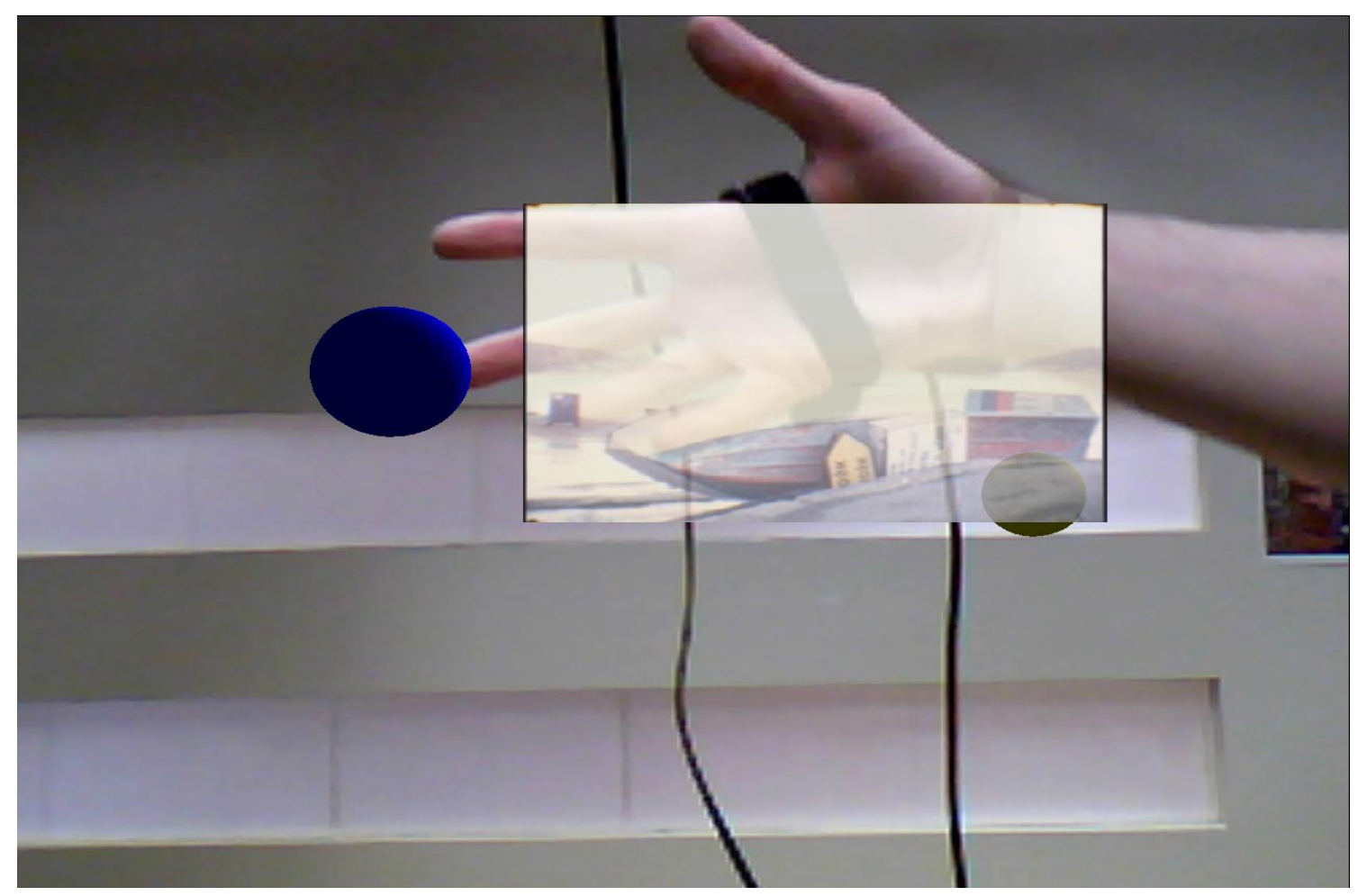

Figure 1.6 The Coat Check screenshot from webcam, immersant in HMD, hand tracker. Media superimposed to real space.

Figure 1.2 to Figure 1.6 show the initial experimentation with motion tracking technology (Intersense IS900), head mounted display (HMD) and hand tracker, using Max/MSP programming language, seen in Figure 1.3. The balls in Figure 1.5 and 1.6 represent video clips placed in 3D lab space. Once triggered by the hand tracker (by coming in touch with the zone the ball stands in for) the corresponding media plays. In the completed project the visualization of the ball markers and the virtual hand representing the tracker are hidden, so the immersant only sees the real space and the media upon displacing the coat. The ball markers become the actual hooks of the circular coat check, a metal ring suspended in the air.

The inertial-ultrasonic hybrid tracking technology, a head mounted display and a hand tracker enables the placement of 24 video-clips on 12 locations, each marked by a hook. 
Once the immersant's tracker-equipped hand places the coat on a hook, a semi-transparent video materializes, allowing the immersant to play it on "any surface in the given space", up close in the palm like on a mobile device or a large projection on the wall if the arm is extended. The video is attached to the hand, becoming smaller as the hand moves close to the body or larger if pushed outwards. It drifts away as a still image if immersant chooses to displace the coat once again to another hook. Next video takes over.

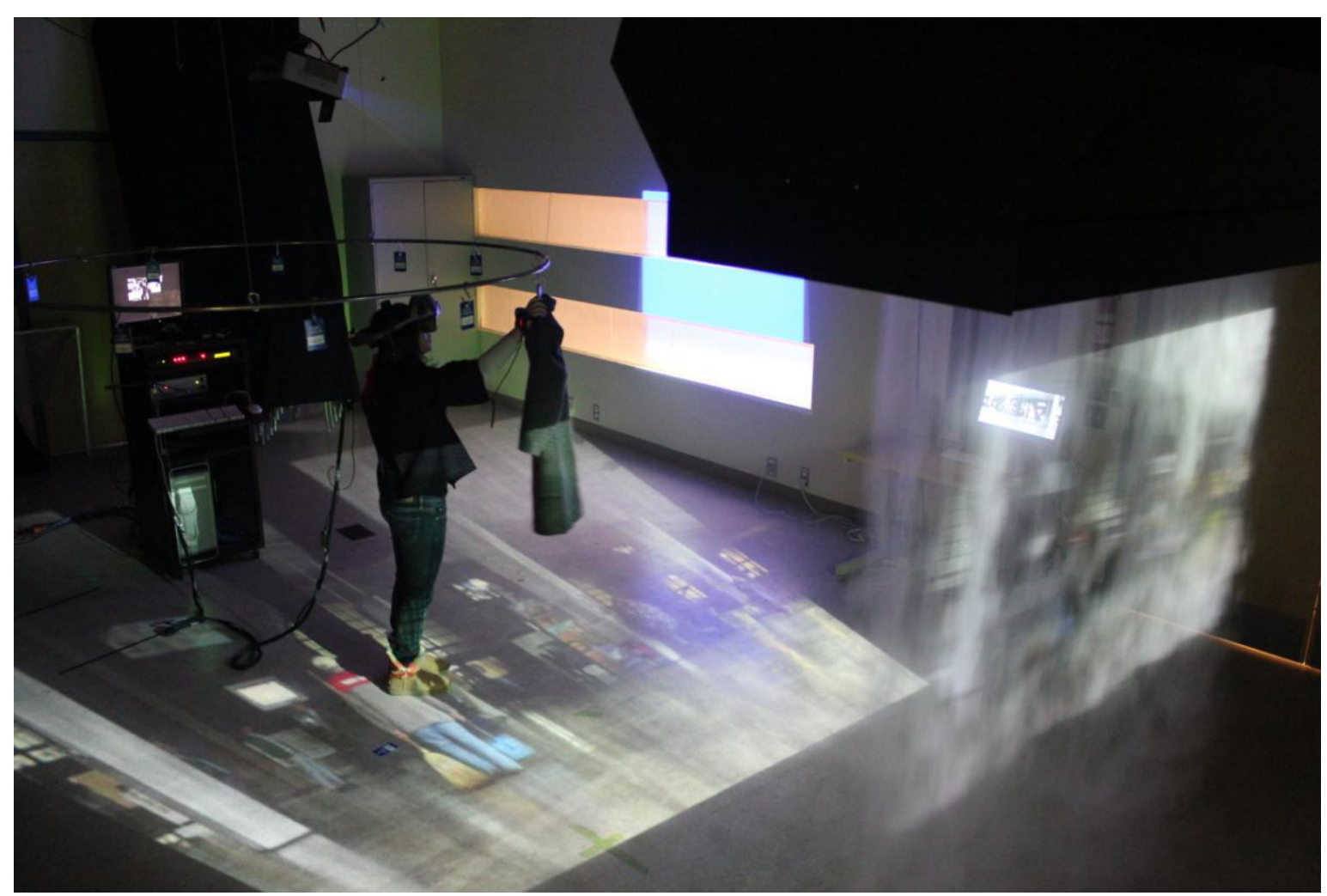

Figure 1.7 The Coat Check overview, immersant in head mounted display, a hand tracker.

In order to monitor and/or document what the immersant sees and hears a webcam is attached to the head-mounted display. Via the webcam we can trace what the immersant experiences. While we take on the role of second-hand viewer (watching what the immersant is seeing on a screen), the immersant sees/hears us as part of her embodied experience. 


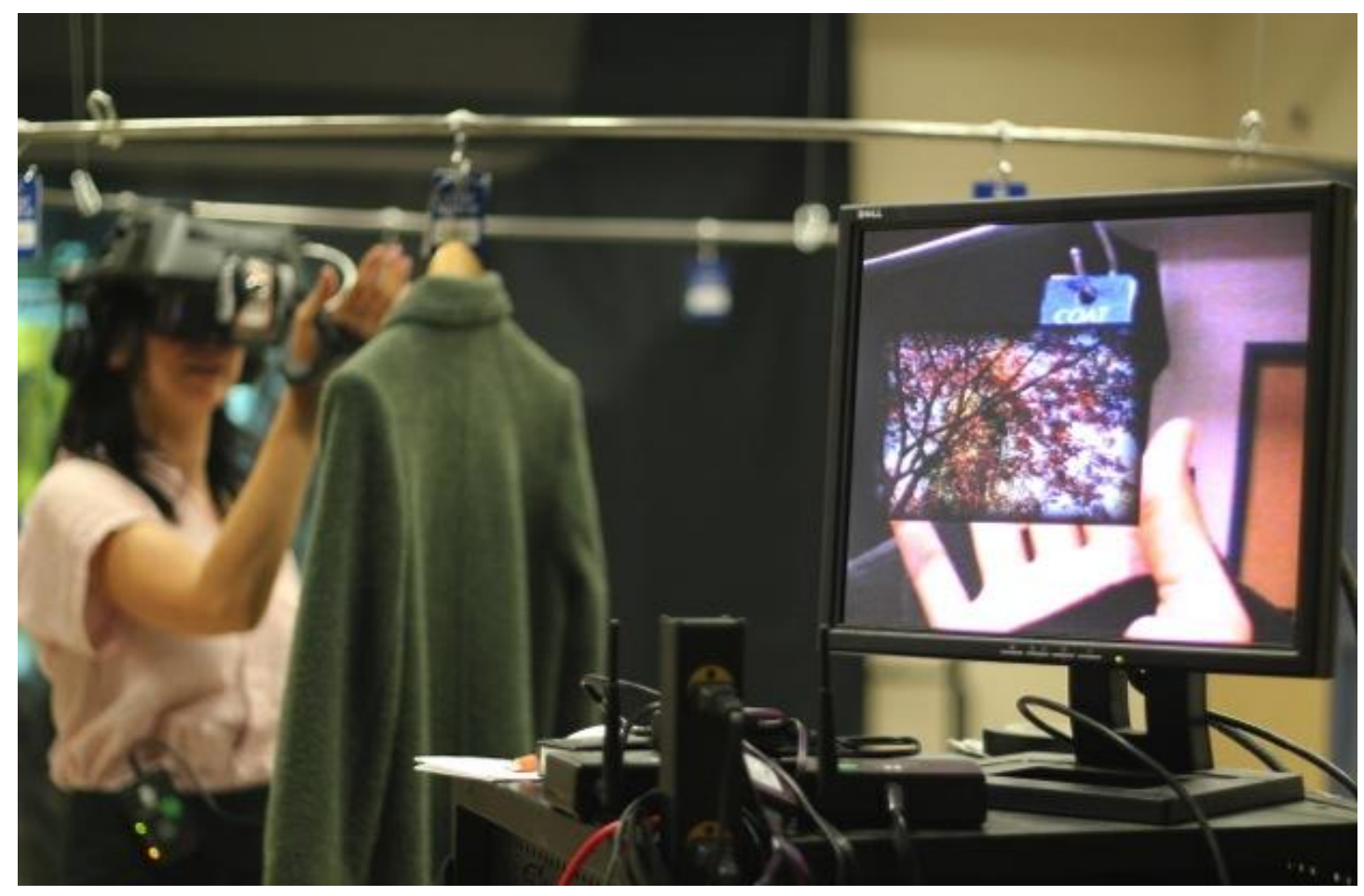

Figure 1.8 The Coat Check, webcam attached to HMD, monitoring immersant's field of vision.

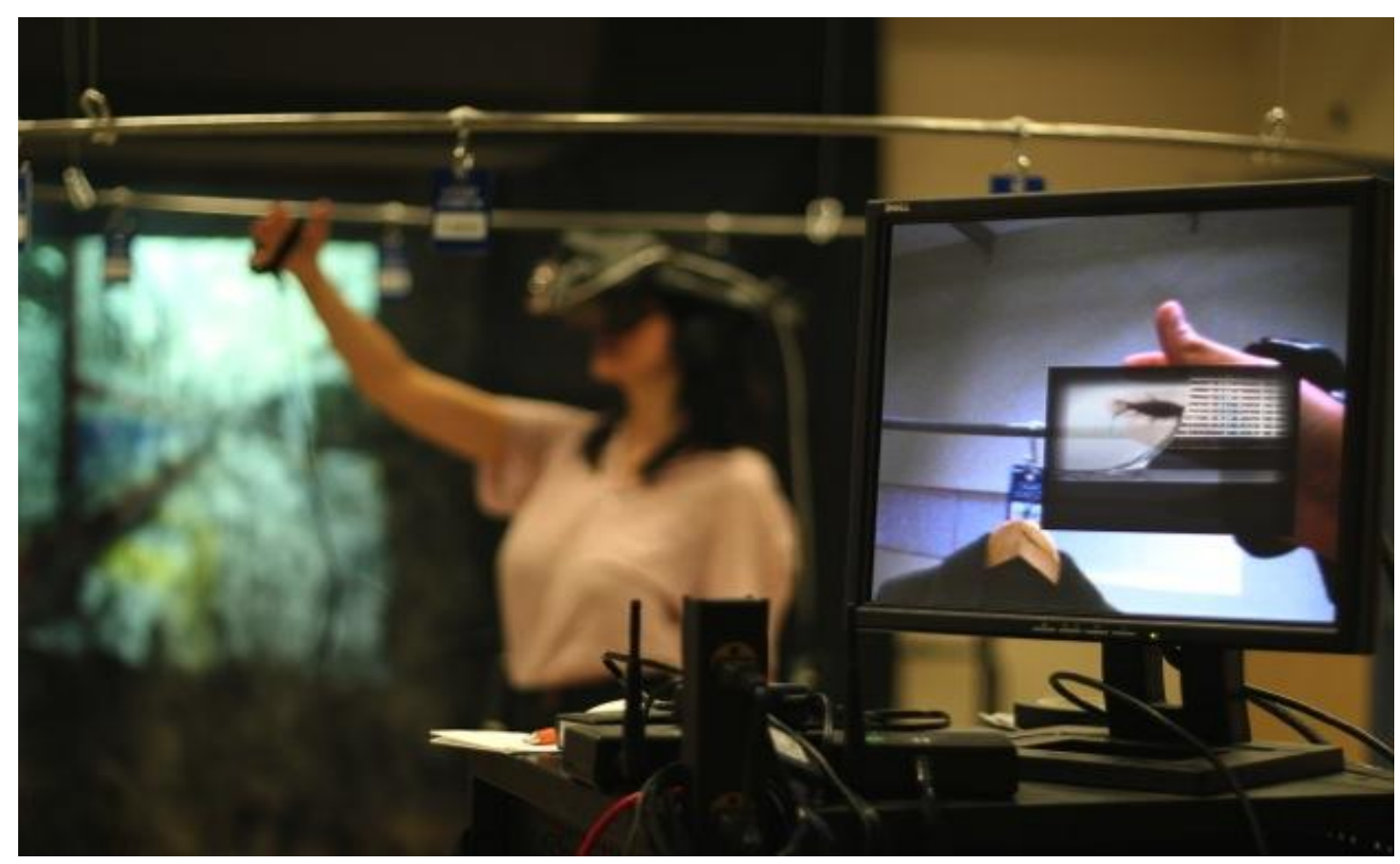

Figure 1.9 The Coat Check, webcam on HDM, monitoring immersant's field of vision.

Although the 24 videos imbedded on 12 points on the ring have symbolic meaning 
for my personal trajectory of displacement (the fish in a bowl shot the day after the suicide of a friend in Toronto, my now deceased great uncle speaking in Turkish about my grandfather's youth in Yesilyurt, Mugla, Turkey, filmmaker Serge Avedikian singing in Armenian on the way to Ottawa to prescreen his Chien d'Histoire, ice fishing in Gaspé, Quebec, the newborn baby of a refugee friend in Montreal...) they are meant to be viewed as abstractions, multilingual, far-fetched in time and geography, perhaps occasionally familiar or alienating.

The immersive experience of the central coat check is surrounded by two projections and a screen based interactive AR piece utilizing markers and a webcam. The first projection is onto a window in the lab, a looping video (shot with a spherical vision camera) of a single coat turning in circles at a real automated coat check. In both form and content, this video refers to round trips and in general cycles of displacement.

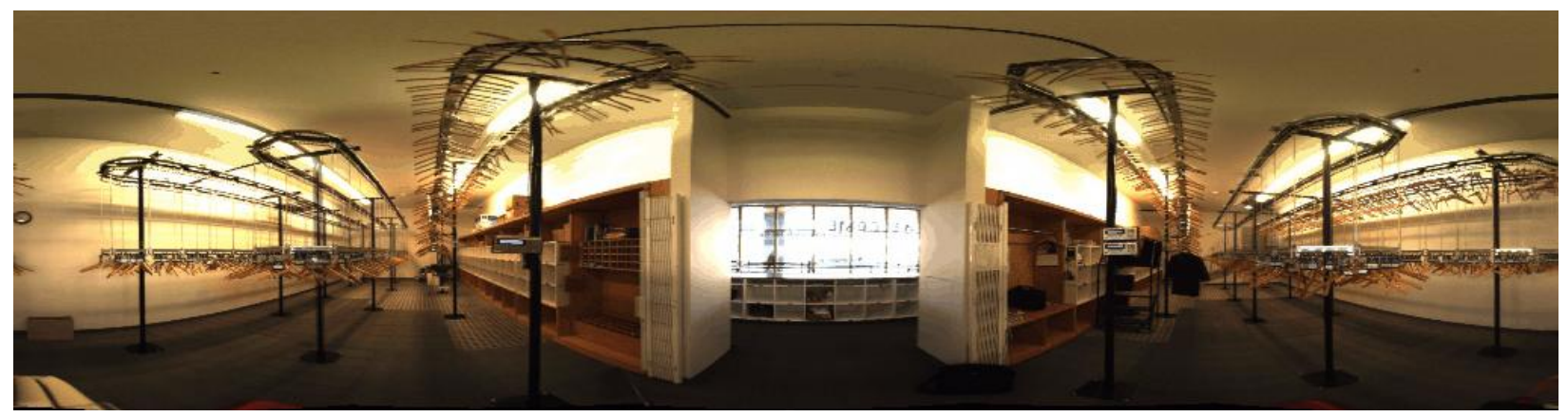

Figure 1.10 The Coat Check lab window projection, coat in automated coat check.

The second one is onto the fog screen. Fog screens are devices that use water and ultrasonic waves that create a thin layer of airflow onto which images can be projected. ${ }^{6}$ Because the theme of movement and transition is central to the conceptualization of The Coat Check, I had planned to showcase a "real emanethane" if only audio visually and

\footnotetext{
${ }^{6}$ Images and demonstrations of fog screens are widely available on the web.
} 
eventually shot sequences at Haydarpasa Train Station, Istanbul. These sequences loop as the immersant and other participants move about and set the tone for the entire installation: here we are entering a world of displacements.

Ironically, I found out that Haydarpasa Train Station, built in 1908 on the edge of the Bosphorus that divides the city in what locals call the Asian side and the European side, no longer had an emanethane. Instead it now has yellow lockers with a touch display and a credit card swipe slot. The station which marked the opening scene of many Turkish movies in the $60 \mathrm{~s}-\mathrm{a}$ family from the countryside gets off the train in awe of the 'modern', the 'Western' world- now has commuters figure out how to entrust their belongings electronically. This turn of events could not have exemplified better the ontological, epistemological changes we go through, in our day to day lives, that indeed we are witnesses of a fading époque.

Projecting images of Haydarpasa Train Station onto the fog screen, especially the sequence in which a train arrives at the station, is a clin d'oeil to early cinematic experiences like L'arrivé d'un train à la gare de la Ciotat (1896, Lumière Brothers), juxtaposing new screens with old yet ongoing fascination with the moving image. 


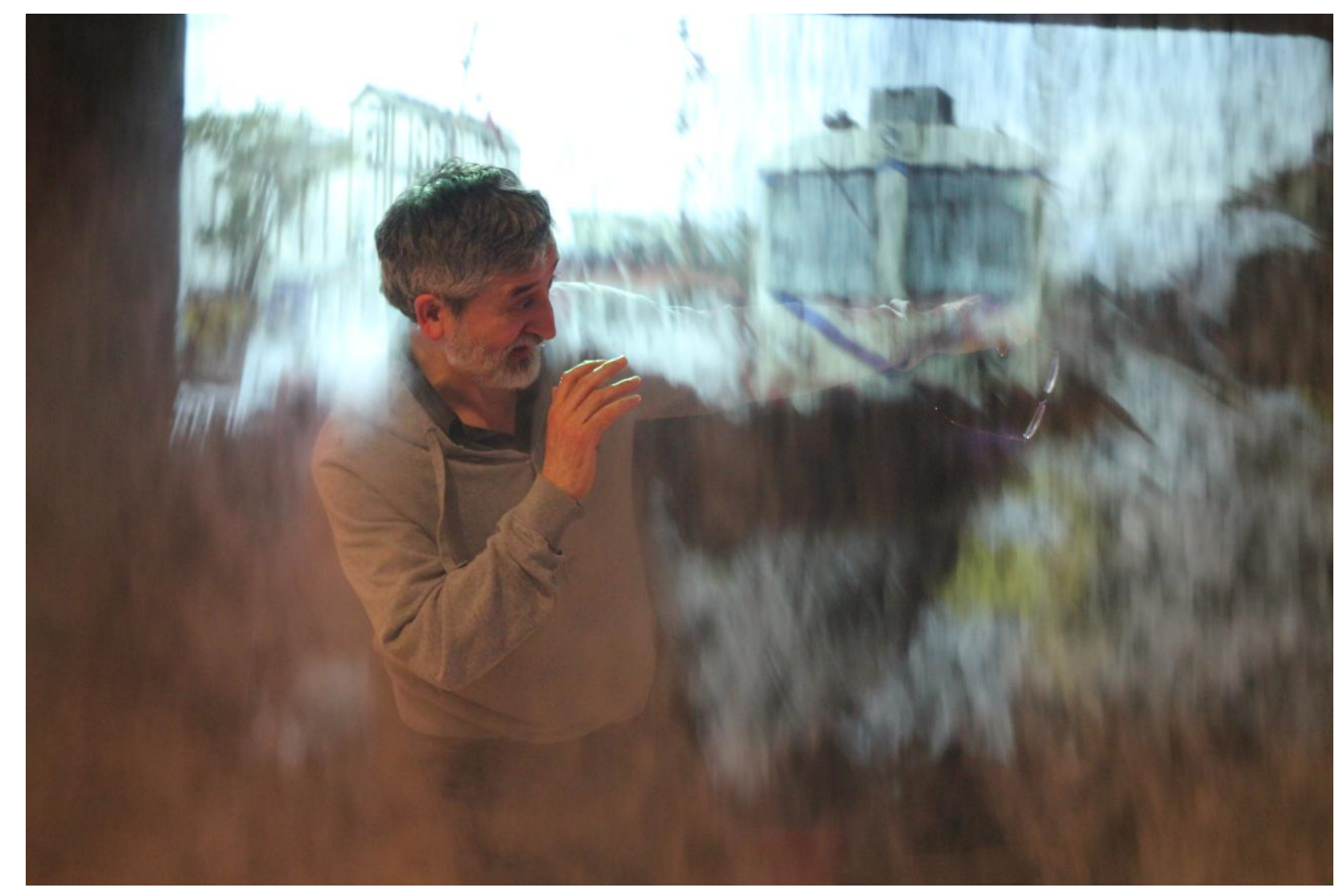

Figure 1.11 The Coat Check fogscreen projection, arrival of train.

Fog screen directly appeals to the senses with its dry fog and transparent surface that is not solid and receptive of the movement around and through it. In a way it counterbalances the heavy presence of (and programming behind) the central coat check and its prerequisite hardware. 


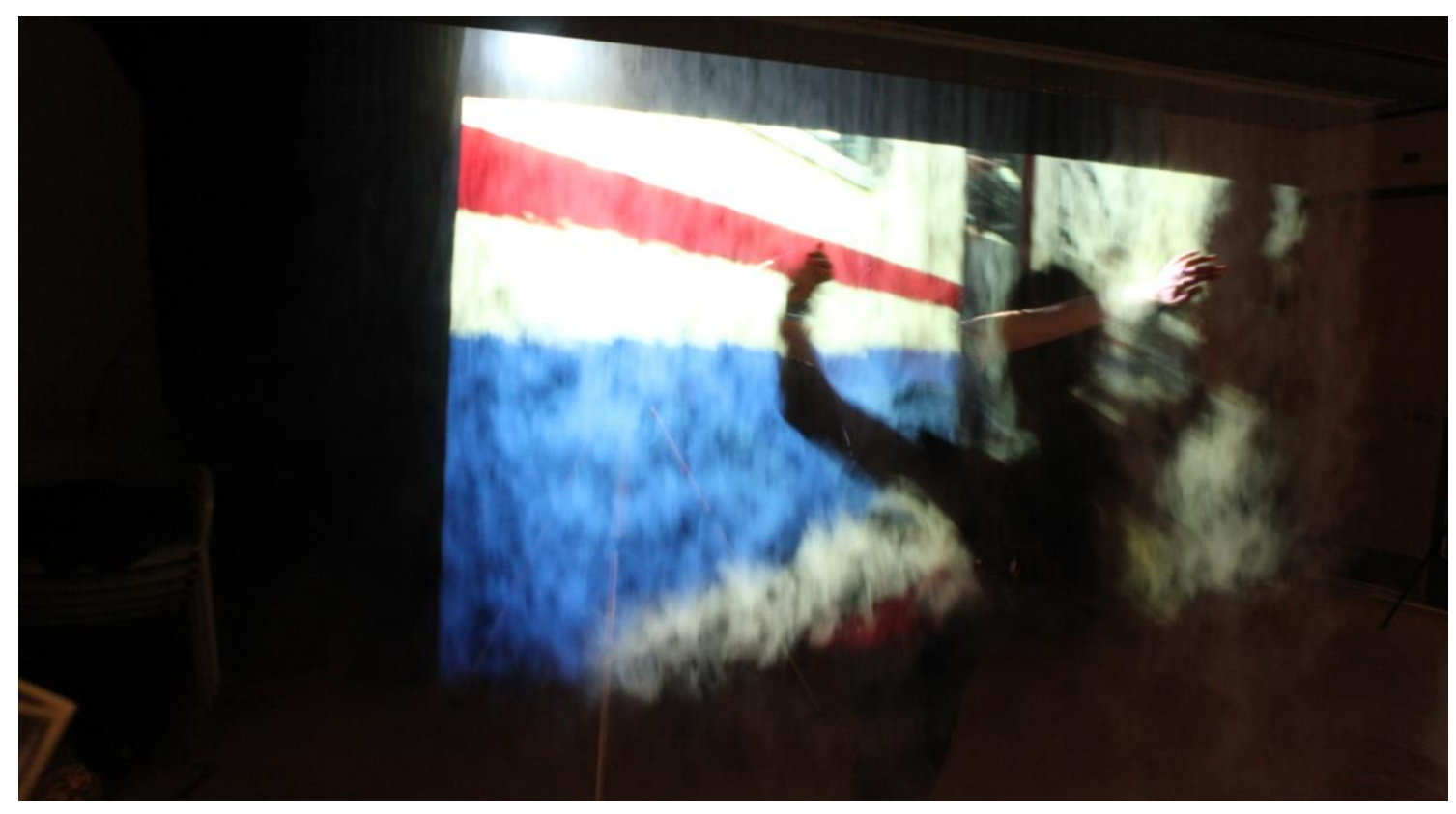

Figure 1.12 The Coat Check, fogscreen projection, exiting train.

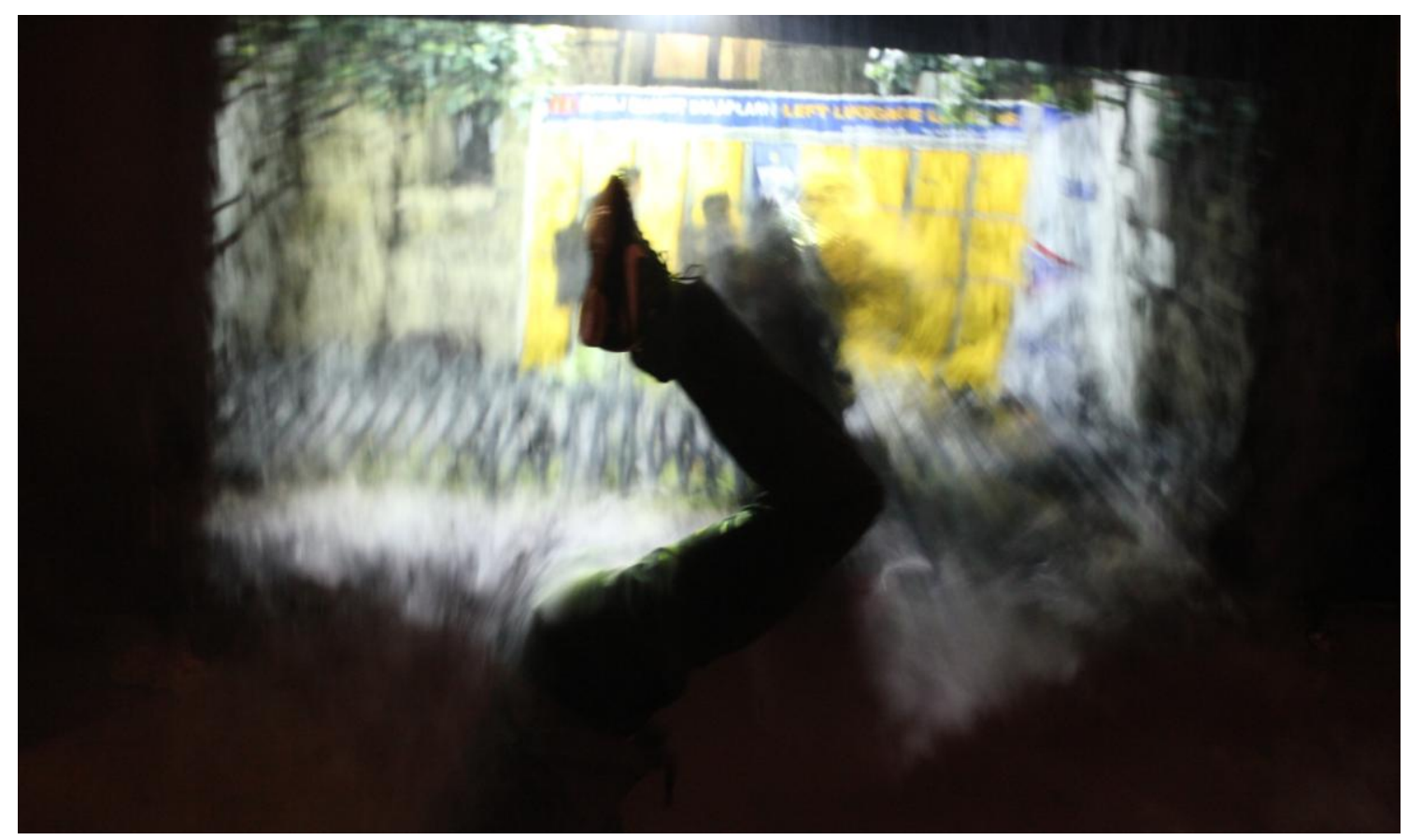

Figure 1.13 The Coat Check, fogscreen projection, participant dancing. 


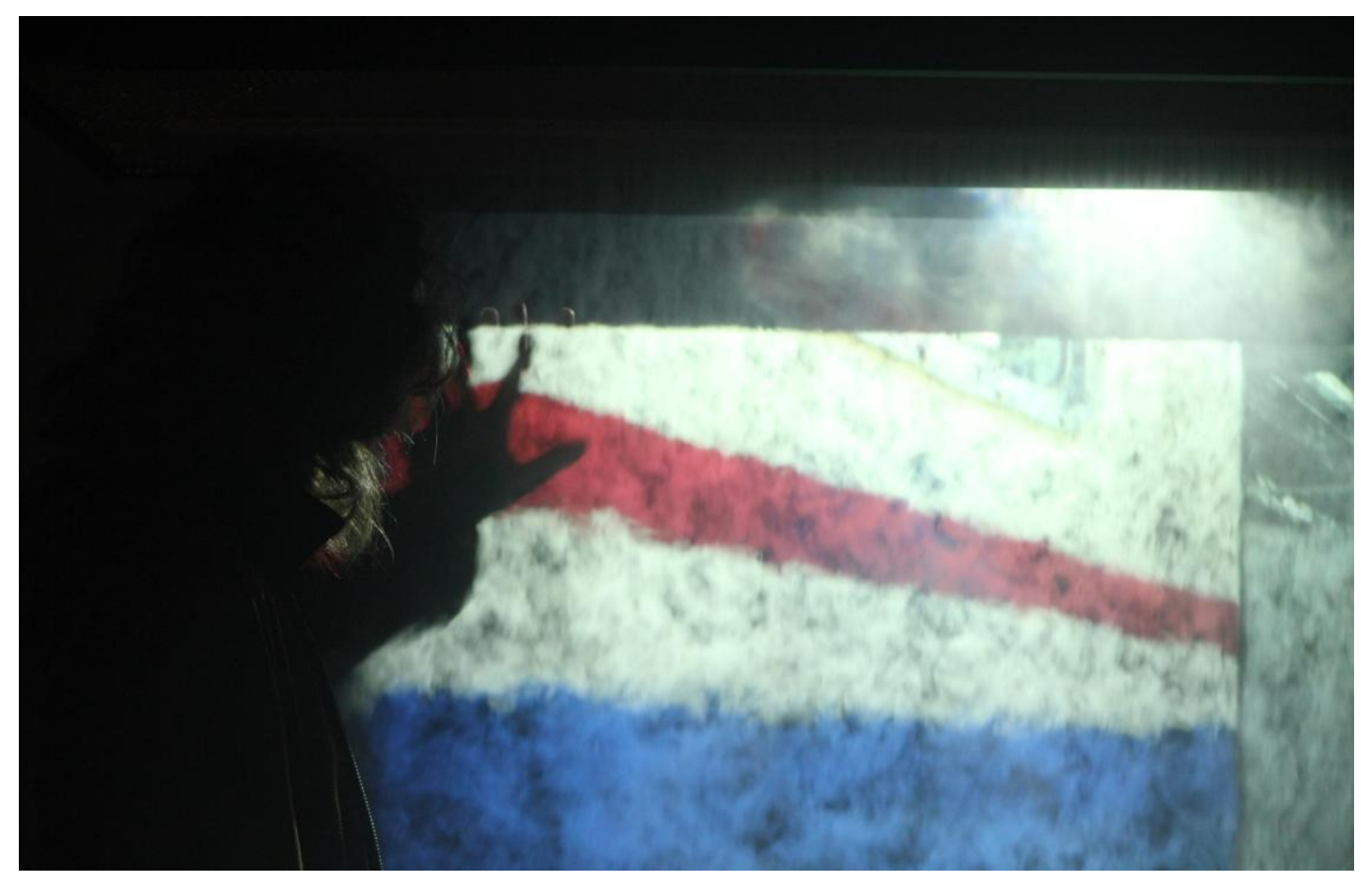

Figure 1.14 The Coat Check, fogscreen projection, touch.

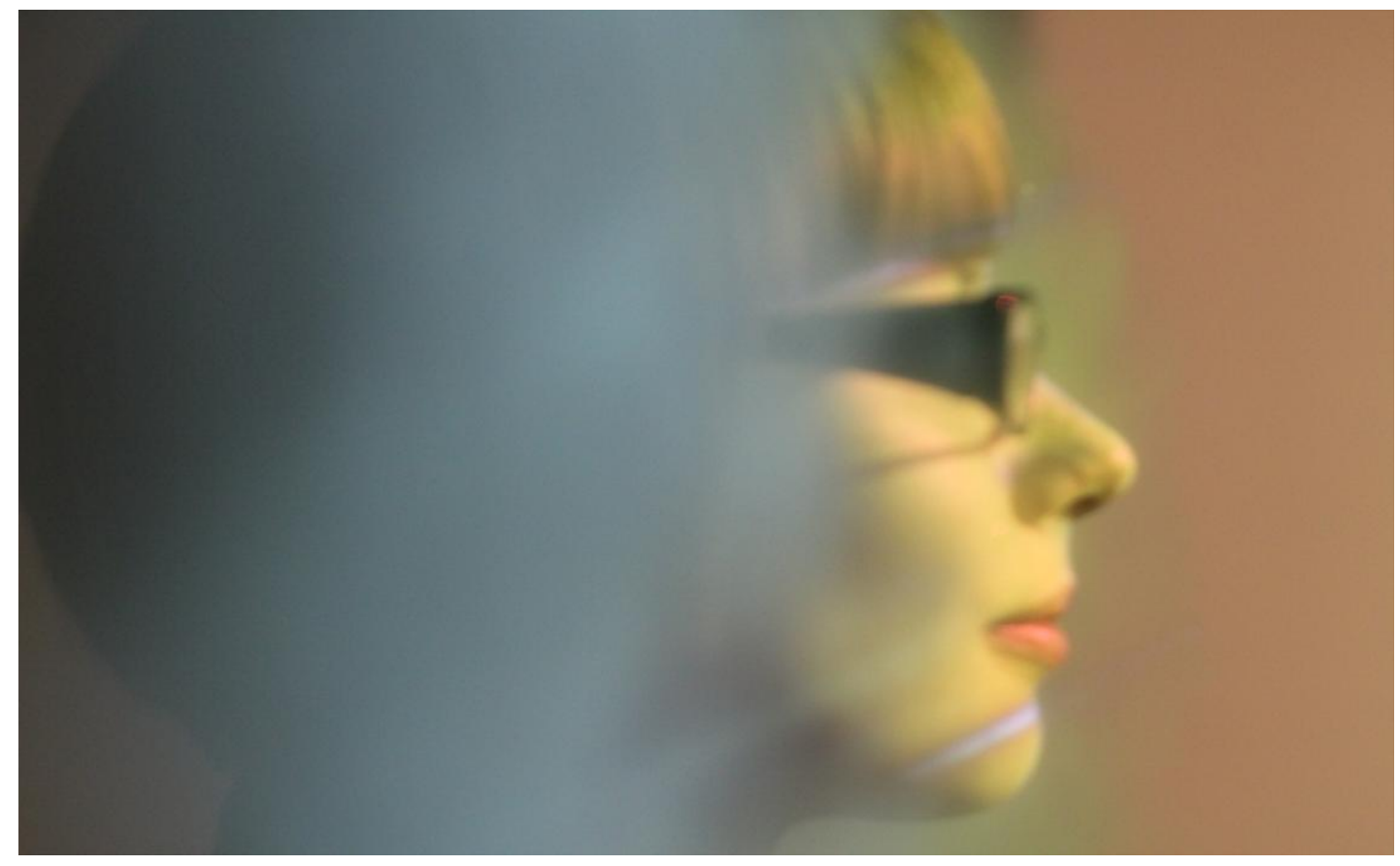

Figure 1.15 The Coat Check, fogscreen projection, participant inside the fog. 
One of the thought provoking effects of creating multiple screens is the plurality of focal points and the ways in which each individual experiential presence or embodied experience results in unique instances. Hazards, point of view and shifting attention work in visceral ways ultimately engendering reflections and critical questions.

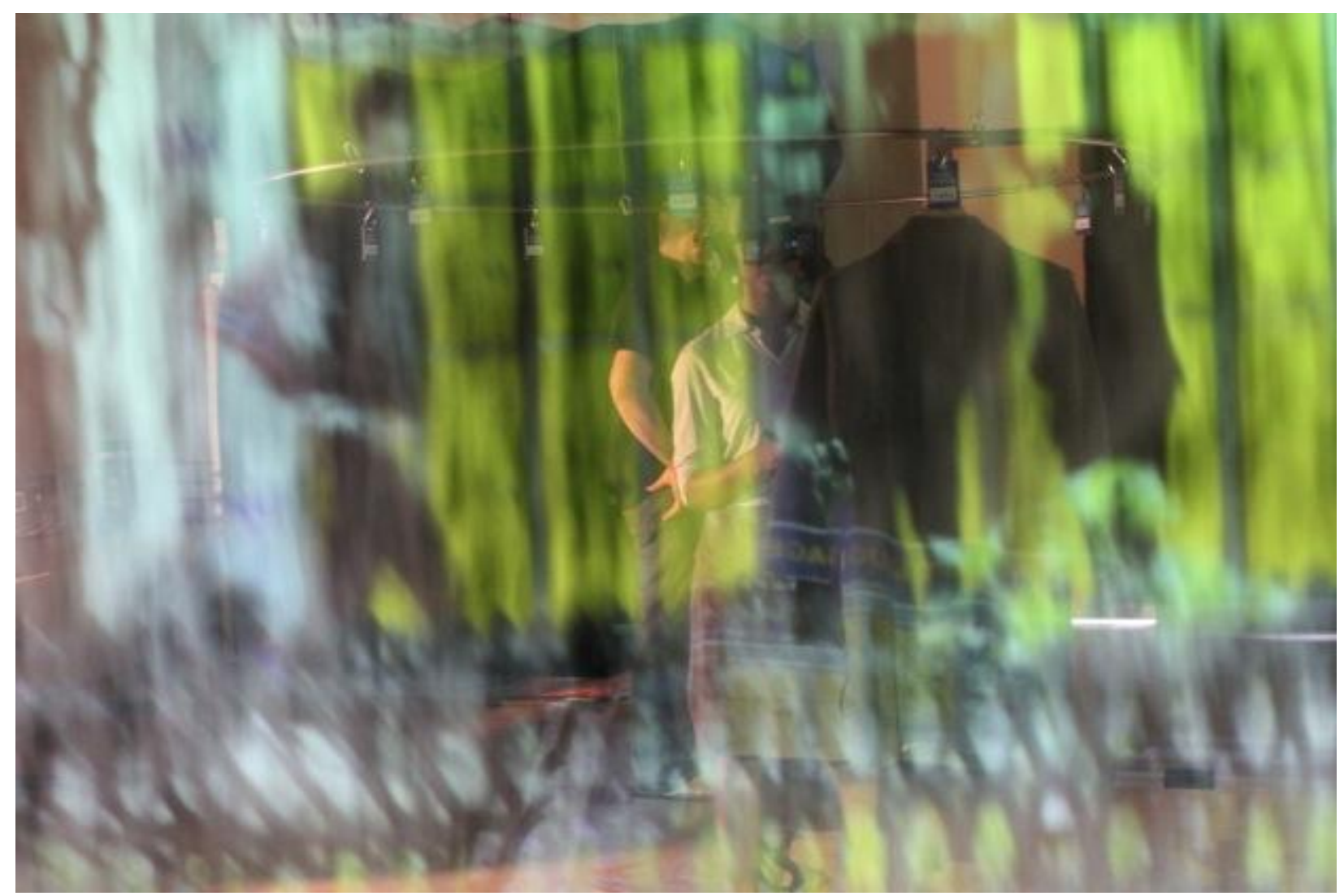

Figure 1.16 The Coat Check, through the fogscreen projection, immersant in the coat check.

In Figure 1.16, what we see is the immersant through the fog screen while the person behind her is monitoring, on the screen that we do not see, what she is watching. To the left, the figure of a man on the fog screen, poised similarly to the person in the lab seems to be watching as well. From the point of view of the camera (I am also looking at the display of the still camera to take this photograph) there are more than two people in the frame. The two real people inhabiting the same space as me are preoccupied with their 
respective screens. The immersant sees me in her screen world while watching one of the videos via HMD but the man monitoring her point of view can only see videos played on a blank background on the computer screen. We are all elsewhere, yet together not only because we are behind different screens but also because installation, as opposed to a cinematic experience in the traditional sense, thrives in movement and positioning (technologically enhanced or otherwise) and real/affective spaces unique and vastly different for each participant.

The innate duality of installation is that it demands physical presence in order to capacitate the aura of being elsewhere. In order to be there, one has to step out, to play along and not be there. Or one is immersed, aware of the confinements of space, layering the installed elements in his/her field of audio/visual perception with evocations from one's own lived experiences. This dual presencing is demanded of the viewer, yet the viewer/participant is already 'game' by being there. He/she is there as a loaded entity, indispensable to the piece. Without his/her physical presence the installation is incomplete, unlived, unexamined, a box of Pandora in the waiting. Interactivity serves as a perfect example of unleashing the contents of the Pandora's box. The metaphor becomes literal with the marker based interactive part of The Coat Check: the luggage.

Filled with travel-related documents such as day passes, transfers, tickets and luggage tags, an old suitcase lies open on a desk, with a webcam pointing into its contents. Using the Snap Dragon AR software developed at the Augmented Reality Lab, York University in association with Mark Fiala, Assistant Professor at the Department of Computer Science, Ryerson University, AR markers attached to travel documents play video vignettes on the computer screen once pointed to the webcam. 


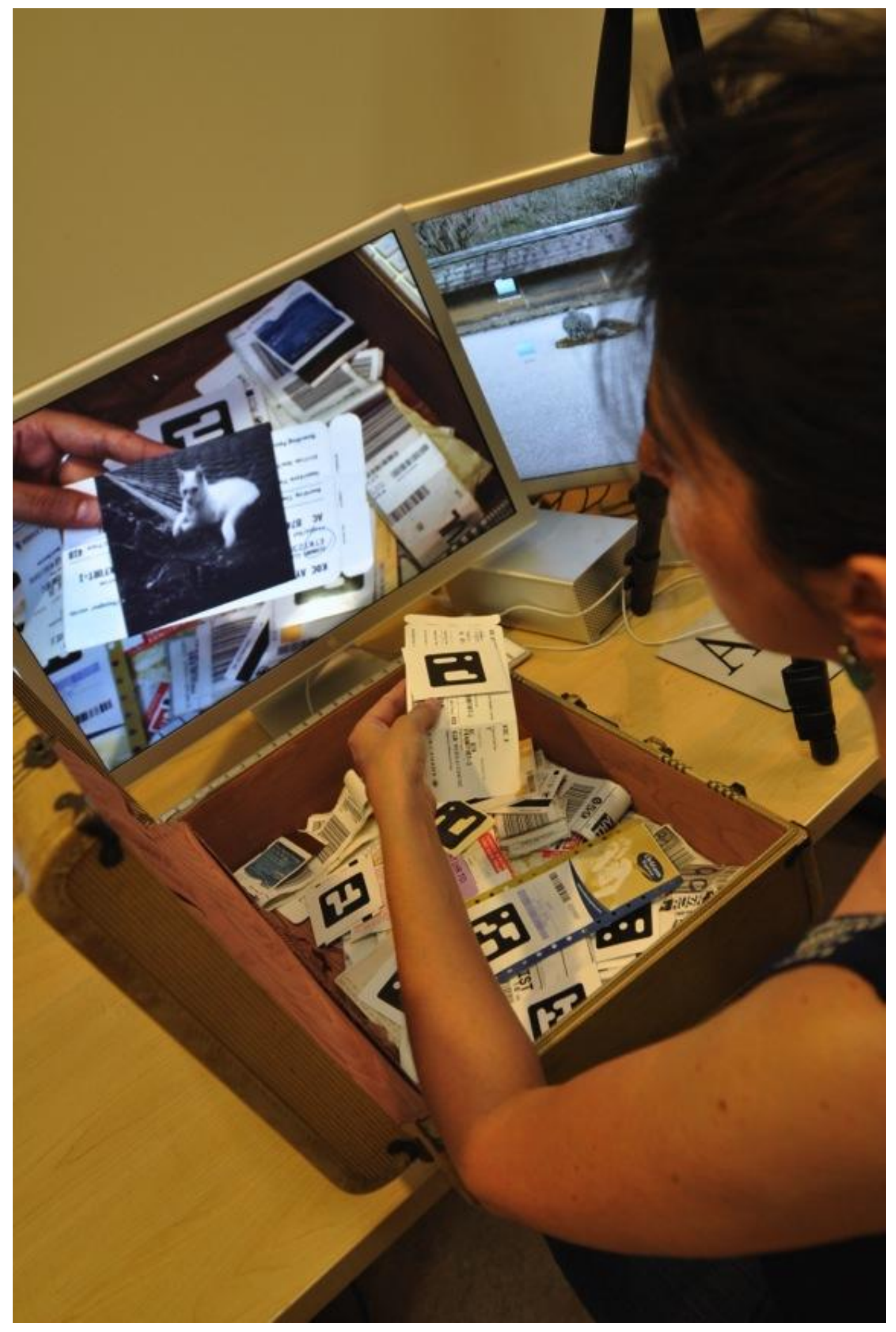

Figure 1.17 The Coat Check the luggage, with AR markers. 


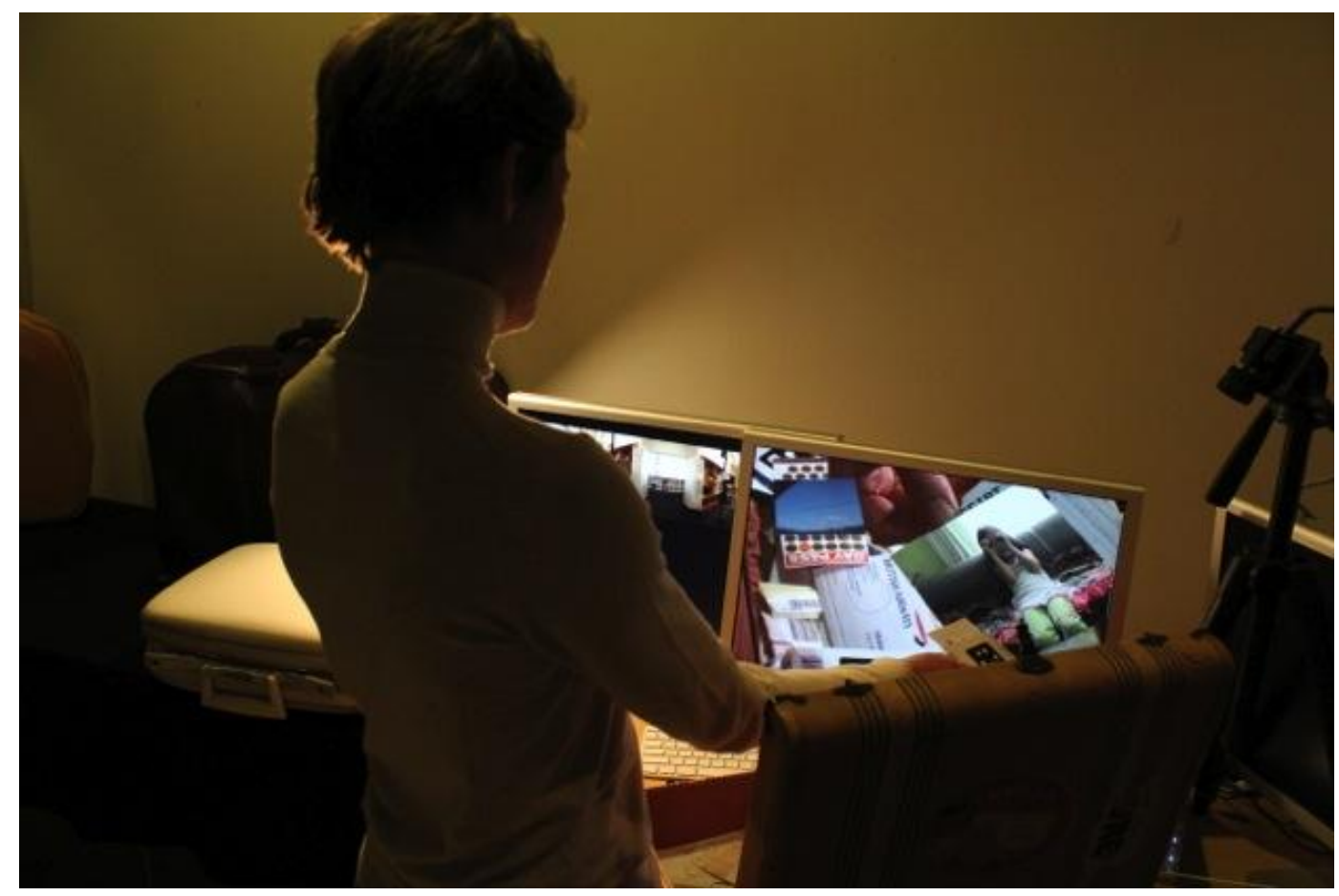

Figure 1.18 The Coat Check the luggage, with AR markers and webcam.

Luggage draws attention to mobility. Veritable documentation and evidence of displacement, tickets, barcoded baggage stickers, public transit transfers both enable and trace our trajectories. They represent and safeguard our identity as travelers, those in transit, people in-between.

The leitmotif that binds these scattered elements -immersive coat check, the fog screen, the spherical vision projection, the luggage- is the notion of displacement and the relevance of memory. What is a coat in a coat check? Where, to whom does it belong? What is its history? Is it placed randomly, does the number it's been given correspond to a reality? What is at stake here is not only the technological displacements that inform and transform the way we live and move but also our identity, collective and individual, that 
transitions as traditional borders (linguistic, territorial and so on) blur and our sense of presence takes on multiple layers of the virtual and the real.

We are entrusted to technology in more ways than we readily admit. An augmented reality (AR) marker, also called a fiducial etymologically derives from the Latin fiducia, meaning "trust". A fiducial marker represents or stands in for virtual media. Displacement is innate in digital technology. The Coat Check comes full circle in its explorations of displace and this place as technology takes on a key role: not only do we tackle the question of global movements and identity-in-flux via technology but also within it. What is at the core of this research creation is the social and political implications of exploring geographic, affective and linguistic displacements with/in technology.

\section{At the intersection of memory and technology}

Physical displacements and technological ones are interlinked. I have so far made a case for a multiplicity of displacements coexisting in the ways in which we inhabit technologically enhanced space, however it would be hiding of evidence if I omit "the affective turn" that triggered this research creation.

Those who move, relocate, or travel for long hours may be familiar with the following: upon waking up in a new place, one feels a void, a total disorientation in relation to time, space and one's own identity. Within a brief moment there seems to be no memory of a lived past or an immediate recognition of the present instance with respect to tempo-spatial elements, even the normalcy of a pre-requisite familiarity of the self on a horizontal plane: the obvious sign of transitioning to a state of awareness. This experience is simultaneously liberating and fearsome: an unbound being for a few seconds, one searches for clues to locate the self tempo-spatially and in one's own memories. Order eventually restored, one 
reminisces of that instance when all was 'out of order' or 'the idea of order ceased to exist.' This instance of purely 'being-in-the-world' is perhaps a starting point of questioning the impact of displacement on identity.

In one such instance I found myself laughing as I opened my eyes in the morning. Shortly after, I also recalled that I had been dreaming. In my dream I was a coat at a coat check. I had no knowledge of the fact that I was a coat at a coat check. Yet I watched myself hanging there in a meta-dream, laughing at the cluelessness of this object-me. How long had I been waiting there? Where, to whom did I belong? Though I found myself in this transitory space there had to be a form of permanence to my existence, elsewhere, I thought. Once fully awake, I was so overcome with a sense disorientation combined with the surreal absurdity of the dream that I began writing down the following:

"What if I am a coat left at a coat check and I don't even know it?"

LOSS: But how can we know if we are at a loss or we are lost if we're in transition? What if we assume we are where we belong? And if we really ever belong, what is the way out?

EMPTINESS: There is room enough to fill up this space with memories, silence and more silence. In the end, all the roominess redirects our attention to emptiness. ABANDONMENT: Just because it is I who left doesn't mean it is $I$ who abandoned. I am abandoned, punished for wandering, cutting loose. I mourn for things that never occurred. I mourn for people and places that would have been otherwise mine. How could I have left if leaving took place before me?

FOREIGNNESS: Let nothing stand familiar. Let all things hover unintelligibly about, let words disintegrate. Foreignness is violence.

I then visualized an installation, even though I had not worked on one before. It was 
a matter of space, and I could not have conceptualized it otherwise.

A SPACE: Hangar-like vast interior, empty, possibly with narrow windows that are high up, with diffused, natural light coming through.

AN OBJECT: a coat stand with a single coat (fairly ordinary, a bit worn out) hanging on a clothes-hanger. The object, juxtaposed to the grand space appears very small.

The soundscape: Intricately woven, the soundscape consists of random silences, rises and falls of multiple layers of track, distancing and drawing near, hummed songs, the sounds of specific places (Toronto, Montreal, Gaspé, Istanbul, Izmir, Mugla) such as the noise of the streets, children playing, people laughing around a table, a street fight, animals, the whistling of the wind, a thunderstorm, boats, trains planes, more sporadic silences, voices blending and growing cacophonies and so on.

Originally conceived in 2007 as a sound-based installation with a single coat hanging in the middle of a gallery space, The Coat Check ultimately became a site-specific and site-bound installation. It evolved to be a continuation of the work I had started in the lab with a prior installation Elsewheres (2008) where I first tackled the questions of presence, absence, displacement with regards to augmented reality. Via Elsewheres I began experimenting with AR as a tool to mimic the mechanics of memory, triggered at sight, sound and touch. 


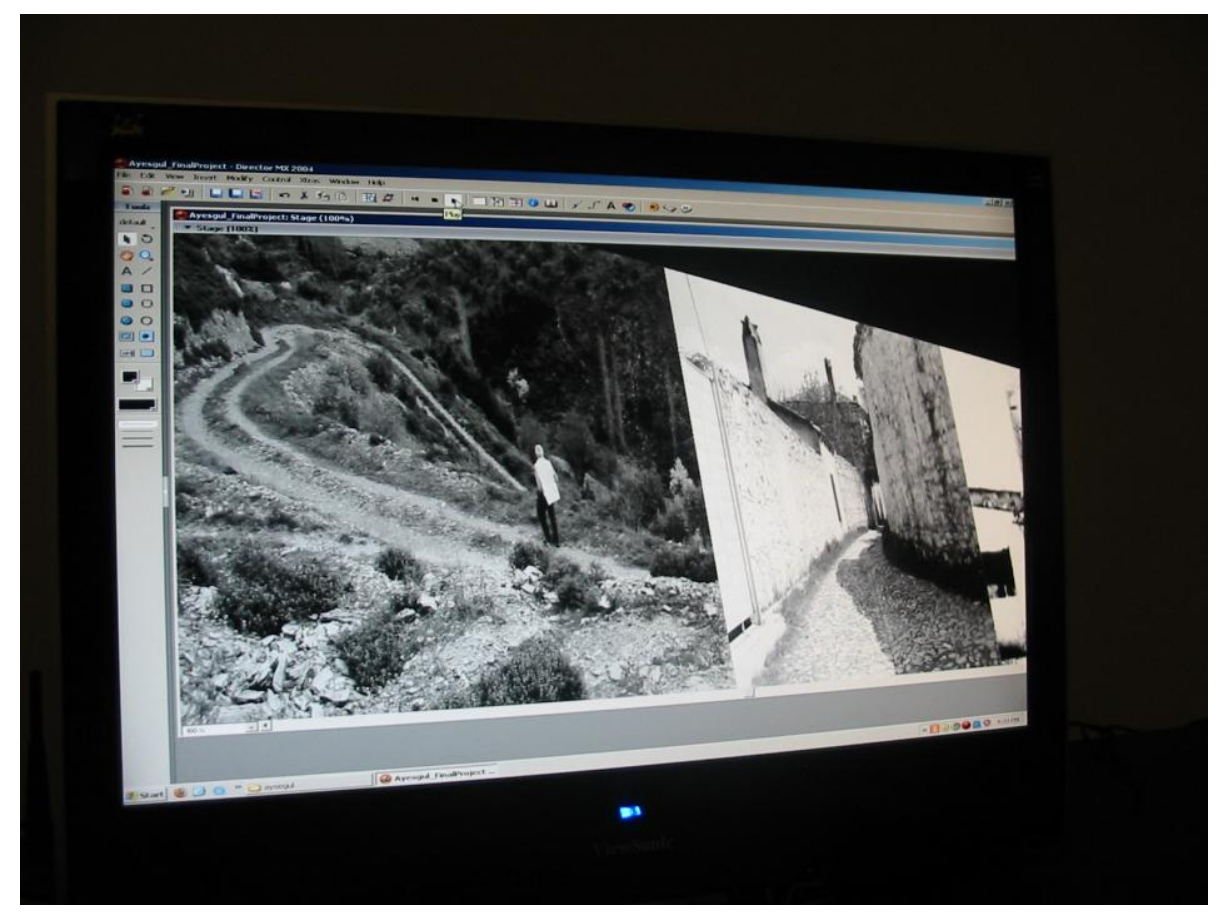

Figure 1.19 Elsewheres (2008) screen shot.

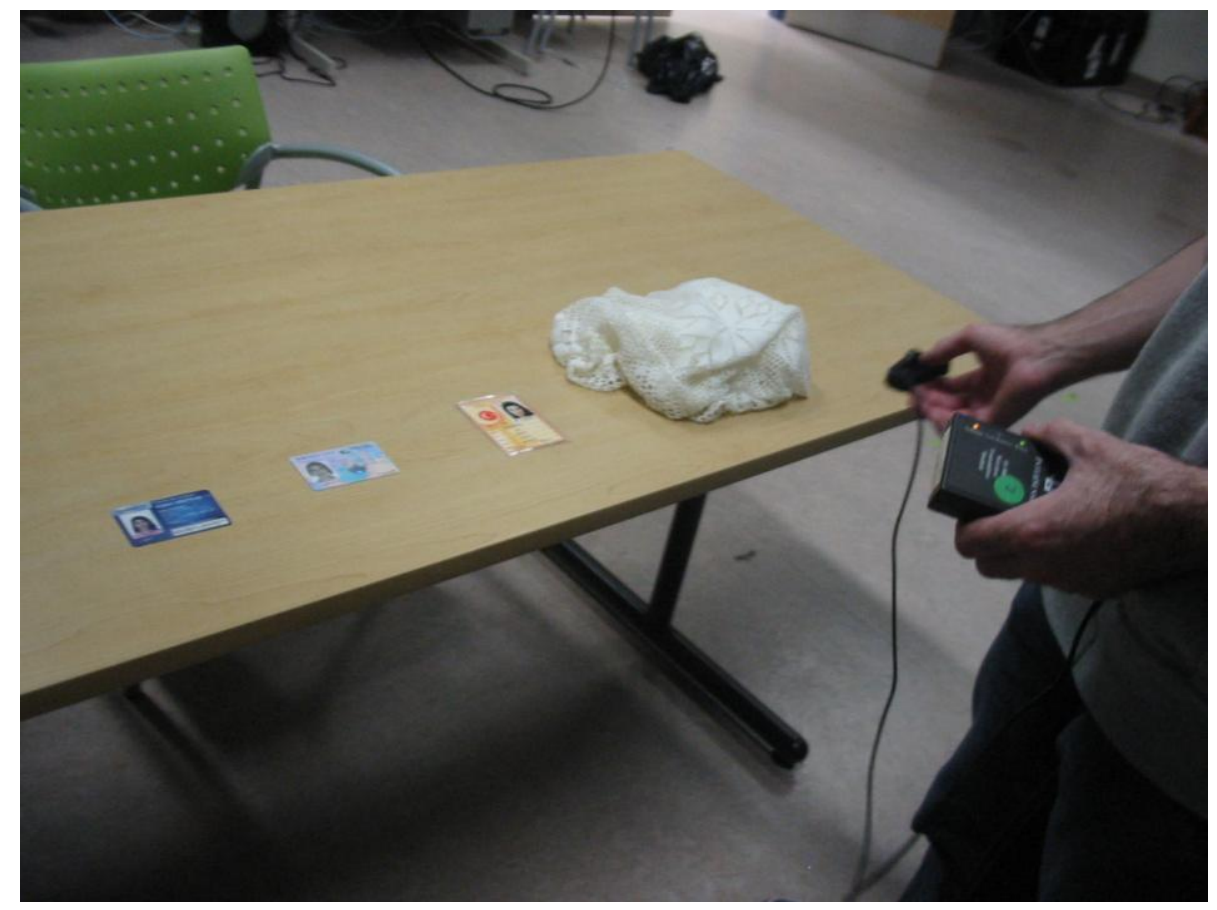

Figure 1.20 Elsewheres hand tracker pointed to lace tablecloth and ID cards. 
It is experientially compelling to superimpose digital media to real spaces, to be simultaneously aware of the virtual and real; irreversibly so, for in order to immerse in augmented reality one needs to accept the terms of co-dependency of both. AR is an experience quite different from that of cinema in the traditional sense where one is absorbed in the big screen, losing, in no matter how brief the instances may be, the presence of the self in a theatre, looking at a screen over a cloud of hair, inhaling the artificial butter flavor of popcorn someone is eating not too far away. Cinematic immersion is another contract between the immersive-world/screen-world and the audience as it involves a voluntary abandoning of the present situation to be drifted into a story-world with its own codes of conduct. AR immersion requires you to be where you actually are and pay attention to that precise 'dual presence' because it is only though this acknowledgement that the experience is possible.

$\mathrm{AR}$ is site specific in the sense that it requires the physical space to function as an integral screen-world. In my research-creation, the Augmented Reality Lab, with its AR facilities and infrastructure but also with its evident experiment-driven raison d'être is deliberately not presented/poised as a gallery space. Its site-specificity not only lies in its technological set up but also its existence in the screen-world playing "itself", the site of experimentation with digitally enhanced space.

In the process of making Elsewheres, there was a moment where I was moved deeply to see the stills of my grandparents' village blown to real-life proportions via a headmounted display superimposed to the lab where real people in motion in my field of vision became ghostly appearances, belonging neither to the village nor to the lab. It became clear to me that this lab-village was a potent, evocative space transcending perhaps borders and 
boundaries that may have been otherwise mutually exclusive.

The Coat Check is also site-bound, which seems inherent in site-specificity but nevertheless I emphasize it here in order to underline the technological investment that is integral to its realization. Reinstalling The Coat Check in a different site would require similar tracking technologies and a fog screen to be in place and programming custom made for the site. It would then be a different installation altogether depending on the nature of the new host space. Bound also by invisible puppeteering of virtual elements The Coat Check is also a reference to our increasing dependency to digital enhancement.

Where is one at any given time and place? Contemporary global mobilities make this an even more challenging question. Who gets to travel, to settle and resettle? Who is interpellated? Who are the authorities in power that can access our images, behaviour patterns, personal information? Is the cultural identity of individuals and communities defined more and more through their technological displacements than the geographical, historical borders that host/contain them? What exactly is it about contemporary digitally enhanced space that distinguishes it from the technological continuum that leads up to the present? Or is the present moment not a rupture? The following chapter is a historical perspective on technology and how installation art involving enhanced space tackles questions of identity in transition such as a critique of the increasing presence of surveillance in our lives. 


\section{Chapter II}

Querying technology and the notion of space

Technology and Historicity: towards an understanding of space Installation, enhanced spaces, identity 


\section{Technology and Historicity: towards an understanding of space}

In the introduction I have mentioned I conceive of digitally enhanced space and practices as part of a larger framework of our dealings with technology historically. In Chapter I, The Coat Check installation, much in the sense of assemblage, brings together technically and historically diverse methods and approaches in form of displacements: Super8 home video and motion sensors, early cinematic references with fluid screens.

We cannot think of space today without considering the role technology plays in our lives, as I have attempted to demonstrate with The Coat Check. Have we really made the transition to technoculture? Where and when have the great turns of a 'technological society' taken place? In what way is historiography linked to idea of scientific and industrial progress? What are the ways in which technology driven systems inform our lives around the globe today? How is technology related to power structures? What is technology?

Stephen J. Kline points out that technology, one of the most important key words of the $20^{\text {th }}$ century, is used simultaneously, cumulatively or singularly to denote things, actions, processes, methods and systems. He notes that the word is also used as an epithet for progress. Kline stresses the significance of such an overlap between progress and technology (and the chaos with regards to the use of the word technology) as hiding critical questions concerning human behavior and an understanding of how humans live on the planet. It is therefore, he concludes, necessary to "unpack" the word "technology". Kline observes four general categories of the usage of the word: first, as hardware or artefacts denoting man-made, manufactured, non-natural objects; second, as sociotechnical systems of manufacture including humans, machinery, resources and socio-political environment; 
third, as knowledge or "know-how", technique (he credits Jacques Ellul's use of the word la technique and its subsequent translations as technology); and fourth, as a sociotechnical system of use where a combined effect of people, manufactured articles, systems and environment perform tasks that extend human capacities. This last use of the word is not a product of a "high-tech age", Kline points out, but dates back to roughly two million years of human evolution. Animals, too, use sociotechnical systems, he reminds us, but what is unique with humans is the purposefulness of continuous innovation to advance the functioning of the very system created. (215-218)

The "naming" or definition of technology goes hand in hand with historicity. To begin with, one can revisit some of the earliest texts that the Western canonical literature builds upon, the ancient Greek philosophy. One of the major concerns whose resonances greatly influenced civilization as we know it today is the understanding of techne and episteme $\bar{e}$. In this regard Socrates has influenced -perhaps most importantly with his dialectic method- the Western scholarship through texts referring to his teachings, most recognizedly that of Plato. Socrates distinguishes craftsmanship from wisdom and theoretical knowledge. Socrates' disciple Plato furthers the distinction between craft knowledge and knowledge of (good) life, claiming the two are two separate phenomena, and that a rational understanding of the essential nature of things is and should be the concern of the philosophers. Aristotle, while in accord with Plato that contemplation of highest things is the preoccupation of the philosophers, countered the idea that theoretical and practical understanding belong in separate realms.

Much later, the relationship between technē and epistemē is taken up by Michel Foucault (among many others) to draw attention to the power exercised over the marginalized, for example in the experiments over homosexuals and patients with mental 
disorders in the name of knowing the innermost truths of beings through technique and science in the $17^{\text {th }}$ and $18^{\text {th }}$ centuries in History of Sexuality. The retrospective reading of that which was promoted as the triumph of reason at the time as being simultaneously the age of repression would not have materialized for the philosophers and scientists of the period alike.

If there is a time when scientific knowledge, innovations and inventions are regarded very highly and considered to be beneficial to humanity almost without reserve, it is the time when theological teachings gave way to scientific explorations in the 16th and 17th centuries. Francis Bacon's methodologies concerning a scientific reformation in education and research are praise to scientific advancement. Bacon, who famously claimed that "knowledge is power" in Novum Organum, also translated his vision of a scientific revolution to utopian constructions in The New Atlantis. While Bacon emphasizes the need to bring philosophy to the level of scientific thinking, Immanuel Kant regards rationality as the natural fulfillment of the purpose of the humans. Between 1851 and 1854 Augu ste Comte publishes his Système de politique positive in which he outlines historical and philosophical overview of three stages of development: theological, metaphysical and scientific/positive. Positivism and Enlightenment leading up to the Industrial Revolution provide the backdrop of some of key issues regarding technology and its implications: technology as a social determinant and sociology as a science of the society. With the Industrial Revolution, as modes of production change, a critique of capitalism, such as in the writings of Karl Marx and Friedrich Engels, evolves toward an understanding of the relationship between machine-powered mass production and the ways in which it alters the meaning of labor and life of the society at large. Although the period leading to the $20^{\text {th }}$ century is in itself very significant, for the purposes of this overview it will only be 
mentioned here, in passing towards contemporary notions of technology.

In the Platonic and Aristotelian schools of thought, there is coherence and competency between thought, reason, arts, crafts, technique and governance. In other words, there is no "anxiety" associated with progress and advancement of techniques that we see in the modern era. It is possible to examine the twofold nature of this "anxiety" in the way in which Western thought and historiography unfolds: on the one hand the Christian doctrines shape an understanding of the humans as subjects to an all-knowing God under whose guidance nature (both physical and psychic) is to be mastered and salvation is to be achieved by progressing towards God. There is a material universe with which humans have a problematic relationship, its seductiveness is to be defeated and its conditions to be altered in the name of God. Especially in Protestant ethics, work and progress take on a crucial role in reaching salvation. On the other hand, a relatively secular, post-positivist, post-industrial and modern worldview "mourns" a "disenchantment as our civilization develops" remarks Charles Taylor. (4) Instrumental reason creates the anxiety, or the malaise of modernity where lives are no longer structured around common values, tradition or belief systems in his view. Taylor argues that the primacy of instrumental reason is evident in the prestige and aura that surround technology, that our "technocraticbureaucratic society" uses instrumental reason to limit freedom and political power.

I will take a brief turn and move from the idea of anxiety, freedom and political power vis à vis technology to the idea of a governing principle, or the core of technology. Heidegger informs us that the essence of technology is not what technology is. Neither is technology neutral. Published in 1949, "Die Frage nach der Technik” becomes one of the most influential writings of Heidegger. He begins his discussion by two standard answers to what technology is: a means to an end and a human activity. If it is so, says Heidegger, "we 
will, as they say 'get technology' 'spiritually in hand', we will master it." (5) However the real challenge is to grasp the essence of technology, which, he argues, is nothing technological at all. Heidegger refers to Aristotelian doctrine of the four causes which are material, form, the end result (causa finalis) and the effect with regards to instrumentality / technology and argues that this view omits the "bringing forth" and the "revealing" of how something is made or becomes something else. The silversmith, he explains, acts as an agent to reveal the material, form, end result and ultimate effect of a silver ring. Latin causa and German ursache come closer to aition, that from which something comes to be. Technē for Greek antiquity is not the same problematic as the modern technik or technology, because through the storing of energy as in dams on rivers, "the river now derives out of the essence of the power station." (16) Heidegger makes the point that, in his choice of words, unlocking, transforming, storing, distributing, switching, regulating and securing energy requires alertness to a revealing, puts at stake the humans themselves as "the standingreserve". Hegel's idea of machine as an autonomous tool is challenged by this enframing of beings as standing-reserve. There is no demonry to technology, Heidegger claims, but rather there is the mystery to its essence, and it is the destining of the revealing that poses a danger. The kind of danger Heidegger talks about cannot be attributed to a determinism or pessimism about technology but rather a call to understand technology in its entirety, not just what technology is or does but rather from what source its doings originate and proliferate. Tapping on this source is essential to understand technology and man's relation to it.

Taking up, once again, the respective notions of praise, apprehension and a sense of being at loss one may look at key historical events and how reflection derives from visible change in the society, not necessarily always in the form of what happens but also what is 
imagined or felt. In 1958 Hannah Arendt observes a pathos accompanying the media coverage of Sputnik's space launch in 1957, the vision that humans are 'no longer imprisoned to earth': “...for although Christians have spoken of the earth as a vale of tears and philosophers have looked upon their body as a prison of mind and soul, nobody in the history of mankind has ever conceived of the earth as a prison for men's bodies..." (2) The artificial world, as an environment, exists but life itself is outside of it as humans belong with other living organisms, Arendt says, continuing to draw a parallel between the desire to become non-earth bound and the desire to "create life in test tubes" or prolong human longevity having the same underlying principle: to escape the human condition. Even the thought of the possibility of such an alteration in life as we know it through scientific and technological advancement requires, according to Arendt, closer examination as it is a political question of utmost importance. Scientists and politicians should not be the decision makers of such alterations. Arendt, who builds her argument of the organization of labor in the reassessment of the human condition on the Marxian paradigm but diverging greatly from it in terms of the distinctions she makes (labor, work and "intellectual, activist labor/work"), focuses on the potential to bring about social change by "the mind's work", the vita activa.

Control, ideology and political action as relating to the society in the process of rapid change with(in) and through technology is discussed widely by scholars such as Jürgen Habermas and Herbert Marcuse. While the former focuses on the need to challenge monolithic aspects of associating instrumental control over the technique with freedom drawing upon Husserl's lifeworld, for example in "Technical Progress and the Social Lifeworld", the latter is concerned, in "The New Forms of Control", with the forces underlying an inflated, "powerlessness in the face of technology" worldview suggesting 
that presenting social and political life as such hides the control mechanisms at play creating an illusion of freedom where freedom is in fact suppressed.

Perhaps the two ends of the spectrum of the technological question can be observed in the writings of Jacques Ellul, who is often cited as a technological determinist and Donna Haraway, who sees a powerful potential in blurring of definitions of natural and artificial, human and machine that technoculture can bring about. What she calls Cyborg world is simultaneously a new space for feminism that forms an alternative to the discourse and terminology of a predominantly patriarchal system (or a potential that can empower the marginal). (151) While Ellul argues that technology is autonomous, refuting the idea that it is an accumulation of technical means and that humans can manipulate it to their best abilities, Haraway deliberately shies away from essentialism and hails a crossing of boundaries, for example in the biological-determinist ideology. (Ellul, 182-186) She sees "technological determination" as a space in which human-machine collaboration or cyborgs can overthrow old forms of binary oppositions (for example that of materialism and idealism). Her post-modern celebration of transgression and human/machine agency contrasts with Ellul's modernist concerns about the fact that the progression of technology utilizes human and machine alike and that the course of its advancement is neither bound by politics not by science alone but serves itself best using the two.

In 1985, almost thirty years after Arendt observed the significance of it, Donna Haraway credits Sputnik's impact on US science-education policy when she speaks about her own formation in her "A Cyborg Manifesto." Late 90s, Lev Manovich writes in the Rhizome listserv that the Internet reminds him of a "Stalin era apartment" alluding to the lack of privacy and surveillance in a message entitled "On Totalitarian Interactivity." (10) In 2006, Wendy Hui Kyong Chun questions the notion of freedom with regards to Internet 
as a mass medium in Control and Freedom: Power and Paranoia in the Age of Fiber Optics. While discourses on rupture versus continuity with regards to technology and its impact on the society -for example if or not digital technologies allow for collapse of certain hierarchies versus them ensuring the status quo politically and economically-are debatable, the quest for making sense of how our lives evolve remains constant and it is at the intersection of philosophy and technology that we can begin touching upon some of the major issues concerning how we live today and how else we could live in the future. 


\section{Installation, Enhanced Spaces, Identity}

Our experience of space begins with very "intimate" places: the womb, the nearness of loved ones, a home. It extends to the periphery of the immediate and the private via the surroundings, the alleyways in a neighbourhood, the hallways of a school, the city, community, the nation, the globe. It is "shrunk" or "amplified" via technologies, the voice of loved ones from across the ocean upon picking up the phone, playing chess with semistrangers (whose acquaintance we have made through the medium) on-line, navigating unfamiliar routes with GPS, being "carried away" watching a film in a movie theatre or listening to music on an iPod on the bus. It stretches via interpellations of various kinds to the apparent limits of our actions and mobility: forms, decision makers, executers and systems of authority regulate the sense of borders, cognitively as much as physically. Political implications of such borderlines, mechanisms triggered at sanctioned or nonsanctioned border crossings impact notions of space and human capacities to reach out, both within the self and towards the Other.

There is interplay between intimate and intimidating/alienating space. The intimidating envelops the intimate in or vice versa. In order to elaborate on this, I will begin with what Gaston Bachelard calls felicitous space in The Poetics of Space, the lived experience of spaces we love, spaces that serve as home to imagination, drifting and daydreaming. (xxxvi) Spaces that are intentionally devoid of any type of sentiment, design strategies and architectures that eliminate senses of security or privacy/intimacy, places that are at the service of the authority in power such as Jeremy Bentham's architectural plan for a state of the art prison model, the Panopticon, will subsequently be discussed.

What renders space intimate is its evocative power to provoke images and hence awaken the imagination. Memory, tells us Bachelard, is in close association with image and 
imagination. The poetic image, housed in the imaginaire (as in mental capacity), for example childhood hiding spots inside a home, moves "the entire linguistic mechanism" before a being is a speaking being. Phenomenologically, this poésie is at the level of "resonance and reverberation", it is a phenomenology of the imagination. (xxii) Bachelard claims that not only what is remembered but also what is forgotten is housed, in ways not necessarily or intentionally retrievable but yet there. This however should not be confused with the psychoanalytic subconscious because Bachelard argues that poetic imagination is beyond psychoanalysis; it rises with a dynamism that is outside of speech or thought per se. Bachelard sees in this dynamism of the poetic image a "direct ontology". (xvi)

Bachelard observes absolutism in the philosophical dialectics of inside and outside, being here and being there. His understanding is that of a complementary relationship between inside and outside: in the poetic imagery there is no geometric equivalent of two things such as in and out. He gives an example from two sentences by Balzac: "He made space withdraw before his advance." and "He left space behind him." To Bachelard, while the first sentence belongs to "space come alive", the second is an "indifferent" space. (231) What Bachelard does not discuss in The Poetics of Space is the intimidating space. The house is enveloped in what makes it an intimate space, namely the space that isn't as intimate. This is not necessarily an indifferent space. The extremity of the non-intimate is a space that will be discussed here, as an apparatus.

Bentham's Panopticon is a podular design in which there is an "observatory/control room", a central tower in the middle from which inner looking cells can be surveyed all at once. Because visibility is one way, the tower sees everything but the cells cannot, the prisoners do not know if at a given time they are being watched or not. The control mechanism functions by what can be called the "omnipresence of authority". The 
prisoners, with an understanding that they can be under watch at all times "participate" in the control mechanism, similar to Althusserian interpellation.

In Discipline and Punish: The Birth of Prison, Michel Foucault discusses the sociopolitical and philosophical implications of Bentham's Panopticon. Foucault argues that the idea of Panopticon, an all seeing eye, is nothing new to European life in order to control and oversee the execution of order. Foucault begins his discussion with a guidebook published at the end of the 17th century, describing the measures to be taken in case of a plague in town that describes how to put under quarantine/control the situation. He then ties the descriptions in the book to power mechanisms at work.

This enclosed, segmented space, observed at every point, in which the individuals are inserted in a fixed place, in which the slightest movements are supervised, in which all events are recorded, in which an uninterrupted work of writing links the centre and periphery, in which power is exercised without division, according to a continuous hierarchical figure, in which each individual is constantly located, examined and distributed among the living beings, the sick and the dead - all this constitutes a compact model of the disciplinary mechanism. (590)

Space as site of surveillance/control is as significant today as was when Louis Althusser wrote "Ideology and the Ideological State Apparatuses: Notes towards an Investigation" in 1969. According to Althusser, for ideology to ensure its own reproduction state apparatuses such as religion, education, communication technologies and so on, it must "hail" individuals as subjects, subjecting them to the ultimate Subject/Authority. This hailing occurs in four stages: firstly, interpellation of ideology takes place; secondly subjects are subjected to the centre; third, mutual recognition between the authority and the Subject, fourth the establishment that this is for the best for all parties that subjection takes place. In how Panopticon functions this can be recognized, as much as in the use of 
surveillance cameras today from apartment buildings and convenience stores to military zones.

Judith Butler, in The Psychic Life of Power: Theories in Subjection responds to the close circuit of Althusserian conception of interpellation by drawing attention to "a space of tension" between? subjects and the Subject. She reminds us that there are, after all, "bad" or unruly subjects. What if critical questions are asked at any given time in the scenario of interpellation? What is there to perhaps imbalance the Authority, to subvert or, mock it? This becomes the preoccupation of many contemporary artists, two of whom will be discussed here with reference to their innovative, playful artistic strategies in using new media technology.

New York based artist Jill Magid has a keen interest in surveillance. For one of her projects, System Azure (2003 ongoing), Magid invents a company called System Azure Security Ornamentation with which she approaches Amsterdam Police Headquarters while taking a residency in Holland. She convinces them that because the cameras are visible, it would be interesting to "ornament" them, for example in the colors utilized by the police force. Jill Magid glues rhinestones using permanent adhesive onto the security cameras at the Amsterdam Police HQ. Although the ornamenting policy is no longer in effect, her website announces, the cameras are still there.

In an interview, Jill Magid says the following on System Azure:

System Azure began as a question: are public surveillance cameras tools to observe and survey space, or are they images: representations of an authority, signifiers of 'safe' spaces? I was curious about the meanings/roles of the cameras, as the visible manifestations of their larger operating systems - including the cameras, recording devices, guards, switchers, other integrated security networks, etc. Was the camera a fetish standing in for the system as a whole (that we imagine is there)? Like a 
gargoyle, can a surveillance camera be ornamental, an accessory of architecture? If so, how does the architecture to which the camera is affixed inform our perception of it? (Perier)

Magid does exactly what Butler suggests: she approaches authority figures with something they do not expect, catching them off guard. She reverses the interpellation scenario only to expose its workings. If as an artist it does not work, she returns in disguise as an entrepreneur (which is the case in System Azure). In Camera One in Wester Park (2005), she has an actual detective take part in her project about investigating a fictitious act, which, upon inspection and the set up of "evidence" is enframed as a "crime".

In her performance entitled Lobby 7 (1999), Magid "hijacks" the information monitor in the lobby of Massachusetts Institute of Technology, interrupting its regular broadcast to disseminate her own agenda: fragmented images of her own body as seen through the openings of her clothing, in real time, using a small camera. This perfectly examples the embodied experience of space wherein the hermeneutic and the phenomenological blend.

Mexican-Canadian artist Rafael Lozano-Hemmer uses stepper motors, surveillance cameras and trackers to suspend in the air leather belts -at the waist level- in his installation Standards and Double Standards (2004). By the computerized manipulation of the trackers, the belts move toward the passers-by/visitors "facing them with their buckles". When more than one visitor is in the gallery space, chaotic patterns of interference is observed. While belts symbolize patriarchal authority the piece draws attention to the interference as a space of negotiation between the parties involved.

Lozano-Hemmer also conceptualizes what he calls relational architecture in his 
artwork such as Pulse Park (2008), Voz Alta (2008) and Pulse Front (2007), each taking place at outdoor public spaces, with the participation of a large number of people in The US, Mexico and Canada respectively. An earlier example of relational architecture is Underscan (2005) a public art installation in Trafalgar Square where passers-by make visible via their own shadows the video images projected to the ground in plain daylight.

Lozano-Hemmer's definition of this concept is as follows: "Relational architecture can be defined as the technological actualisation of buildings and public spaces with alien memory. Relational architecture disorganizes the master narratives of a building by adding and subtracting audio-visual elements to affect and re-contextualize it. Relational buildings have audience-activated hyperlinks to predetermined spatiotemporal settings that may include other buildings, other political or aesthetic contexts, other histories, or other physics." (1998)

Relational architecture resonates both with the Foucauldian heterotopia and what Nestor Garcia Canclini calls in "Hybrid Cultures, Oblique Powers” transtemporal: a gathering and citing, often out of context, all in fragments as most visibly being the intrinsic quality of video. (225) Drawing on Bachelard's work, Michel Foucault moves from topophilia to heterotopia, a space in which we live, in which "the erosion of our lives, our time, our history occurs". In heterotopia sites are represented, contested, re/invented. This, in the fabric of the society, Foucault argues is found in all cultures. Heterotopias are changeable and negotiable, and they are what make juxtaposition or superimposition of space a possibility. In order to stress the temporal relation that accompanies heterotopia, Foucault coins heterochronies and together they make up a layered, multifold experience of "having lived or living at a time and place".

In "Othering Space”, Wendy Hui Kyong Chun takes up the term heterotopia from 
where Foucault leaves off and suggests that cyberspace offers room enough both to imagine and to tie its roots into existing systems (for example in e-commerce). According to Chun, the navigability of the Internet creates a kind of high tech Orientalism through the conflation of information networks and cityscape. Chun argues that high tech Orientalism is different than mere spatiality in that it promises pleasure and an intimacy with the Other on the one hand and resurrects virtual frontiers when deemed appropriate on the other. (241254)

In order to discuss what is different in more recent digital technologies than former ones, Lev Manovich revisits Walter Benjamin's “The Work of Art in the Age of Mechanical Reproduction," where Benjamin discusses the unique presence of artwork's aura as a paradoxical distancing in order to attain nearness. With mass production there is a preoccupation to bring things closer. There is a collapse of physical distance. Manovich then traces distancing to historicity by way of comparing the account of Benjamin to that of Paul Virilio (in Big Optics) to expose what is considered natural (painting for the former, film for the latter) differs greatly whereas the sentiment of being at loss in distancing remains the same. Manovich argues that telepresence changes the notion of proximity because the user of telecommunication technology can "affect change on material reality over physical distance in real time.” (174)

In Migrancy, Culture, Identity weaving geographical, political and affective space together, Iain Chambers talks about understanding dwelling as a mobile habitat, inhabiting time and space not as fixed structures but as openings that allow critical provocations and articulations. (4) As such he refers to Rilke and Heidegger for 'another sense of home' one that is not fixed and secure in the sense that it does not seek security. In The Practice of Everyday Life, Michel de Certeau draws our attention to the distinction between place and 
space, arguing the latter is "actuated by the ensemble of the movements within it." (117) Space, in de Certeau's view, is practiced place. De Certeau takes the reader to a virtual tour of the cityscapes, cognitive maps, vertical and horizontal lines, contours of walls, buildings and railroad tracks somewhat similarly to the way Bachelard lets us roam a dreamy house, intact with its staircases and closets.

From Orlan's facial modifications -she uses her own body as an artistic site - and "selfhybridizations" to Robert Lepage's The Image Mill Project where fragmented, non-linear history/story spills onto the surfaces of the cityscape (to coronate the 400 years of history of Quebec City) from science-fiction dystopias to database cinema, from Char Davies' userinterface based full body immersion in closed, spherical space experimentation in Osmose and Éphemère to multi-authored, web-based evolving narratives space, place, geography and proximity continue to be central to contemporary work of art as much as social theory and philosophy. The former challenges the latter two as they, in turn, inform or inspire the former. The Coat Check investigates space, relational dynamics and mobility through these rich interdisciplinary discussions. 


\section{Chapter III}

Dispositive displacement, an artistic inquiry

Displacement: an overview

This Place/Displace: Mona Hatoum's intimate and intimidating spaces

This Place Meant/Displacement: Kutluğ Ataman's memory work The Coat Check as a series of displacements 


\section{Displacement: an overview}

In contemporary global conjuncture, the term displacement is generally used in association with migration, most notably forced, but also voluntary, exiles of various kinds

- from dissident poets forced to flee their homeland to deterritorialized aboriginal peoples. Postcolonial, transnational human flows are creating communities where cultural, sociopolitical identity is re-shaped within global economy and political agendas. Here, I will be discussing displacement as it relates to discourses on identity and its role in providing a cultural critique of power.

To begin with, I will visit some of Edward Saïd's writings as he has most eminently articulated the significance of understanding displacement in global conjunctures today, connecting it to the history of hegemony (of the West over "the rest" in Orientalism, the Palestinian deterritorialization vis à vis Israel's formation and the later policies of the Israeli government in The Politics of Dispossession and so on). In his memoir, Out of Place, the late Saïd makes clear that he is a displaced person, a scholar of Arab-Palestinian origin living in New York as an American citizen with academic formation in the States and a scattered extended family in Egypt and Lebanon. From literary criticism to political activism and self-writing, his work is influenced by the fact that he is and has been, in his own words, in exile.

Written after Saïd was diagnosed with cancer (an important detail that Saïd credits for the need to look back into his own life), Out of Place revisits his many displacements, starting even before his birth, with his father's acquiring American citizenship and his family's eventual move to Egypt. Born in Jerusalem (under the British Mandate of Palestine) to Protestant Palestinian parents, Saïd recounts in his memoir his return to 
Jerusalem in 1998. Seeing the birthplace on his American passport, the customs officer asks him when exactly he left Israel. He responds by saying he left Palestine in 1947. Then he is asked if he had relatives in Jerusalem. "No one" he replies, “...and this triggered a sensation of such sadness and loss as I had not expected. For by the early spring of 1948 my entire extended family had been swept out of the place and has remained in exile ever since." (9) In his other writings, too, Saïd explores displacement but none describes the minute details of the psychic implications of displacement as vividly as Out of Place. Saïd recounts for example that he packs too many things and personal memorabilia each time he travels, which he comes to realize with an innate fear lest he never comes back. In this sense, displacement is an enduring phenomenon that one never fully grows out of, an indelible marker ingrained in the individual.

In Orientalism, Saïd focuses on the systematic institutions and discourses originating in Europe starting in the late $18^{\text {th }}$ century and continuing on to $20^{\text {th }}$ century, and indeed with repercussions today, which produce the Orient as an entity of both fascination and domination. This takes the shape, for example, in the writings of Gustave Flaubert or Gérard de Nerval, as much as fantasy and romanticism as economic exploitation and political subordination. The Orient is invented and is mis/placed on the map of resources for Europe. The Orient is an endless source of fantasy and fascination with the Other.

In Reflections on Exile and Other Essays, a collection of his intellectual oeuvre over thirty-five years, Saïd explores, via critical readings of theoretical and literary texts, the sharpened vision that exile can produce. He draws on diverse philosophers such as Maurice Merlau Ponty whose phenomenological approach he credits as best reflecting the predicament of reality without absolutes. The inhabited time and space is of crucial importance in understanding the exile which Saïd claims is "as close as we come in the 
modern era to tragedy." (183) The multifold possibilities range from a reactionary selfinflicted distancing, a "making a fetish of exile" to too quick a desire in the new setting to belong at the expense of an intellectual, moral, emotive reserve. On the one hand to live within a sense of the temporary erodes the capacity to inhabit space and time and results in "a permanent cynicism"; on the other the sense of security and taking a habitat for granted results in partial perspective. He refers to Adorno (an exile like many great thinkers of the time, from Walter Benjamin to Hannah Arendt) who seeks a sense of home in writing and reflection, instead of physical commodified places that house individuals.

The person(s) in exile however also has the advantage of multiple vantage points. "Most people are principally aware of one culture, one setting, one home; exiles are aware of at least two, and this plurality of vision gives rise to an awareness of simultaneous dimensions, an awareness that -to borrow from music- is contrapuntal. For an exile, habits of life, expression, or activity in the new environment inevitably occur against the memory of these things in another environment. Thus both the old and new environments are vivid, actual, occurring together contrapuntally." (186) Saïd argues that there is pride in this, because one could act as if at home in multiple places as well as derive a unique pleasure from this kind of apprehension, especially if a critical distancing from orthodox positions and a sense of empathy is achieved.

My theorization of multiplacement is connected to Saïd's sense of contrapuntality and focuses on multiple vantage points. In The Coat Check augmented reality installation, the superimposition of personal archival footage over the physical space in semi transparency (the footage being see-through so that the real space is visible) creates a heightened awareness and an acute distinction of both media and real space.

Similarly, historian Tzvetan Todorov explores the role of a distancing and drawing 
near that comes from the fact of being in and belonging with two cultures and languages in his autobiographical account of leaving, living elsewhere, and returning to his country of origin in L'Homme Dépaysé. Having chosen to live in France as an adult and emigrating from his native Bulgaria, Todorov is not in Saïd's shoes but nevertheless shares with the latter a certain sense of loss as well as a contrapuntality. Playing on the double meaning of the word "dépaysé" meaning disorientation (in the negative sense) and change of scenery, airing (in the positive sense) Todorov possibly arrives at a third sense, that consisting of the prefix "dé" and the word "pays", man who is devoid of a single country or nation. In this personal account, the author of Morals of History explores his attachment to his adopted country, France, first by trying hard to be assimilated then by giving in to a double sensibility. On returning to Bulgaria after eighteen years passed away from it, he finds, to his surprise family members and friends tell him in a complementary way, he has not changed at all. This ignoring of the time outside of the country as if it were a dream makes him all the more conscious of how deeply he has changed after all. Todorov concludes that the dépaysé ultimately disorients the native, as he is in "the astonishment of things", the first step, he tells us, in the discovery of the self.

The notion of displacement takes us to the idea of the diaspora and post-coloniality via the nation building processes of the $19^{\text {th }}$ and $20^{\text {th }}$ centuries. Benedict Anderson, in his seminal Imagined Communities, examines the phenomenon of how an idea of the nation and national belonging forms between individuals who do not know each other or share common experiences. To him, nations are imagined communities where groups of people believe in the unity of a society on arbitrary grounds, developing senses of a homeland, ethnic origins and so on. These communities are exclusive and sovereign -dreamed in terms of freedoms within territorial claims and segregations of various kinds. Nation building 
processes around the world have different histories but commonly these histories involve degrees of inclusion and exclusion, borders and outcasts, victims and perpetrators. The formation of the Turkish Republic for instance, modeled after the French ethnic nationalism where formerly a multicultural and multi ethnic Ottoman Empire had been, involves forced migration, assimilation and "elimination" of non-Muslim, non-Turkish subjects of the empire. Erik J. Zürcher sees this period as part of the Turkish modernization program by the Young Turks Movement. This program results in, for example, the forced population exchange starting in 1923 and continuing on to 1930 between Turkey and Greece and their newly drawn national borders. This means, following new definitions of nationhood, populations who have lived for centuries side by side in the Aegean would be uprooted and reinstalled to align Greek speaking Orthodox Christians of Anatolia with the Greek nation state, and Turkish speaking Muslim minorities of the Greek mainland and islands with the secular Turkish nation state. According to the archival work and interviews with survivors in Bruce Clark's Twice a Stranger: The Mass Expulsions that Forged Greece and Turkey, the cultural and economic toll of this scheme alone has been extremely traumatic for both communities concerned.

For a predominantly inclusive model of nation building, one may look no further than Canada. Canada, observes Edward Saïd in an interview, is unique in the way in which it turns the idea of exile into an institution, creating public policy and even a ministry devoted to multiculturalism. From Will Kymlicka's arguments on the minority rights starting with the Québecois and the Aboriginal peoples as different from polyethnic groups to Bouchard-Taylor Commission's report on accommodements raisonnables concerning tolerance to immigrants in Quebec Canada continues its nation building on the premise of immigration from diverse communities and faces issues related to the dynamics of such a 
construction of its identity.

Diasporic, post-colonial, hybrid identities become prominent markers of contemporary societies around the globe. Arjun Appadurai argues that electronic media and migration are two major forces intertwined, that create a rupture from the earlier sense of a singular transformative/modern moment as described in the writings of Marx, Weber and Durkheim and others. Appadurai claims that electronic capitalism works beyond national or international levels. Electronic media change the way we understand mass or traditional media because its scope enables imagined selves in ways that were not possible before. When mass migrations are combined with "rapid flow of mass-mediated images, scripts, sensations" he tells us that "we have a new order of instability in the production of modern subjectivities." ("Here and Now", 174) Globalization is linked to the modern through the unpredictable co-working of the people in movement and media. Appadurai claims that with electronic dissemination, imagination has widely become part of the quotidian of ordinary people. Imagination is distinct from fantasy in that media provokes agencies that are no longer in the monopoly of the elites, artists and the like. Sodalities of transnational/post-national nature form within and through the human and electronic/virtual human flow.

In Writing Diaspora, Rey Chow observes the American media coverage of the students' and workers' demonstrations in Tiananmen Square in June 1989 as claiming to objectivity, bringing to the spectators yet another confrontation outside of the US, through the neutral lens of journalism. Repeatedly, non-European confrontations overlap with "objective" media coverage with intentionally, politically selective agendas guised as reality, Chow warns. As political power uses media by way of speed and acceleration, movement risks "going nowhere", in the end becoming a self-absorbed mechanism able 
only to concentrate on more speed without aim or any sense at all. Chow argues that the effects of such speed are evident mainly in bodies "caught" between the first and third worlds. Chow gives the example of certain hostage crises and the uses of the Western terminology "freedom, human rights, democracy" in negotiating political and or economic power between the states (for example U.S versus China) for their own gain using the "humans involved" as tokens of exchange. The direct result, Chow argues, of an obsession with speed (dividing anew the first and third worlds as those who speed up and those who try to catch up) is the emergence of the migrant who are condemned to eternal homelessness, the only home "state". (179)

On the other hand, Homi K. Bhabha argues that the migrant, in-between positions are where we can look in order to reconsider and transform the society. To him, it is important not to focus on points of origin in considering hybrid subjectivities. The inbetweenness is a potential that one has to be careful not to celebrate without the full awareness of the forces that has created it (colonial, hierarchical histories) and yet it bears the open articulations of a contra-modernity, a testimony to its own existence and its latent power to subvert, resist and transform. This idea resonates in the writings of Ella Shohat and Robert Stam, who see a great potential for hybrid identities and artwork by "picking up the leavings of the colonizers only to transform and inverse them to turn the gaze critically back to the West" as characterized in garbage aesthetics and Third cinema. (1997)

What are the ways in which discourses on displacement could be furthered? Although I recognize the socio-political implications of displacement as a term denoting forced human flow or a reminder of historical processes that lead up to it and continue onwards, it is also possible to consider movement a point of reference within the phenomenology of the everyday life. Dislocation and relocation is more than a schizoid 
division between the past and the present, here, there and other dichotomies of the same nature. Especially contemporary media and communication technologies challenge traditional notions of community, affective ties, time and space in ways in which displacement is constituted as an always already condition -or perhaps this is a condition in and of itself of displacement regardless. The overlapping of multiplacements and mobilities has the potential to engender positionalities that are possibly better understood in the way they constantly evolve rather than the essentialism inherent in displacement, referring to an original breaking with where one needs to be. The critical potential of hybridity as pointed out by Homi K. Bhabha, Ella Shohat and Robert Stam among others, dwells on multiple perspectives, cultural, affective and linguistic affliations. As such, multi-placement is not only a possibility but quite probably the zeitgeist of our times.

One of the focal points of The Coat Check and this study is the exploration of digitally enhanced space as an affective topography. Before the realization of The Coat Check, I turned to two artists whose work resonates with me on a personal level and with whom I have an affinity because their work exemplify how a deeply political critique of displacement is imbedded in seemingly benign objects, videos, juxtaposition of vastly diverse, even contradictory concepts Artists Mona Hatoum and Kutluğ Ataman both project their experiences of displacement into diverse installation and video work that question the idea of home, community, nation, alienation and belonging. The political undertone of their work urge the viewers/participants to rethink global identities and un-familiarize themselves with given paradigms. They put forward an epistemological and methodological re-reading of space, displacement and identity with regards to contemporary global sociopolitical conjunctures, themes that The Coat Check takes up using augmented reality technology. This also necessitates a discussion of the role technology plays as a leitmotif in 
understanding identity in a more and more mediated world. This position parallels -but is not limited to- the post-colonial interventions to Western scholarship, most notably exemplified by Trinh T. Minh-Ha, in that it questions the normative and the canonical to create Other spaces.

It must be emphasized that even though my main concern is the transition from/to or simultaneous occurrence of physical and technological displacement, Hatoum and Ataman cannot be singled out for their use of new media, certainly not augmented reality. There are artists working in locative media, technologically enhanced experiences of embodiment and the like, however Hatoum and Ataman, regardless of the medium they utilise, subvert preconceived ideas of displacement in an intellectual and affective "deep focus"/depth of field that aligns their work with the central question at stake in this study. 


\section{This Place / Displace: Mona Hatoum's intimate and intimidating spaces}

\section{On Hatoum: the familiar estranged}

“There are bodies out of place. There are plenty of people in free fall.” (Stewart, 97)

Mona Hatoum was born in 1952 in Beirut, Lebanon to Palestinian parents. Among close to a million Palestinians forced to leave the country in what is known as the al-Nakba or the Palestinian exodus following the 1948 Arab-Israeli war, her family settled in Lebanon where they were not granted citizenship status. Hatoum's autobiographic displacement begins before her birth within the trauma of exile embedded in the intricate and conflict-ridden identity crisis that marks the Middle East. She studied graphic design at Beirut University College between 1970 and 1972. In 1975, civil war broke in Lebanon while she was on a short visit to London, England, preventing Hatoum from returning to Beirut. 'Stranded', she studied at Byam Shaw School of Art, graduating in 1979 and Slade School of Fine Art, in 1981.

Her earlier work mainly consists of performances, video and body art that evolve around the notion of confinement, limits of the self and boundaries negotiated between the self of the Other. Political in its undertones, fragile (e.g., images of her mother's naked body and intimate letters read out loud in Measures of Distance), voyeuristic (e.g., macro scale video close ups of her body in Corps étrangers), playful (featuring interactivity, e.g., spectator pulling the artist's hair in Pull, 1995) in its execution, this oeuvre foretells Hatoum's transition to installation. As she withdraws her own presence in her latter work Hatoum follows up on her fascination with permanence, temporality, permeability, durability and the familiar un-familiarized by focusing on objects and their relationship to 
space, both constructed (her own work within the gallery space) and found (the gallery). Situating her work against such 'given' space -the giant Mouli-julienne (1999) at grand, spacious, imposing Tate and Present Tense (1996) against the worn-out floors of Anadiel Gallery in Jerusalem- Hatoum weaves a delicate web of positionalities that bind the artist, the artwork, the contextual space and the spectator.

\section{Home as an impossibility or anywhere is home: Homebound}

"Familiarity and strangeness are locked together in the oddest way, adjacent and irreconcilable at the same time. For not only does one feel that one cannot return to the way things were but there also is a sense of just how acceptable and 'normal' these oddly distorted objects have become, just because they remain very close to what they have left behind." ("Entire World as a Foreign Land”, Saïd)

Mona Hatoum's Homebound (2000) dwells on the interplay between intimate and intimidating in both form and content. The installation is composed of a 'home' space created within the gallery and yet divided from it by vertical wires. This home is composed of familiar elements, tables, kitchen gadgets, chairs, coat rack and so on. They are bound to one another by electric wires, light bulbs that buzz from inside seeves, graters and such familiar objects. The circuit of electricity traverses the objects, rendering them unusable, alien, out of what they seem to be made for. Harmless becomes harmful, inanimate becomes charged with energy, transformed. The piece is political in many ways: what gives a sense of rootedness is where the conflict is. The acquired, partitioned space (individual home) is also what divides one from the Other. Hatoum talks about both national borders, space as a promised land that fails to deliver and on a more personal level the conflicts and tensions that arise in the most intimate human relationships often taking shape within 
homes.

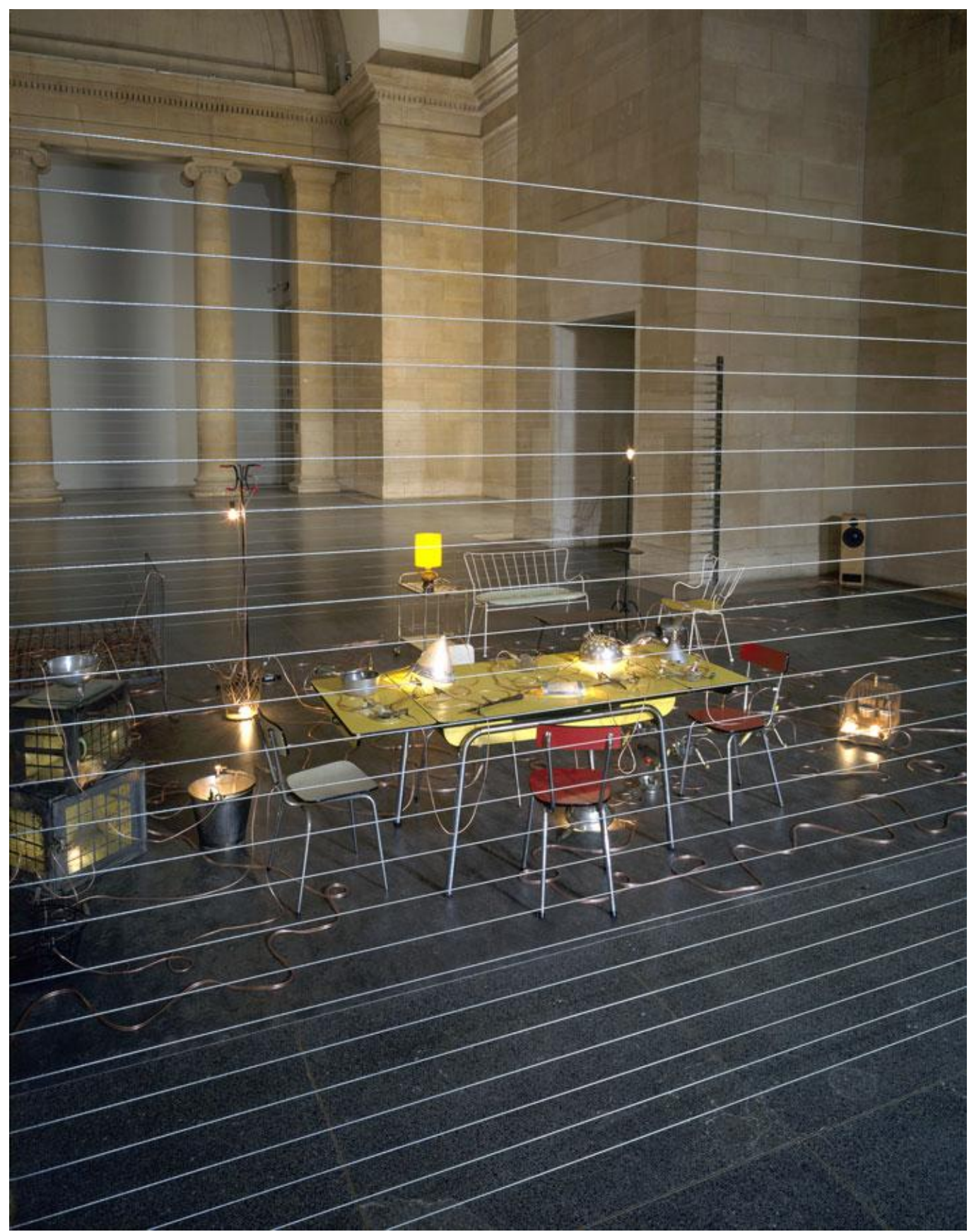

Figure 3.1 Homebound (2000) Mona Hatoum

Displacement is central to this piece. Hatoum, whose family is Palestinian immigrants in Lebanon, who left Lebanon as a young student to study art in London, 
England when the Lebanese war broke out, is no stranger to the phenomenon. When there is no home to return to, when home is barred out and one is excluded from it (in her case twice, first being the loss of Palestinian statehood and its consequences on the lives of Palestinians) one goes through a profound transformation: the outside becomes the inside, exile becomes the forced home while 'home as we know it' is reconditioned, reinvented as 'outside'. Playing on such transgressive dichotomy Hatoum makes the spectator reflect on his/her stance with regards to physical, psychological and political frontiers.

The electric wires that connect the objects in this heated, disturbed domicile (a toy truck on the ground, a baby's crib, lamps and a bird's cage) are attached, latched on to the objects via metal clips. They seem to allude to instruments of torture; for example, the coat rack with hangers refer to one of the most common methods of torture of the 'Ta'liq.' A network of tortured elements points to individual and collective suffering. The metaphor of prison is reinforced not only by the wires that surround the home but by the very elements that render it home: the grid texture of the bed, the crib, vertical and horizontal lines of the table, the chairs, even the bench where one is supposed to rest one's back is made up of vertical metal bars, which also, seen from the outside where the spectator is situated, gives the illusion of a grid.

The title of the installation Homebound is double sided in itself, adding a linguistic affirmation to the dual nature of inside/outside, intimate and intimidating, familiar and alien. It plays upon how the individual objects and the ensemble of what constitutes this space as home are 'bound' together by a relationship charged with electricity and audible tension. It is ready for a short circuit, and thus an annihilation of the whole system before our eyes. But it is also an impossible attempt to move towards 'home', an unsanctioned territory. If or not this home is welcoming remains an 'always already' afterthought to its 
immediate inaccessibility. One may choose to make one's home within conflict or one may embrace the tensions. In this case we are not given the choice but stare at it from a safe distance, the gallery space, a serving space, empty, indifferent with its colossal presence. This may allude to Mona Hatoum's autobiographic relationship to England, where she was 'stranded', unable to return to war-torn Lebanon, being forced to become a spectator from afar. It also implies an abandonment of the idea of an essential rootedness, that within the uprooting, the trauma and distance are possibilities engendered by sheer movement.

The Coat Check, on the other hand creates tensions and restrictions via difference: linguistic (Turkish, French, English, Armenian), spatial (geographies on multiple screens versus actual room) in the media utilized, and most importantly via the prerequisite physical confinement of the central piece: the HMD, handtracker and the cables that attach the immersant to the main board. The duality here lies in the fact that the physical confinement enables a digital enhancement, a liberty to play with archived footage, at will.

\section{Inside and Outside, Here and There: Interior Landscape (2008)}

"This side and beyond are faint repetitions of the dialectics of inside and outside: everything takes form, even infinity. We seek to determine being and in doing so transcend all situations, to give a situation of all situations...the dialectics of here and there has been promoted to the rank of an absolutism according to which these unfortunate adverbs of place are endowed with unsupervised powers of ontological determination." (Bachelard, 212-213)

Gaston Bachelard's reflection on the inside and outside, here and there, this side and beyond as interlinked in ways that are not complimentary but also overlapping, transposable, contradictory and bound by language parallel one of the major preoccupations of Hatoum's art. Indeed, he questions such a simple statement as être-là (being there) 
meaning, being here, where focus is more on an imposing situation of the need to 'situate' là overpowering the 'être' (being). The imagery he draws is that of a forefinger pointing and relegating the intimate being to an exteriorized place. Being is miniaturized by the 'there' that doubles as 'here'. In any case a divide is created, an exterior is 'fetched'. In the intentional divides and partitions of Hatoum's various installations such 'ontological determinations' are carefully 'supervised' (one could also say 'orchestrated' to allude to a Saïdian use of the word contrapuntal) so as to draw our attention to their absurd absolutism. Hatoum re-designates territories, plays with scale, substance and proximity and plays with spaces, objects and ultimately our sense of orientation amongst things we know, things charged with their own history, cultural and symbolic codes.

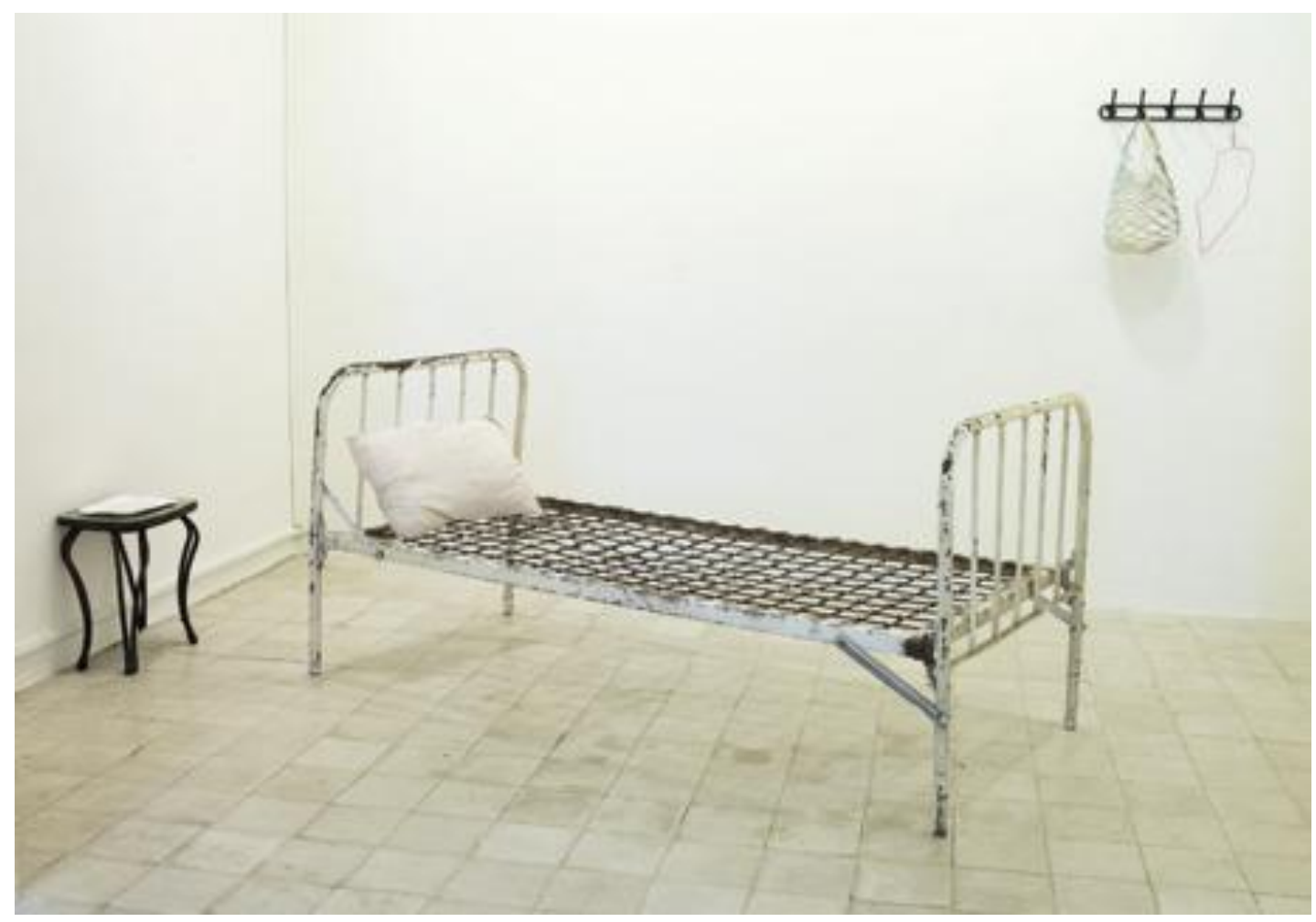

Figure 3.2 Interior Landscape (2008) Mona Hatoum 


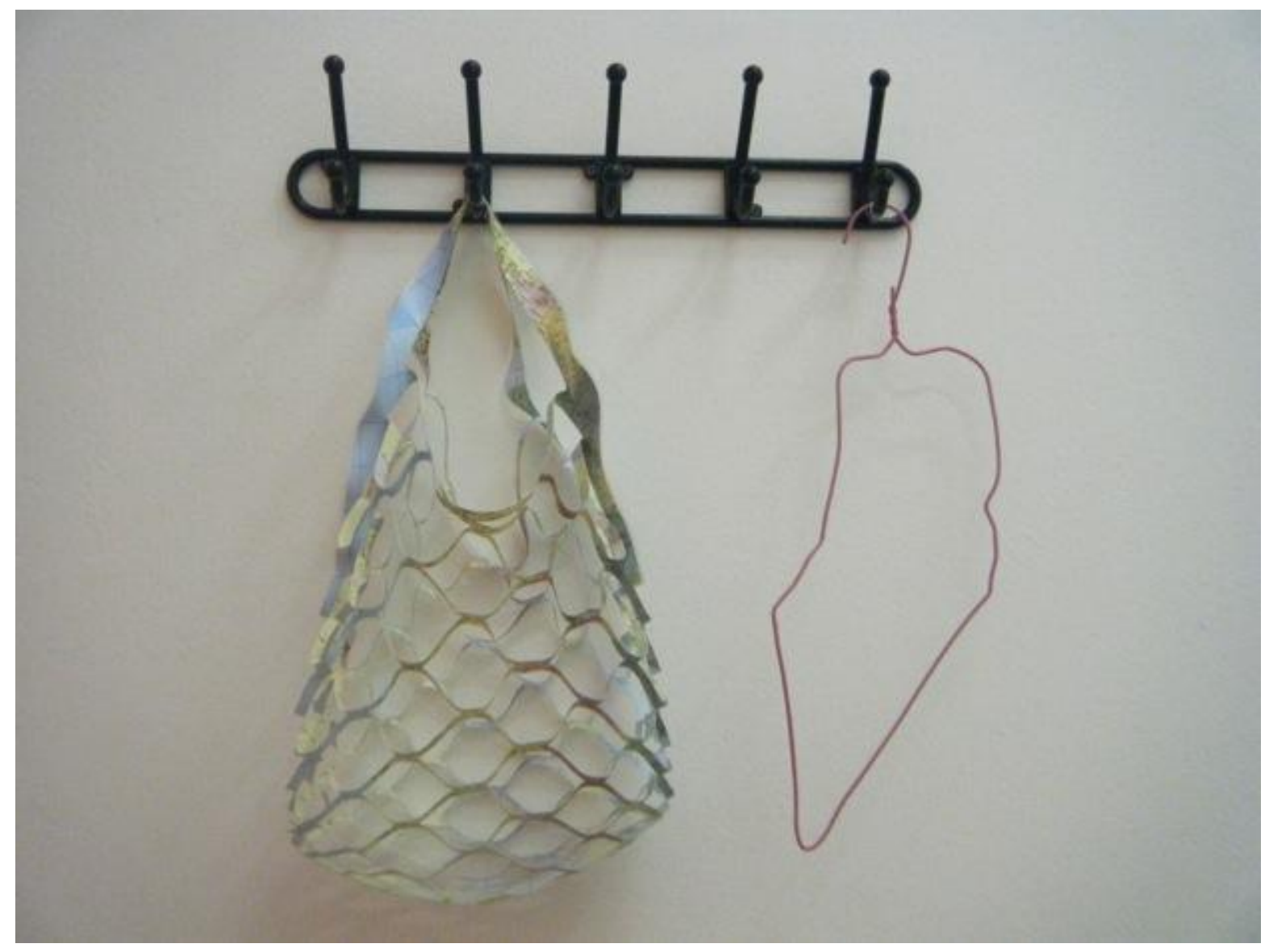

Figure 3.3 Interior Landscape detail

Bachelard refers to Jules Supervielle's writings (the link between agoraphobia and claustrophobia: 'trop d'espace nous etouffe beaucoup plus que si il n'y en avait pas assez') to explore such notions 'outside as prison', 'exterior dizziness' 'interior immensity', but, claims the relationship between inside and outside is not that of symmetry. "Memory keeps insisting these objects are known to us, but somehow aren't anymore, even though memory clings to them relentlessly." (221)

In the same vein, Hatoum's Interior Landscape plays on memory, of barbed wire, of partition, restlessness as a fact of life, simple and banal like a bare room. The role of memory is interlinked to topography, both affective and real, as Hatoum literally reshapes 
images we readily take for granted such as the map of the world. Who decides to draw the map of the world as we know it? Her installation titled Present Tense (1996) features a map of the world drawn by embedding red glass beads to a series of soap bars laid side by side on the floor of a gallery space. The perishability of soap bars -a reference to time, erosion of memory, and perhaps (ethnic) cleansing- plays against red glass beads -reference to blood feuds, the red 'you are here' dots on city maps, global 'hot spots'-, implanted for the time being to what seems solid. Yet, the 'raison d'être' of soap bars is to melt, to change form and in doing so change the chartered territories designated by the beads into a chaotic mess, scattered in space. There is no map without a solid structure. The undoing is also a strong current in Hatoum's work, like the self effacing lines in sand in + and - (1994).

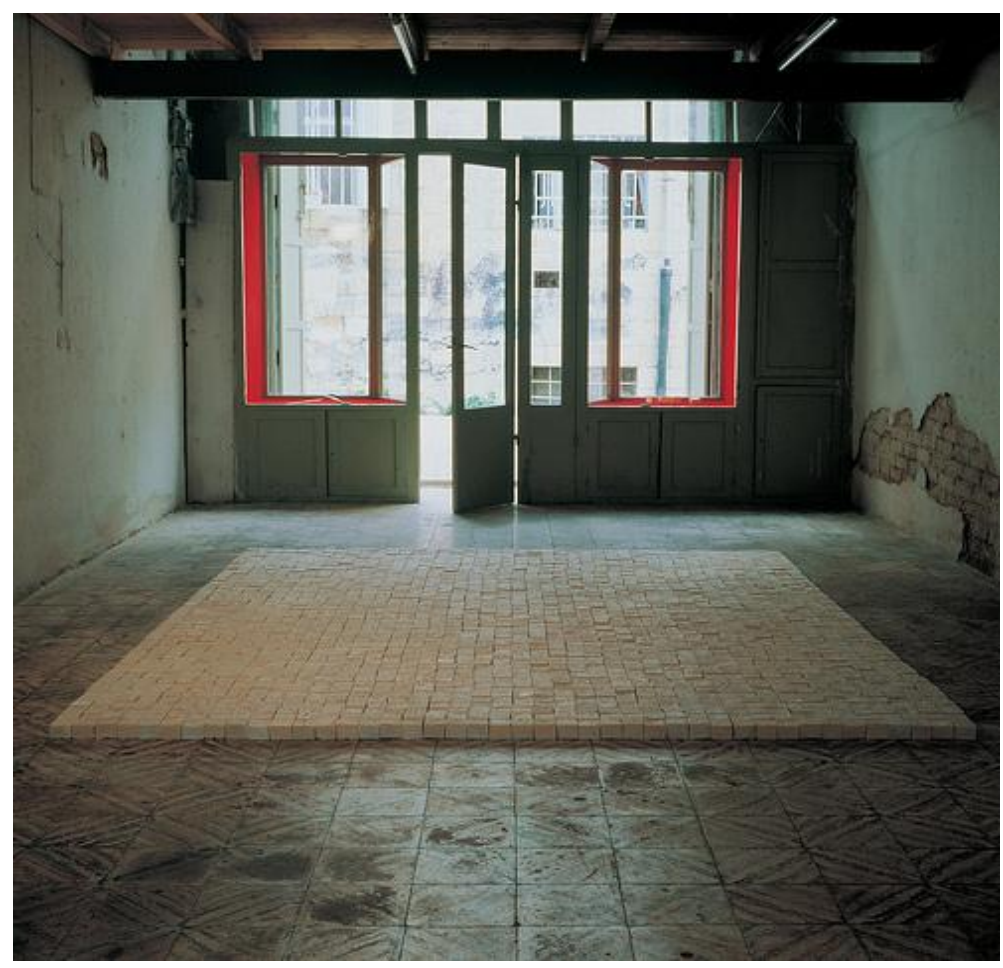

Figure 3.4 Present Tense (1996) Mona Hatoum 


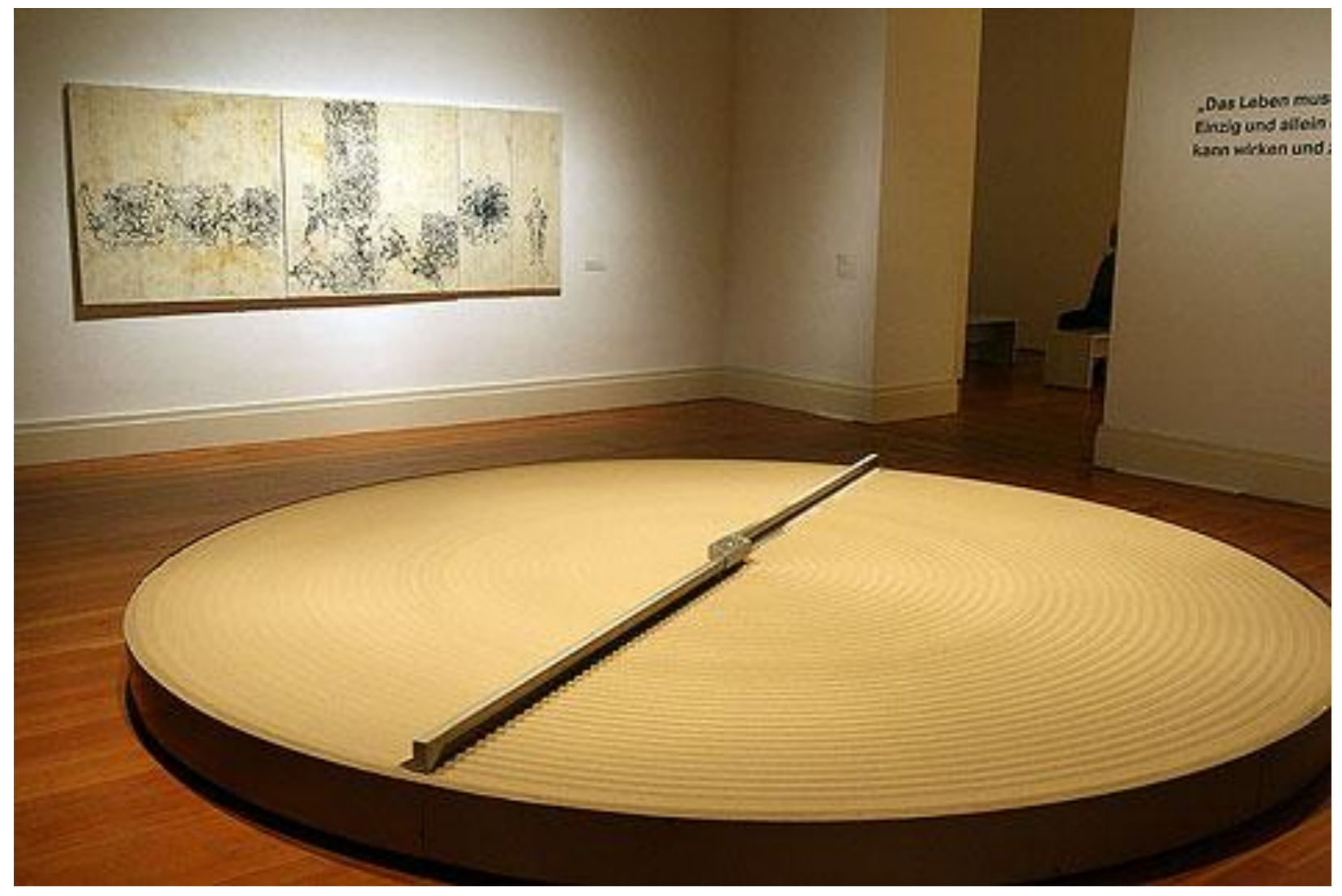

Figure $3.5+$ and - (1994) Mona Hatoum

This Place, Dis-place, Misplace

Hatoum turns the most intimate and comforting images into intimidating, alien ones. A bed, a lamp, a kitchen utensil become everything but what they seem, what they have been associated with, what they implicitly or explicitly imply. They are the artifacts of a world turned upside down, a place of no guarantee or security, where what 'is' can turn into what it 'cannot be, should not be, dare not be' any second. One can see the ground being taken under Hatoum's feet in her work and she drags along viewers into foreign, dangerous and yet liberating territories. Homelessness works both ways: on the one hand it alerts you to a constant state of agitation, on the other it allows for the possibility of 'anew' 
anywhere, at any given circumstance, against all odds. Thus Hatoum's forced displacement becomes her major strength and renders her work deeply political.

Bachelard tells us the importance of daydreaming and he does so guiding us into the crevices of a domestic fantasy, a home where childhood, play and daydreaming are housed. In this kind of intimate space there doesn't seem to be room for intimidation. We can take for granted the comforts provided by this house, this mental scape of serenity and wellbeing. In Hatoum's work home is an impossibility contrasting what Bachelard depicts. 'The unsafe is the only safe we can know of' her work seems to say, as she focuses on underlying tensions that mark our relationship to the ordinary. In the same vein The Coat Check deliberately creates a transitory, ephemeral space where familiarity and foreignness, the private and the public blend, destabilizing yet allowing for what Saïd describes as "flowing currents" upon waking hours. 


\section{This Place Meant/Displacement: Kutluğ Ataman's memory work}

Where to go, if memory follows? (Koc, 2012)

Born in Istanbul, Turkey in 1961, Kutluğ Ataman navigated different artistic terrains in different continents, passing from feature length fiction film to video art, documentary based installations (Women Who Wear Wigs, 1999) to playful enactments (Turkish Delight, 2007) to a blurring between fiction and reality in multiple screen installations (Never My Soul, 2001). Having earned an MFA degree in Film at UCLA, Ataman began making films in the 90s Karanlik Sular (Serpent's Tale, 1994), Lola + Bilidikid (1998) while he also made his first single screen video installation, semiha $b$. unplugged (1997), almost an 8 hour intimate portrait of larger-than-life Semiha Berksoy, one of the first opera singers of the Turkish Republic. In the following decade Ataman continued to make installations such as The 4 Seasons of Veronica Read (2002) and Küba (2004) an epic non-linear narrative about the inhabitants of one of the most underprivileged and immensely diverse neighbourhoods of Istanbul. Split into forty old TV screens is each character, telling her/his own story: as the viewer/participant moves from one seat to another in front of each screen, the multitude of voices weave a panorama of a community in its fantasies, stark reality and vividness of everyday life. 


\section{Of Running in Circles}

Time never dies. The circle is not round... Once you know the faces, you will begin to understand the story... (Manchevski, 1994)

It's a Vicious Circle (2002) is a multi screen video installation where a Jamaican born man (Troy Lopez, a friend of Ataman's) talks about living in Berlin as a foreigner. The screens are placed to form a closed circuit, where the medium close up of a talking head is multiplied, and the addressee is seemingly the videographer or the audience but the subject delves into his own psyche and closes in, much like the isolation and hardship he is recounting about his experience of being a foreigner. This dual closing, first by the society then by the individual himself is accentuated by the circular monotone in which his voice is not reinforced through the twelve screens in the sense it reaches out and is ultimately transformed but rather by the very fact that it grows tedious by repetition and enclosure. In this respect the inside and the outside are clearly defined on a surface level where the audience is outside the circle but Ataman also positions us in relationship to the 'inside within inside': inside the circle, inside the box, inside the man's thoughts and underlines our 'outsider-ness' with regards to where the audience stand, onlookers who, more or less find themselves in layers of isolation within the same spatial, affective, societal planes as well. 


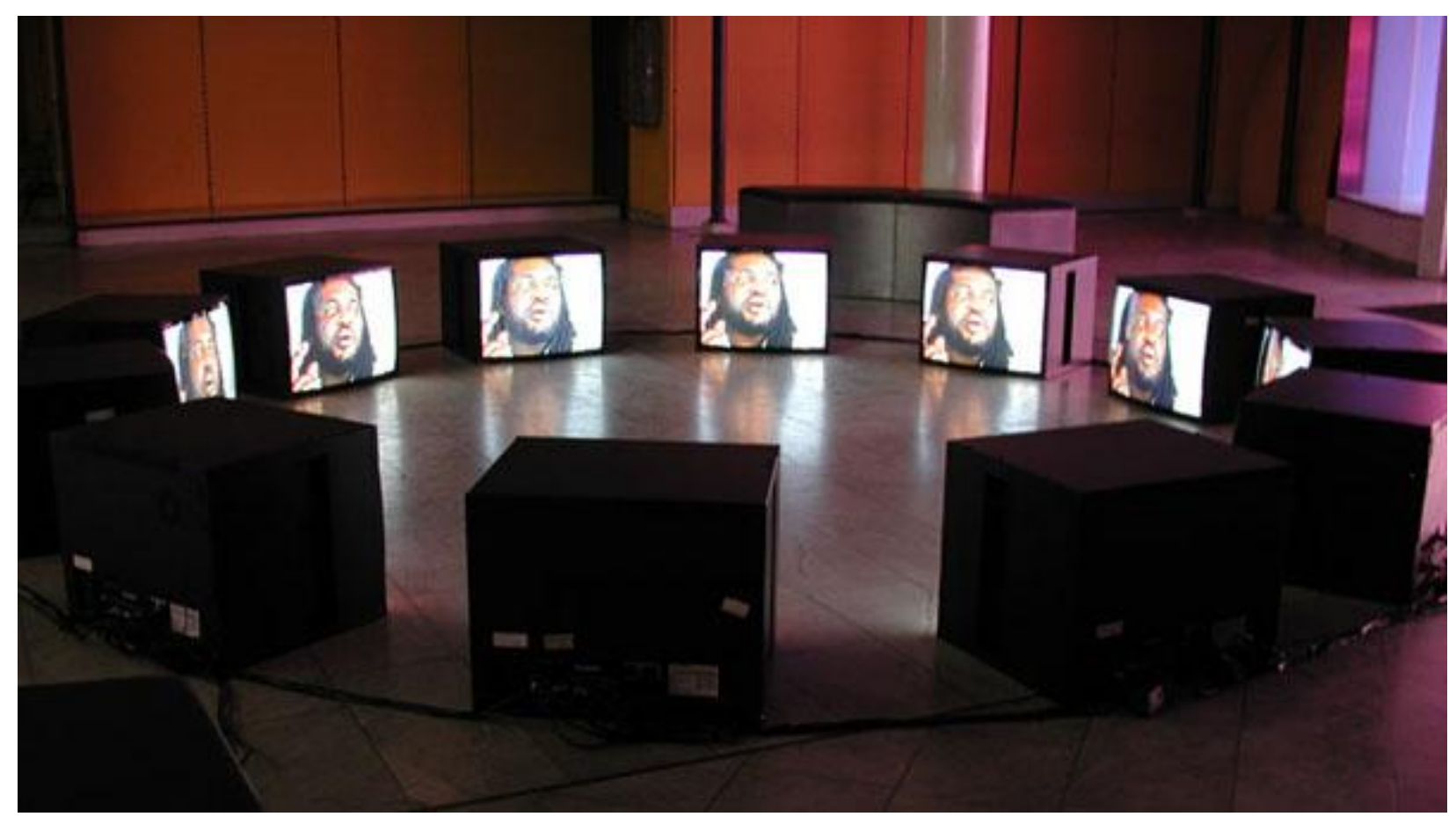

Figure 3.6 It's a Vicious Circle (2002) Kutluğ Ataman

In Paradise (2007), Ataman invites the viewer to multiple voices of Orange County, California residents whom he interviews or simply shows doing things like 'laughing therapy' in groups. Presented in a circular manner but with individual headphones and space enough to roam between the screens, this installation portrays diverse characters that make up a hyperreal Americana à la Baudrillard. As the viewer moves from one narrative to the other, however, much like It's a Vicious Circle, stories and individuals become isolated, turned towards their own reality and illusions. The overall effect of this ensemble speaks more of multiple solitudes than a community bound by the characteristics of a common identity. Ataman is concerned more with the singularity of each and every 'face' he encounters and the specific circumstances that surround it than the dialogue that may or may not be taking place amongst these residents or even between the viewer and the 
interviewees. The circular structure in both It's a Vicious Circle and Paradise divides the space of 'entry' into the narrative and designates an interior and an exterior that transpose for each other.

Like Women Who Wear Wigs, Küba and The 4 Seasons of Veronica Read, It's a Vicious Circle and Paradise are first person accounts, fragmented documentaries that leave much of their montage or assemblage to the audience. As Hatoum scrutinizes everyday objects, loading and unloading them with alternately danger, comfort, closeness, distance, familiarity and estrangement, Ataman presents us with faces, gestures and obsessions of individuals who challenge the borders of fiction, fantasy and reality; rooted in the quotidian, seemingly banal but a weaving together of timeless studies in human nature. His methodology of documentary/documentation/archive turn into 'an absurd interrogation' when he directs his lens to a subject who does not remember, touching upon the social amnesia of the Turkish Republic with regards to minorities, in the case of Testimony (2006) an amnesiac Armenian nanny who looks at photographs of a bygone era. 


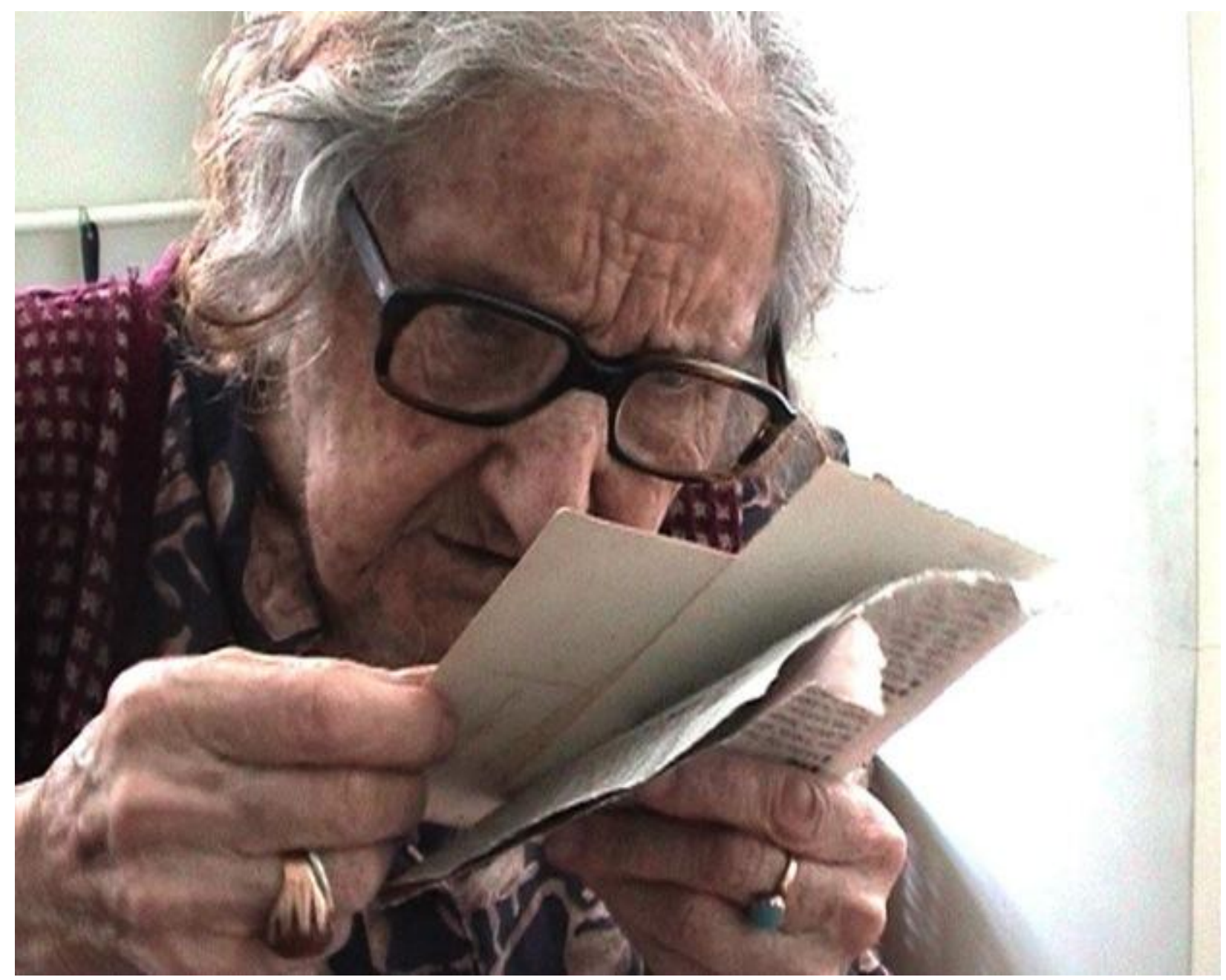

Figure 3.7 Testimony (2006) Kutluğ Ataman

\section{Memory, Amnesia and Hypomnesia to Hypermnesia}

There is no archive without a place of consignation, without a technique of repetition and without a certain exteriority. No archive without outside. (Derrida, 11)

We have to open up the archives and then we can open up the possibility of reconciliation. Such has been the framework of the discourse among some groups of intellectuals in Turkey, with regards to what is referred to as 'the Armenian question' in the 
Turkish official lexicon. The archives in question are the ones in the National Library in Ankara, dating back to the first quarter of $20^{\text {th }}$ century, mainly in Ottoman, created by the Ottoman government, stored away by the Turkish National Library. Turkish official position concerning Ottoman Armenian subjects been the forced migration thesis, that lives lost are calamities and casualties of World War I, ethnic groups killing other ethnic groups, equal loss on both sides.

Ataman's preoccupation with memory and archive inspired The Coat Check. Jacques Derrida traces arkhe as commencement and commandment all at once; simultaneously the point where things begin, and that place where authority and social order are exercised. Arkheion is a house, a domicile, an address. (A people sans-domicile, who archive instead? Is a question I raise with The Coat Check.) Derrida, in Archive Fever, talks about the spectrality of archive, neither present, nor absent 'in the flesh', neither visible, nor invisible, a trace always referring to another whose eyes can never be met. (84) Derrida revisits the story of Hanold, (already visited by Freud) the archeologist falling in love with a woman, Gradiva, depicted in a relief walking in Pompeii. The impossibility of the archeologist chasing Gradiva, tracing her trace, to be one with her, and her trace at the very moment of the imprinting of the trace. To house such a desire, this very archontic principle is troubled and troubling. In archive, there is an irreconcilable desire to return to the authentic and singular origin, a return concerned to account for the desire to return: for itself. (85) Hanold's desire, Freud's desire (who had a plaster cast of the relief in his study) and that of Derrida's. Freud, argues Derrida, in his excavation of the desire, conjures it. It is known that Freud did everything possible to not neglect the experience of haunting, spectrality, phantoms, ghosts. He tried to account for them. Courageously, in as scientific, critical and positive fashion as possible. But by doing that he also 
tried to conjure them. Like Marx, his scientific positivism was put to the service of his declared hauntedness and his unavowed fear. (85)

That which he does not reveal, that which has burned in him, or burned him, this unconditional right to secrecy is the very same inviolable secret of Gradiva. These impossibilities called archives, these very ashes where it can no longer even make sense to say 'the very ash', lure us.

The Ghosts of Mardin, the 2005 short film by Daniel Drapeau consists of family photographs, appearing and fading away with a soundtrack of hushed voices, telling the story of how Drapeau's family fled their native Mardin, now part of Turkey, to Egypt, then to Montreal, Canada. In Calendar (Atom Egoyan, 1993), a photographer 'loses' his wife to a homeland, Armenia, that was never his, to a man who speaks a mother tongue that he cannot speak. The woman returns to 'the place of origin' and stays there whereas the man returns to Canada, to an empty apartment where women speaking foreign languages talk on the phone -hired to do so by the photographer. Both films are about the melancholy of intangibility, that which is so close and essential, intangibility of belonging, loss, haunting memories, stories, separation, uprooting, solitude, imagination and death. What is archived is not solely in the photographs of Drapeau's short and the photographs of old churches that the photographer sets out for in the first place in Calendar, but in the archiviolithic impressions, as Derrida calls them, that we see in both films.

Archiviolithic drive leaves no monument, bequeaths no document of its own. As inheritance it leaves only its erotic smilacrum...lovely impressions. These impressions are perhaps the very origin of what is so obscurely called the beauty of the beautiful. As memories of death. (11) 
The institutional archives where documents regarding 1915 lie quietly are the storages of that which we do not speak of, places on occasion visited by scholars perhaps, and others, to 'retrieve' a number or two, a picture or two, to peek into fading papers, perhaps now transferred to microfilms or digitally scanned and available electronically. They are entrusted to an indefinite future. Their contents, the concept of these documents having contents of utmost importance, historical value, validations of an identity, a people, an existence, in their vastness, in their very presence evoke imagination. Archives meant to remind us of denial. Archives as monuments of recognition seeking... But archives as sites of reconciliation? Is this ever a possibility? Have we not dumped the past, bits and pieces into these caves, into the archives so as not to have to reconcile? Reconciliation: to look in the face of the Other at the moment of leaving the trace, of being that Other and its yet to be left trace. Topographical, typographical archives... Memory, amnesia, hypomnema...

The Coat Check installation dwells on the question of the archive, particularly in view of Ataman's Armenian nanny in Testimony who seems to mix dates, people and places belonging to different decades. One of the clips in the central coat check is of an Armenian friend making a "sarma", stuffed wine leaves in his home in Montreal. Behind the camera I chat casually about the song "Sari Gelin", the Turkish version of an Armenian song, Sari Aghjik. Behind our casual shared culinary interests and musical affinities lies a history that brings both of us as immigrants to a land where despite historical atrocities we forge relationships of next of kin. The installation does not make explicit this link, and in the plurality of time-space, historicity of the work, this also lies at the border of the inside and outside.

"Where is the outside?" Derrida asks early on, as the ultimate question concerning the archive. Archive's very own external substrate, devoid of the inscription on the body- 
proper, à meme. Referring to Freud, Derrida says that the death drive, the destruction and aggression it entails, not only incites forgetfulness but more importantly the eradication of that which cannot be reduced to mneme or anamnesis. Archive is hypomnesic, Derrida claims. Archive takes place at the place of the originary breakdown of the memory. Archive thus works against itself. (12) What of this obsessive compulsion to collect, to gather, to bury, to remove from the sight of the eye? What of the mystic writing pads? Scripture that precedes the sign. That which is beyond ourselves, the sense of it, comes to us through these impressions.

\section{The Coat Check as a series of displacements}

The Coat Check is informed by a critical reading of the installations of Mona Hatoum and Kutluğ Ataman. Inquiries about the inside and the outside, memory and forgetting are both philosophical and political in nature. The Coat Check AR installation utilizes tracking technologies, fog screen, spherical cameras to explore the relationship between technology and global displacements and challenge notions of identity based solely on territorial, national and ethnic affiliations. It consists of a series of displacements in its conception, form and ultimate experientiality. Consisting of personal archival footage placed in three-dimensional space via sensors, AR applications and video projected on a fog screen, The Coat Check dwells on multiple linguistic, geographic and affective realms. It recounts the traumatic experience of displacement only to displace further, to layer many displacements, to "trigger" memories -interactive video- at the touch of a physical object. The idea of emanet / entrustment draws attention to the role technology plays in experiencing space and tempo-spatial relationships and ultimately our identity. 
The Coat Check does more than using digitally enhanced space towards an end. It places digital enhancement/digital technologies at the core of a discussion on identity. Based on theories of hybridity and artwork that challenges traditional dichotomies of $i s$ and is not it tackles the question of digitally enhanced world by creating one. It also puts forward the argument that contemporary digital technologies challenge traditional spaces, leading us to "digital-affects-in-the-forming", global movements, reassessing transnational ties, capitalist world hierarchies.

What is the link between physical, actual displacement and the mediated one via technology, such as talking to a friend on skype or being immersed in a 3D computergenerated filmic world? In what way does our relationship to space change via electronic accessibility? What are the socio-political implications of overlapping displacements, for example being in exile and reconnecting to a homeland one is banned from via digital technologies? These are some of the questions that led me to research creation in the field of new media, particularly in augmented reality. Augmented reality, a simultaneous coexistence of real and virtual environments, seems to be both a manifestation of and a metaphor for displacement.

\footnotetext{
${ }^{7}$ I coin this word to emphasize the link between the digital and affect.
} 


\section{CONCLUSION}

Technological Displacement: The Coat Check Interactive Augmented Reality

Installation in Perspective explores identity, mobility and tempo-spatiality in relation to digitally enhanced space. Philosophical and socio-cultural implications of displacement with regards to technologically enhanced space guide this study rooted in cultural studies, arts and applied technology. Jason Farman remarks in his Mobile Interface Theory: Embodied Space and Locative Media, "As we connect with each other, with objects and with data across material and digital landscapes, these hybrid spaces are transforming the ways we conceive of embodied space. The stakes related to the ways we conceive of embodied space are significant, including the ways we imagine identity, community, and cultural objects we create including art, games, performance and narrative.” (15)

In the same vein, this research makes the case that socio-political questions and cultural identity are directly at stake in how digitally enhanced environments are created and embodied. While pointing to the innate displacement of data storage and transfer within digital technologies, specifically augmented reality, The Coat Check probes the very notion of displacement as a physical and affective phenomenon. In this sense not only does it refer to the idea of space as a dynamic experience that engenders sediments of meaning but also to the ways in which its technological restructuring generates new relations of presence, reframing already contested dichotomies of inside and outside, virtual and real, here and elsewhere.

Technological displacement occurs in the paradigm of global mobilities of peoples,

firmly grounded in historicity and the human desire to navigate terrains and negotiate borders. Two questions arise out of this claim: if indeed technological displacement is a 
subcategory of a historical continuity in human flows, migrations, border crossings, if it is posited not so much as a rupture, for we may be inclined to see digital technologies under the light of innovation and heralding a new era, then what are the terms and conditions under which movement is organized and funneled? This question is directly linked to surveillance and control, the development, use and distribution of tools, infrastructure and networks.

The Coat Check is created with this first question in mind. To begin with, tracking technologies integral to the installation are mechanisms and markers of surveillance and control. They are designed to dissect space into manageable bits and capture the stillness or movement of its inhabitants. Their development, implementation and use relate to powerof state, corporations etc. The second question, then, is that of agency: what are the ways in which these terms and conditions challenged, inverted and subverted? This, I believe, is the domain of artistic practice. The Coat Check traces movement to its historical fil conducteur, in this case the author's dispersed trajectory of journeys, life snippets scattered over a time span and geographies. In doing so it not only highlights a non-linear narrative of a displaced / multiplaced person but reclaims the co-existence and cooperation of an imageworld that is personal and political in its content and an exclusive digital technology.

I argue that it is important to see digitally enhanced movements in a historical continuum. If we take digital technology to its core binary system of operation, then we trace a series of displacements at work: data displacing numeric code, computing replacing manual human skills, ubiquitous computing urging individuals and communities to be in environments beyond their immediate, non-mediated one, 'absencing' and 'presencing' in shared spaces and physical displacement in the sense of movement of peoples relating to and making use of technologically modified proximities. Historically movement, 
expansiveness and the phenomenon of displacement commend trade routes, explorations, dissemination of knowledge and territorial partitioning of the globe. Digitally enhanced mobilities and 'multiplacements' in this sense are an extension of humankind's larger quest to implore, chart out and venture into the unknown, to reveal what is concealed and make possible what lies at the verge of the status quo.

By the same token Heidegger reminds us in his seminal essay The Question Concerning Technology that technē means not only a "bringing-forth" and "revealing" of truth but also poiēsis of fine arts, a safekeeping of truth in its original Greek use. Though he distinguishes the modern concept of technology as a "challenging forth" and an "enframing" (that which does not relate to the essence of technology, which conceals instead of bringing forth the truth, a danger related to the instrumental approach to technology) from its original counterpart he nevertheless sees a potential that "...the frenziedness of technology may entrench itself everywhere to such an extent that someday, throughout everything technological, the essence of technology may unfold essentially in the propriative event of truth." (264) Heidegger's modern, industrial, “technologically frenzied" world bears striking resemblance to the ways in which we perceive technology in a digitally driven era.

Practice of digitally enhanced, embodied space is always a question of identity. As we negotiate the terms of our binding contract with technology our gaze is fixed to the pace with which we adapt to these enhancements. The pace itself seems enhanced and domineering, hence an urgency to keep up, a sense of anticipation pervades lest we fall behind the times, or ironically lest times fall behind our anxious civilization and we lament what we have lost, though it is something we fail to remember.

The Coat Check queries the relation between archive, memory and identity as well 
as the dialectics of the interior and exterior in a digitally enhanced environment. The installation speaks of how memory is incoherent and nebulous, how archive is impaired and how borders are in flux, created in movement, done and undone in positionalities that the experience of space brings about. Although the media disseminated throughout virtual and real space is composed of personal archives, The Coat Check deliberately refrains from constructing a back story that is recognizable or traceable to an origin. There may and may not be a relationship between the twenty-four short videos hanging virtually on the steel ring in the middle of the room, the images projected onto the fog screen, the videos attached to travel documents in the luggage and the video of a coat that incessantly turns in circles on the lab window. There is a sense of disorientation that alludes to the hybrid potential Saïd talks about upon waking hours, a state of 'out of place', an identity not bound to a single time and place but rather to flowing currents, a heightened awareness within movement.

\section{Technological Displacement: Coat Check Interactive Augmented Reality}

Installation in Perspective is both a technologically driven artwork and a critique of technology, space and identity. It is an installation realized in order to understand digitally enhanced space with regards to movement while creating that very space itself. This metadisplacement bears witness to the link between global displacements and technological ones. 


\section{References}

Althusser, Louis. "Ideology and the Ideological State Apparatuses: Notes towards an Investigation." Lenin and Philosophy and Other Essays. Monthly Review Press, 1971.

Anderson, Benedict, Imagined Communities: Reflections on the Origin and Spread of Nationalism. Verso, 2006.

Appadurai, Arjun. "Here and Now" in The Visual Culture Reader, ed. N. Mirzoeff, Routledge 2006.

Appadurai, Arjun. Modernity at Large: Cultural Dimensions of Globalization. University of Minnesota Press, 1996.

Arendt, Hannah. The Human Condition. Chicago: University of Chicago Press, 1998.

Aristotle. Nichomachean Ethics. Hackett, 1985.

Ataman, Kutluğ. Serpent's Tale. 1994. Film.

semiha b. unplugged. 1997. Video Installation.

Lola+Bilidikid. 1998. Film.

Women Who Wear Wigs. 1999. Video Installation.

Never My Soul. 2001. Video Installation.

The Four Seasons of Veronica Reed. 2002. Video Installation.

Vicious Circle. 2002. Video Installation.

Küba. 2004. Video Installation.

Testimony. 2006. Video Installation.

Paradise. 2007. Video Installation.

Turkish Delight. 2007. Video Installation.

Bachelard, Gaston. Poetics of Space, Boston: Beacon Press, 1994.

Bacon, Francis. Great Instauration and Novum Organum. Kessinger Publishing, 1997.

Bacon, Francis. New Atlantis (1626). Ideal Commonwealths, P.F. Collier \& Son, New York. Oregon State University, 1996. Web.

Before the Rain. Dir. Milcho Manchevsi. 1994. Film.

Benjamin, Walter. "The Work of Art in the Age of Mechanical Reproduction." Illuminations. ed. H. Arendt, New York: Schocken Books, 1969.

Bentham, Jeremy. The Panopticon Writings. Verso, 1995.

Bhabha, Homi K. The Location of Culture. Routledge, 1994.

Blade Runner. Dir. Ridley Scott. 1982. Film.

Bouchard, Gérard and Taylor, Charles. The Bouchard-Taylor Commission Report. Web.

Butler, Judith. The Psychic Life of Power: Theories in Subjection. Stanford University Press, 1997.

Calendar. Dir. Atom Egoyan. 1993. Film.

Canclini, Nestor, Garcia. "Hybrid Cultures, Oblique Powers." Media and Cultural Studies. ed Durham and Kellner, Blackwell, 2001, 488.

Chambers, Ian. Migrancy, Culture, Identity. Routledge, 1994.

Chien d'histoire. Dir. Serge Avedikian. 2010. Short Animation Film.

Chow, Rey. Writing Diaspora: Tactics of Intervention in Contemporary Cultural Studies. Indiana University Press, 1993.

Chun, Hui Kyong, Wendy. Control and Freedom: Power and Paranoia in the Age of Fiber Optics. The MIT Press, 2008.

Chun, Hui Kyong, Wendy. 'Othering Space', in The Visual Culture Reader. ed. N. Mirzoeff, 
Routledge, 2006.

Clark, Bruce. Twice a Stranger: The Mass Expulsions that Forged Greece and Turkey. Harvard University Press, 2006.

Coat Check, The. Aysegul Koc. 2011. Interactive Augmented Reality Installation.

Compte, August. Système de politique positive. Les Presses universitaire de France, Third Edition. 1969.

de Certeau, Michel. The Practice of Everyday Life. Berkeley and Los Angeles, CA: University of California Press, 1988.

Davies, Char. Osmose. 1995. Virtual Immersive Installation. Ephemère. 1998. Virtual Immersive Installation.

Derrida, Jacques. Archive Fever: a Freudian Impression. Trans. Eric Prenowitz. Chicago: University of Chicago Press, 1995.

Dick, Philip K. Do Androids Dream of Electric Sheep? Random House Publishing Group, 1968.

Ellul, Jacques. The Technological Society. Vintage Books, 1964.

Elsewheres. Dir. Aysegul Koc. Interactive Augmented Reality Installation. 2008.

Farman, Jason. Mobile Interface Theory: Embodied Space and Locative Media. New York: Routledge, 2012.

Foucault, Michel. Discipline and Punish: The Birth of Prison. Trans. Alan Sheridan. Pantheon, 1978.

Foucault, Michel. History of Sexuality. Volume I, Vintage Books, 1990.

Foucault, Michel. "Of Other Spaces". The Visual Culture Reader. ed. Mirzoeff, N. Routledge, 2006.

Ghosts of Mardin, The. Dir. Daniel Drapeau. 2005. Short Film.

Habermas, Jurgen. "Technical Progress and the Social Lifeworld". Technology and Values: Essential Readings. (ed) Craig Hanks. Wiley-Blackwell, 2010.

Haraway, Donna. "A Cyborg Manifesto: Science, Technology and Socialist-Feminism in the Late Twentieth Century", Simians, Cyborgs and Women: The Reinvention of Nature. Routledge, 1991.

Hatoum. Mona.

Measures of Distance. 1988. Film.

Corps Etrangères.1994. Installation.

+ and - 1994. Installation.

Pull. 1995. Installation.

Present Tense. 1996. Installation.

Home. 1999. Installation.

Mouli-Julienne. 1999. Installation.

Homebound. 2000. Installation.

Interior Landscape. 2008. Installation.

Hatoum, Mona. The Entire World as a Foreign Land. Exhibition Catalogue, Tate Gallery, London: 2000.

Hatoum, Mona and Bell, Kirsty (ed.). Mona Hatoum: Unhomely. Berlin: Galerie Max Herzler, 2008.

Hatoum, Mona and Bertola, Chiara (ed). Mona Hatoum: Interior Landscape. Exhibition Catalogue. Milano; New York: Charta, 2009.

Haotoum, Mona and Heon, Laura Steward (ed.). Mona Hatoum: Domestic Disturbance. MMass MoCA, 2001. 
Hatoum, Mona and Sam Flynn et al. (Production Team). Illuminations, Eye (Interview)

Series. London, 2005. DVD.

Heidegger, Martin. The Question Concerning Technology and Other Essays. Harper Torch Books, 1977.

Image Mill. Robert Lepage. Ongoing. Site-specific Projection/Installation

Kant, Immanuel, "Idea for a Universal History from a Cosmopolitan Point of View".

Philosophy of Technology: The Technological Condition. eds. R. C. Scharff and V.

Dusek, Blackwell Publishing, 2003.

Kline, J. Stephen. "What is Technology". Bulletin of Science, Technology and Society. Issue 5, Sage, 1985.

Kymlicka, Will. Finding Our Way: Rethinking Ethnocultural Relations in Canada. Oxford University Press, 1998.

L'arrive d'un train en gare à la Ciotat, Dir. Lumière Brothers. 1896. Film.

Leo Burnett Corporation. leoburnett.com Web.

Lozano-Hemmer, Rafael. Standards and Double Standards. 2004. Installation.

Pulse Park. 2008. Installation.

Voz Alta. 2008. Installation.

Pulse Front. 2007. Installation.

Underscan. 2005. Installation.

Magid, Jill. System Azure. Installation.

Lobby 7. 1999. Performance and Documentation.

Camera One in Wester Park. 2005. Installation.

Manovich, Lev "The Poetics of Augmented Space". Visual Communication: 5, Sage 2006.

Manovich, Lev. The Language of New Media. Leonardo Books, MIT Press, 2002.

Marcuse, Herbert. "New Forms of Control". Philosophy of Technology: The Technological

Condition. eds. R. C. Scharff and V. Dusek, Blackwell Publishing, 2003.

Marx, Karl and Engels, Friedrich. "Capitalism and the Modern Labour Process."

Philosophy of Technology: The Technological Condition. eds. R. C. Scharff and V.

Dusek, Blackwell Publishing, 2003.

Nature Journal, nature.com. Web.

Nettime. Nettime.org Web.

Perier, Miriam. "Look! About Jill Magid's work on surveillance and security tools", Cultures et Conflits, 2008. Web.

Plato. Republic. Penguin Classics, 1955.

Saïd, Edward. Orientalism. New York Vintage Books, 1979.

Saï, Edward. Out of Place. Knopf 1999.

Saï, Edward.Reflections on Exile and Other Essays. Harvard University Press, 2000.

Saï, Edward. The Politics of Dispossession: The Struggle for Palestinian Self

Determination 1969-1994. Vintage Books, 1995.

Scarff, Robert C. Dusek, Val. Eds. Philosophy of Technology: The Technological

Condition. Blackwell Publishing, 2003.

Seigworth J. Gregory and Gregg, Melissa. (eds) "An inventory of Shimmers." The Affect

Theory Reader. Duke University Press, 2010.

Shohat, Ella and Stam, Robert. "Narrativizing Visual Culture: Towards a Polycentric

Aesthetics." The Visual Culture Reader. ed. N. Mirzoeff, Routledge 2006.

Shohat, Ella and Stam, Robert. Unthinking Eurocentrism: Multiculturalism and the Media.

Routledge, 1994. 
Stewart, Kathleen. Ordinary Affects. Duke University Press. 2007.

Taylor, Charles. The Malaise of Modernity. House of Anansi Press, 1991.

Todorov, Tzvetan. L'Homme Dépaysé. Éditions du Seuil, 1996.

Todorov, Tzvetan. Morals of History. Minnesota University Press, 1995.

Virilio, Paul. "Big Optics." On Justifying the Hypothetical Nature of Art and the NonIdenticality within the Object World. ed. Peter Weibel, Cologne, 1992.

Zürcher, J. Eric. Turkey: a Modern History. I. B. Tauris \& Co Ltd., 1997. 


\section{Appendices}

The Coat Check Installation Poster April 26, 2011 Session I

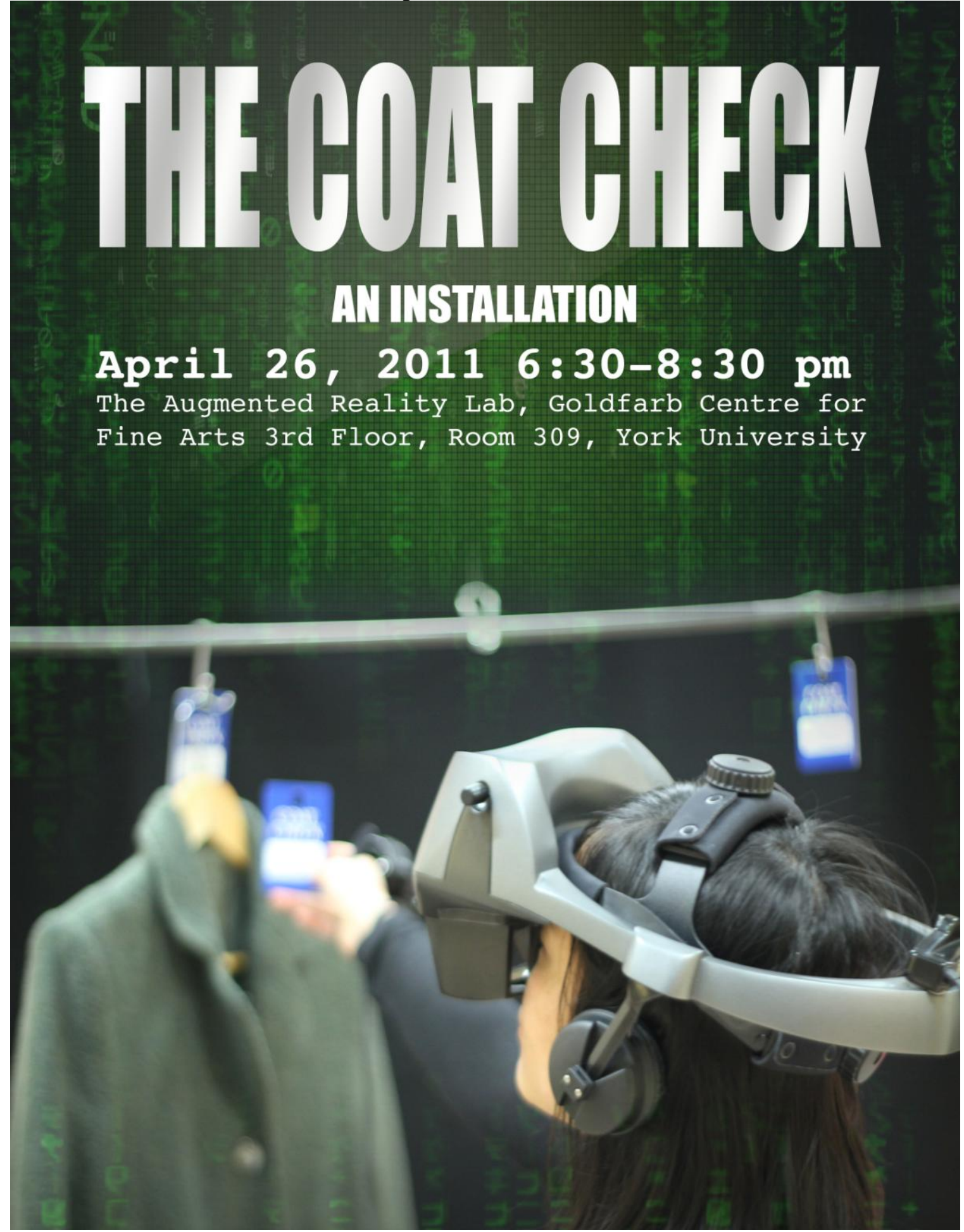


The Coat Check Installation Poster May 26, 2011 Session II

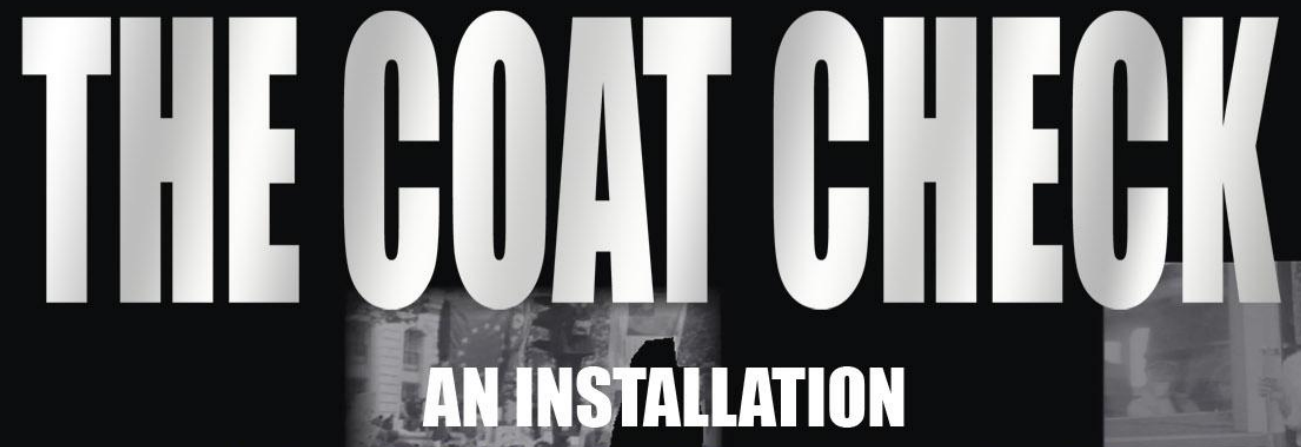

May 26, 2011 6:00 pm - 8:00 pm The Augmented Realiti Lab Goldfarsb Gentre for Fine Arts 3rd FloOF, Room 309, Rork University




The Coat Check Installation Flyer (back)

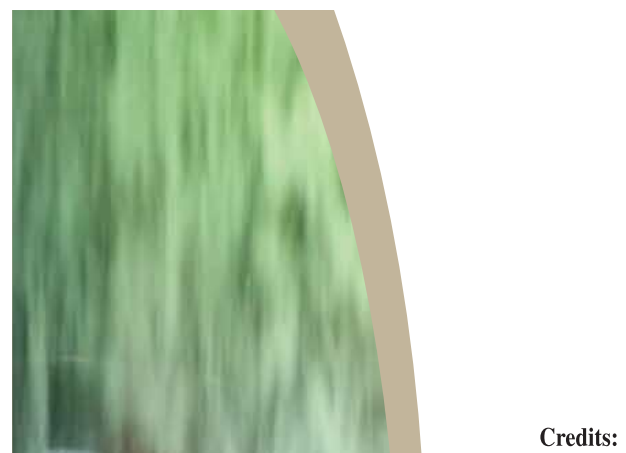

Aysegul Koc -Research Creation Lingying Cheng -Computer Programming Andrew Roth -Technical Supervision

\section{Thanks:}

Caitlin Fisher, Michael Zryd, Michael Prokopow, Colin Mooers, Debora Foster, Matthew Moreland, Sal Greco, Ryan Sykes, Ken Hama, Jon Hedley, Claudius Pinto, Carmen Schifellite, Bill Byers, Karl Reinsalu, Doris Haidner, Mukaddes Koc, Eva Korenkova, Boris Pantev, Ismet Yigit, Félix Houde-Billette, Chris Aimone, Tomek Bartczak, Ian Flett, Frantz Gheller, Dynamic Iron Ltd, The Art Gallery of Ontario, Liaison of Independent Filmmakers of Toronto, Ryerson University Rogers Communication Centre Editing Facilities, York University Film Department, The Future Cinema Lab, Graduate Program in Communication and Culture, York and Ryerson Universities
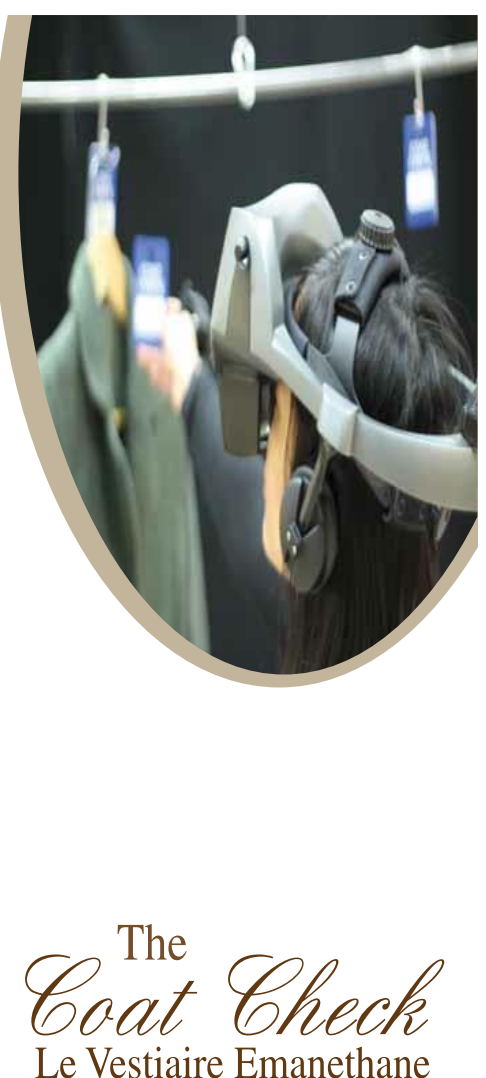


\section{The Coat Check Installation Flyer (Front)}

The Coat Check is an interactive augmented reality installation. Composed of seemingly disparate elements -a central metal ring suspended mid air that serves as a coat rack with a single coat hanging on it, a fog screen featuring images from Haydarpasa Train Station in Istanbul, a luggage filled with travel docu ments, tickets and transfers, a window onto which a $360^{\circ}$ video of a coat turning in circles in an automated coat rack is projected- Coat Check explores movement vis-à-vis time and space. The leitmotif that binds these scattered elements is the notion of displacement and the relevance of memory. What is a coat in a coat check? Where, to whom does it belong? What is its history? Is it misplaced, does the number it's been given correspond to a reality? And from here, is it going elsewhere?

The word emanet means the entrusted, and emanethane a place for temporary safekeeping. Haydarpasa Train Station, built in 1908 on the edge of the Bosphorus that divides the east and west side of the city, no longer has an emanethane. Instead it has yellow lockers with a

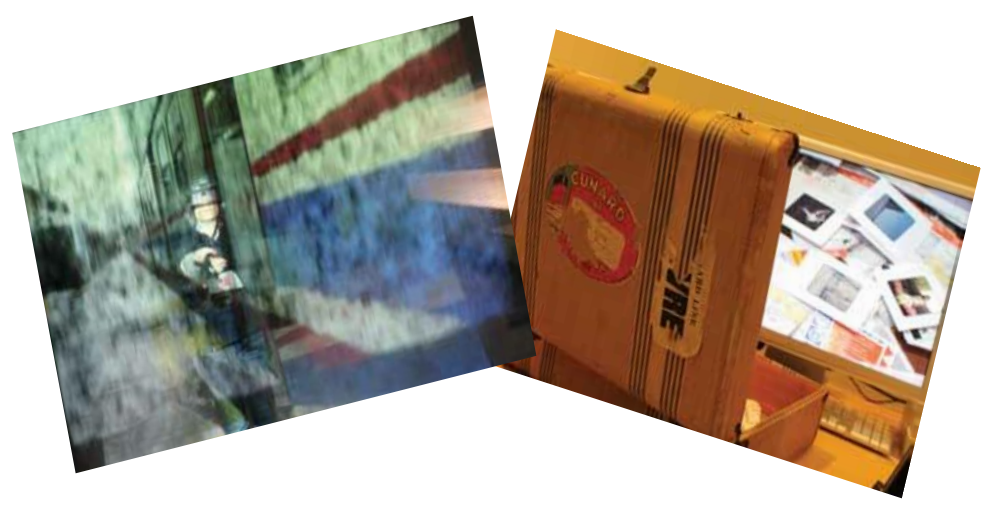

touch display and a credit card swipe slot. The station which marked the opening scene of many movies in the $60 \mathrm{~s}$-a rural family gets off the train in awe of the 'modern', the 'Western' world- now has visitors, suburbaners and Istanbulers figure out how to entrust their belongings electronically.

We are entrusted to technology in more ways than we readily admit. Augmented reality (AR) markers - now seen in ads, magazines to function with web cams, cell phone apps- are also

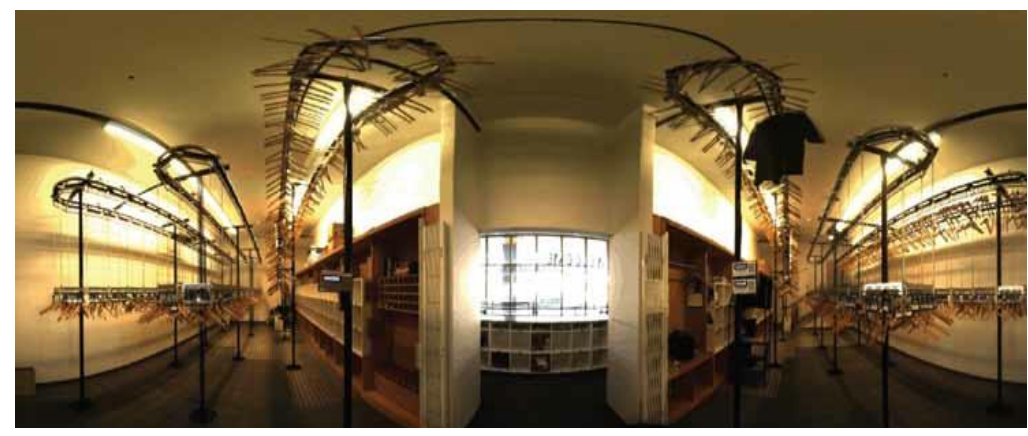

called fiducials, the word derives from Latin fiducia, meaning "trust". A fiducial marker represents or stands in for virtual media. Displacement is innate in digital technology. Emanethane/Le Vestiaire/The Coat Check comes full circle in its explorations of dis-place and this place as technology takes on a key role: not only do we tackle the question of global movements and identity in-flux via technology but also within it. The socio-political implication of exploring geographic, affective and linguistic displacements with/in technology, especially in relation to filmic immersion experiences and interactive installations is a vast territory.

Links:TheFutureCinemaLab http://futurecinema.ca/arlab/

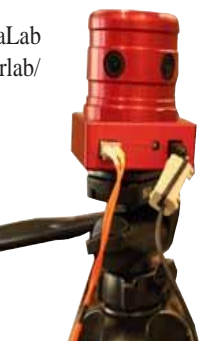




\section{List of stills and videos (on line)}

\section{Vimeo Video Links}

1- The Coat Check AR Open House 1: Andrew Roth on AR Lab (This video establishes the spatial context and the infrastructure at the AR Lab)

http://vimeo.com/63538486 (5' 58")

2 - Immersant's POV via webcam (This video demonstrates how the central coat check ring serves as an archive. The immersant's head mounted display is attached to a webcam to monitor what she sees on the screen on the right. The function of the hand tracker is also shown via the virtual hand, here seen in black, which is hidden in the final work.) http://vimeo.com/64859180 (5' 52")

3- The Coat Check Screen Shot: Immersant's POV (This video is a direct screen shot via feed from head mounted display. The video sequences appear much bigger -sometimes filling the screen- as opposed to webcam feed.)

http://vimeo.com/64848772 (4' 44")

4- The Coat Check: Immersant Behind Fogscreen (Shot from behind the fogscreen, this video demonstrates the layering of virtual and real elements. The imersant is simultanously aware of the fog screen and the video vignettes playing in her field of vision, superimposed to the fogscreen images.)

http://vimeo.com/64846078 (3' 08")

5-Immersant, Fog Screen at the Background (This video focuses on the audioscape that the immersant is experiencing. It also features fogscreen projection at the background.) http://vimeo.com/64856090 (47")

6- Ladybug sequence (This is the spherical vision camera sequence projected on the window of the lab.)

http://vimeo.com/63536895 (18")

7-The Coat Check Luggage Snap Dragon AR (This video shows The Snap Dragon AR application and the luggage with travel documents in it. Tickets and transfers are attached to AR markers that play back video, via webcam.)

http://vimeo.com/64848547 (47")

\section{Flickr Photograph Sets}

\section{1- Coat Check AR Installation in Images}

http://www.flickr.com/photos/36361567@N02/sets/72157633041669670/

2-Coat Check: The Fog Screen

http://www.flickr.com/photos/36361567@N02/sets/72157628250617159/

3- Luggage 
http://www.flickr.com/photos/36361567@N02/sets/72157627632701916/ 4- Photo Shoot I (general)

http://www.flickr.com/photos/36361567@N02/sets/72157627636812117/ 5- Photo Shoot II (photos by Preethy Sivakumar)

http://www.flickr.com/photos/36361567@N02/sets/72157627887489834/ 